\title{
The role of the novel endosomal protein Rush hour (CG14782) in endosomal trafficking in Drosophila melanogaster
}

\author{
PhD Thesis \\ in partial fulfilment of the requirements \\ for the degree "Doctor of Philosophy (PhD)" \\ in the Molecular Biology Program \\ at the Georg August University Göttingen, \\ Faculty of Biology
}

submitted by

IEVA GAILITE

born in

Riga, Latvia 



\section{Affidavit}

I hereby declare that I prepared the $\mathrm{PhD}$ thesis "The role of the novel endosomal protein Rush hour (CG14782) in endosomal trafficking in Drosophila melanogaster" on my own and with no other sources and aids than quoted.

Ieva Gailite

Göttingen, March 31st, 2010 



\section{Contents}

Contents 1

Acknowledgements __ 3

Abstract __ 4

List of figures

List of tables

1. Introduction __ 8

1.1. Endocytosis _ 8

1.1.1. Endocytic compartments

1.1.2. Rab GTPase cycle___ 11

1.2. Cell polarity 13

1.2.1. Epithelial cell polarity __ 13

1.2.2. Endocytosis in regulation of cell polarity 17

1.2.3. The Par/aPKC complex in regulation of endocytosis___ 18

1.3. Rush - a new endosomal protein __ 20

2. Materials and Methods _ 23

2.1. Materials _ 23

2.1.1. Chemicals and enzymes ___ 23

2.1.2. Primers 23

2.1.3. Vectors 25

2.1.4. Bacterial strains $\longrightarrow 26$

2.1.5. Antibodies 27

2.2. Molecular biology methods__ 28

2.2.1. Polymerase chain reaction ( $\overline{\mathrm{PCR})} 28$

2.2.2. Long template PCR 29

2.2.3. Agarose gel electrophoresis 30

2.2.4. Estimation of DNA concentration 30

2.2.5. Gateway cloning technology 31

2.2.6. Cloning of inserts into pGEX-4T-1 vector 32

2.2.7. Transformation of chemically competent $\overline{E . \text { coli cells }} 33$

2.2.8. Purification of plasmid DNA __ 33

2.2.9. Site-directed mutagenesis _ 34

2.2.10. Sequencing of DNA 34

2.2.11. Isolation of genomic DNA from flies 35

2.2.12. Culture and transfection of Schneider 2 cells ___ 36

2.3. Biochemical methods _ 36

2.3.1. Protein extraction from embryos 36

2.3.2. Protein extraction from S2 cells 37

2.3.3. Determination of protein concentration 37

2.3.4. SDS-polyacrylamide gel electrophoresis 37

2.3.5. Western blot 38

2.3.6. Coomassie staining __ 38

2.3.7. GST and MBP fusion protein purification

2.3.8. MBP fusion protein pulldown __ 39

2.3.9. Lipid overlay assay ___ 39

2.3.10. Endosome fractionation assay __ 40

2.4. Immunohistochemistry __ 40

2.4.1. Fixation of embryos 40

2.4.2. Immunostaining of embryos 41

2.4.3. Fixation and immunostaining of ovaries __ 41 
2.4.4. Fixation and immunostaining of S2 cells __ 42

2.4.5. Staining of DNA $\quad 42$

2.4.6. Staining of lysosomes with LysoTracker

2.4.7. Staining of actin microfilaments ___ 42

2.4.8. Dextran uptake assay ___ 43

2.4.9. Confocal microscopy, image acquisition and statistical analysis___ 43

2.5. Fly genetics

2.5.1. Fly breeding 43

2.5.2. Fly stocks 44

2.5.3. The UAS-GAL4 system__ 46

2.5.4. Generation of transgenic flies 46

2.5.5. FLP/FRT mediated gene deletion___ 47

3. Results 50

3.1. Localization of Rush $\quad 50$

3.1.1. Colocalization of Rush with polarity markers _ 50

3.1.2. Rush associates with endosomes

3.1.3. Effect of Rush overexpression on endocytic compartments __ 56

3.2. Rush modifies the shape of Rab5-induced early endosomes___ 61

3.3. Lipid binding properties of Rush __ 66

3.4. Generation of rush mutant allele __ 71

3.5. Characterization of rush null allele ___ 72

3.6. rush genetically interacts with $c d c 42$

3.7. Rush interacts with Rab GDI and Drosophila homolog of GDF _ 83

4. Discussion — 88

4.1. Localization of Rush __ 8

4.1.1. Subcellular localization of Rush__ 88

4.1.2. Role of lipid binding domains in Rush localization ___ 89

4.2. Function of Rush in endocytosis _ 90

4.2.1. Rush regulates late endosome formation

4.2.2. Rush changes the morphology of Rab5CA vesicles __ 92

4.3. Possible role of Rush in signaling pathways ___ 93

4.4. Genetic interaction between rush and $\mathrm{Cdc42}$

4.5. Rush interaction with Rab GDI and GDF _ 96

4.6. Model of Rush function ___ 97

5. Summary and conclusions __ 99

6. Bibliography _ 101

Abbreviations__ 115

Appendix — 117

Curriculum vitae _ 122 


\section{Acknowledgements}

First of all, I want to thank Prof. Andreas Wodarz for the supervision during these years, for the support and advice during the many turns of the project, and for giving me the possibility to develop my own ideas.

I thank Prof. Ivo Feussner and Prof. Reinhard Schuh for being a part of my thesis committee and for the helpful comments during committee meetings.

I am grateful to Dr. Steffen Burkhardt, Ivana Bacakova and Kerstin Grüninger from the Molecular Biology program for the enormous support of students and for the excellent organization of the program.

I want to thank all members of the Stem Cell Biology department for making these years highly enjoyable. Thanks to Mona, Katja and Claudia for the excellent technical support and for keeping the lab together and running, Tobi for many untranslatable German expressions, Nils for surreal conversations, Hamze and Karen for the fun times in the big lab, Gang for the optimism and delicious Chinese food, Michael for the help in the world of flies, Sasha for the best fly food and Patricia for the guidance through the kingdom of papers and documents. Thanks to Tanja for being the best supervisor and for the help in the first year, Soya for the optimism and for the collaboration, and Ankathrin for the introduction to the fly work.

Thanks to my office mates Irina, Ulli and Fred for the great atmosphere, mutual support and for keeping the spirits up.

Thanks to Konstantina, Katharina and Marija for the friendship through these years and the infrequent, but necessary escape from the lab life, Martina, Nora and Kerstin for extended Gromo breakfasts, Achim and Adema for the fights of Titans, and Ilze for keeping me from forgetting Latvian language.

Special thanks to Sabi for the immense support in my „hatching“ as a doctor, for the great time together and for making me feel at home in Germany.

My biggest thanks to my family for supporting their „lost“ daughter/sister and for their constant belief in me and my abilities. 


\begin{abstract}
Endocytosis regulates multiple cellular processes, including the protein composition of the plasma membrane, intercellular signaling and cell polarity. Cell polarity is defined by asymmetric localization of membrane-associated protein complexes. Defects in endocytosis can lead to faulty distribution of polarity proteins and ultimately to the loss of cell polarity. The small GTPase Cdc42 has recently been described to regulate endocytosis of polarity proteins in Drosophila epithelial cells. While the role of $\mathrm{Cdc} 42$ in the regulation of early endocytotic steps is quite well described, it is still not known how Cdc42 influences late endosome formation. Here I describe Rush hour (Rush), a previously uncharacterized and highly conserved protein that genetically interacts with $\mathrm{Cdc} 42$ in regulation of late endosome formation. Rush is a lipid interacting protein and localizes to the lateral plasma membrane of epithelial cells and to late endosomes. Rush promotes late endosome formation and rush mutants have a decreased late endosome size. Rush interacts with Cdc42 in regulation of endocytosis of the apical polarity protein Crumbs, and loss of rush rescued the phenotype caused by overexpression of dominant negative Cdc42. Rush binds directly to Rab GDI and could regulate endocytosis by affecting Rab activation on the membrane of late endosomes. Lysosomal marker staining is decreased in Rush overexpressing cells, indicating that Rush might regulate the transition between late endosomes and lysosomes. In addition, Rush causes fractionation of enlarged early endosomes that are formed by overexpression of constitutively active Rab5. These results suggest that Rush might act in trafficking steps both from the early to late endosomes and from late endosomes to lysosomes.
\end{abstract}




\section{List of figures}

Figure 1-1. A simplified scheme of endocytosis 9

Figure 1-2. The Rab GTPase cycle

Figure 1-3. Comparison of epithelial cell membrane domains in Drosophila and vertebrates

Figure 1-4. Interactions between Par/aPKC, Crb and Scrib complexes in Drosophila epithelial cells

Figure 1-5. Possible effects of the Par/aPKC complex on endocytosis of Crb and Ecadherin 20

Figure 1-6. Protein structure of Rush 21

Figure 2-1. Gateway recombination reaction 32

Figure 2-2. FLP/FRT mediated deletion of rush gene 49

Figure 3-1. The localization and structure of rush 51

Figure 3-4. Colocalization of Rush with endosome markers 55

Figure 3-5. Rush colocalizes with endosome markers in the oocyte 55

Figure 3-6. Rush cofractionates with endosomal markers 56

Figure 3-7. Overexpression of Rush-GFP does not affect localization of polarity markers57

Figure 3-8. Rush-GFP colocalizes with late endosome markers 58

Figure 3-9. Rush colocalizes with Hrs and endocytosed dextran in wing discs 59

Figure 3-10. LTR staining is decreased in Rush-GFP overexpressing follicle epithelium 60

Figure 3-11. Overexpression of Rush-GFP in the follicle epithelium causes germline apoptosis 61

Figure 3-12. Rush-GFP changes the shape of Rab5CA-induced endosomes 63

Figure 3-13. Rab5CA expression changes the localization of Rush-GFP 64

Figure 3-14. Rab7 localizes to Rush-GFP and YFP-Rab5CA vesicles 65

Figure 3-15. Localization of Rab11 in Rush-GFP and/or YFP-Rab5CA expressing follicle epithelium 66 
Figure 3-16. Lipid binding specificity of Rush 68

Figure 3-17. Subcellular localization in Rush lipid binding defective mutants 69

Figure 3-18. Generation of rush null allele 72

Figure 3-19. Loss of Rush does not affect localization of Baz 73

Figure 3-20. Egg chambers of rush $^{4}$ flies display defects in oogenesis 75

Figure 3-21. The effect of rush deletion on endosomal compartments 76

Figure 3-22. Formation of early endosomes is not affected in rush mutant cells 77

Figure 3-23. Overexpression of Rush-GFP in embryonic ectoderm leads to an increase in

Crb endocytosis 79

Figure 3-24. Cdc42DN causes mislocalization of $\mathrm{Crb}$ and E-cadherin 79

Figure 3-25. Cdc42DN causes formation of enlarged Rab7 endosomes 81

Figure 3-26. Loss of rush rescues arm $>$ Cdc42DN phenotype 82

Figure 3-27. Rush directly interacts with CG1418 and GDI 84

Figure 3-28. Localization of GDI and CG1418 in S2 cells 85

Figure 3-29. Localization of GFP-GDI and GFP-CG1418 in the follicle epithelium 86

Figure 3-30. GDI associates with endosomes 87

Figure 4.1. Model of Rush function in endocytosis 97 


\section{List of tables}

Table 1-1. Localization of evolutionarily conserved proteins in epithelial junctions of Drosophila and vertebrates

Table 2-1. List of oligonucleotides 23

Table 2-2. List of vectors 25

Table 2-3. List of bacterial strains 26

Table 2-4. List of primary antibodies 27

Table 2-5. List of secondary antibodies 28

Table 2-6. Standard PCR program 29

Table 2-7. PCR mix for verification of Rush deletion. 29

Table 2-8. PCR program for long template PCR. 30

Table 2-9. PCR program for site-directed mutagenesis reaction 34

Table 2-10. PCR program for sequencing reaction 35

Table 2-11. List of fly stocks. 44

Table 2-12. Transgenic constructs used for injection in flies. 47 


\section{Introduction}

Endocytosis is one of basic cell functions and acts in a multitude of cellular processes, including regulation of the plasma membrane lipid and protein content. Endocytosed molecules can then be degraded or sent back to the plasma membrane. Thus endocytosis allows fine-tuning of the amounts of different plasma membrane components. Cell polarity is established by action of conserved protein complexes that asymmetrically localize at the plasma membrane. Epithelial cells are one of best characterized polarized cell types. In addition to having distinct membrane domains, epithelial cells adhere to each other via intercellular junctions. Uptake of polarity complexes or junctional proteins by endocytosis leads to changes in cell polarity or in the rigidity of the epithelial layer. Interestingly, polarity proteins like $\mathrm{Cdc} 42$ are able to regulate endocytic trafficking and therefore affect cell polarity by an additional mechanism. The mode of action of these polarity complexes in regulation of endocytosis is still largely unknown. In this work I describe characterization of CG14782, a new endosome associated protein. Due to the phenotype associated with the deletion and overexpression of CG14782 we named the gene rush hour (rush). The role of Rush in epithelial cells in regard to regulation of the endosomal pathway and uptake of polarity proteins was investigated in this work.

\subsection{Endocytosis}

Cells are limited from the extracellular space with a plasma membrane, which is impermeable for large molecules. While small molecules like ions, sugars or amino acids can cross the membrane via specialized channels or transporters, uptake of larger molecules is mediated by endocytosis. During the process of endocytosis, vesicles that contain the cargo bud off from the internal side of the plasma membrane. Internalized molecules are then processed through several endocytic compartments and are either degraded or delivered back to the plasma membrane. Diverse functions of endocytosis include regulation of signaling pathways, nutrient uptake, neurotransmission and regulation of cell polarity. Several modes of molecule internalization have been described, including clathrin-mediated endocytosis, caveolae-mediated endocytosis, phagocytosis and pinocytosis (Doherty and McMahon, 2009). These pathways differ in the type of endocytosed cargo and in molecules that are involved in vesicle budding and separation from the plasma membrane. Nevertheless, the vesicles formed by diverse internalization 
pathways converge in common compartments and are then further processed along the endocytic pathway (Gruenberg, 2001). The properties of different endocytic compartments will be described in more detail in the following chapter.

\subsubsection{Endocytic compartments}

The endocytic pathway is comprised of a variety of organelles - early or sorting endosomes, recycling endosomes, late endosomes or multivesicular bodies (MVBs) and lysosomes (Fig. 1-1). These organelles are highly interconnected by exchange of endocytosed material and membrane. Although dynamically connected, each of the organelles has a distinct function and molecular markers that allow to distinguish these vesicular compartments. Among the most widely used markers of the endocytic pathway are Rab proteins. Rabs are small GTPases that are specifically located to different compartments and are thought to maintain the functional identity of endosomes (Pfeffer, 2001; Zerial and McBride, 2001).

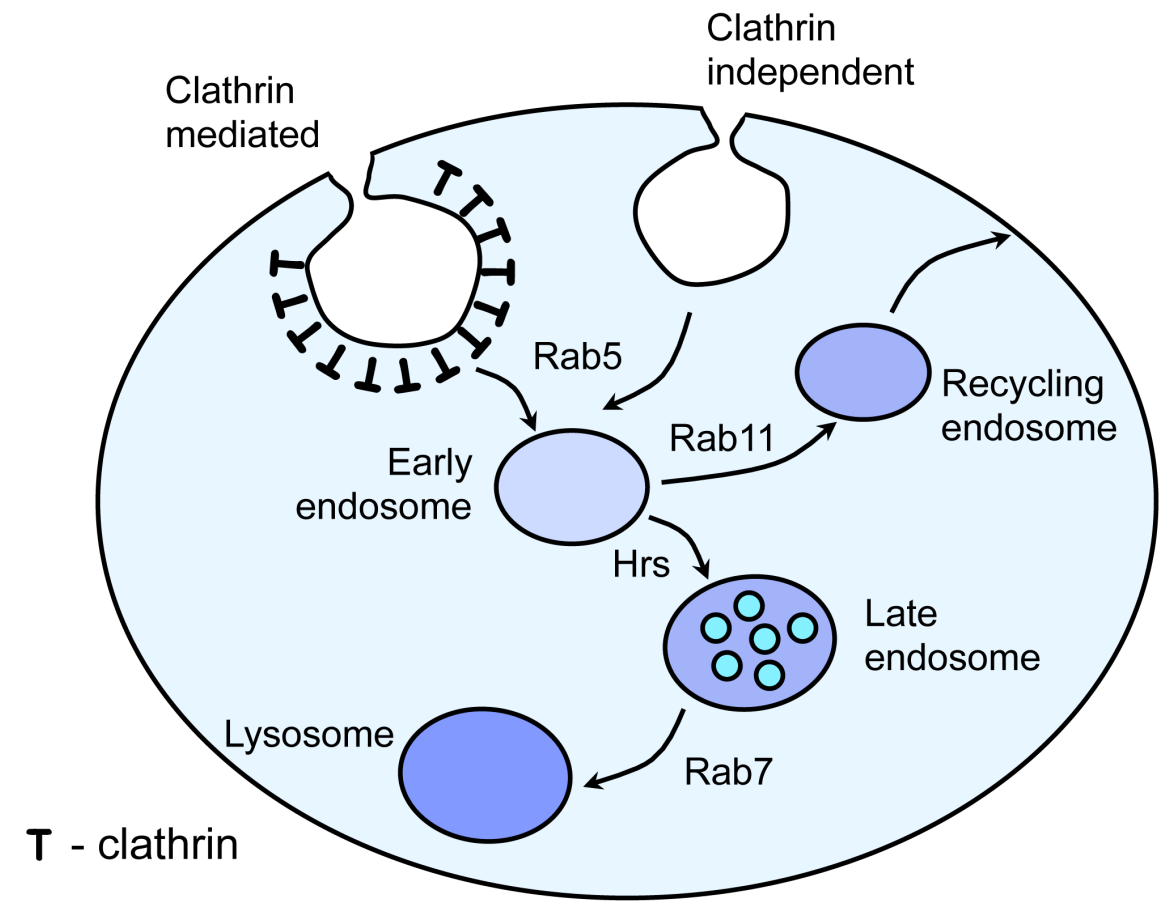

Figure 1-1. A simplified scheme of endocytosis. Cargo is taken up by either clathrin dependent or independent endocytosis and then transported to early endosomes. Molecules are then either sent back to the plasma membrane via recycling endosomes or degraded via late endosome/lysosome pathway. 


\section{Early endosomes}

The early or sorting endosome is the first station at which various endocytosed vesicles converge. At this level sorting of cargo takes place. Molecules that will be delivered back to the plasma membrane are delivered either directly from the early endosome or sorted into recycling endosomes (Sheff et al., 1999). Endocytosed molecules that are destined for degradation will end up in late endosomes and finally in lysosomes. Rab5 is the main molecular marker of early endosomes. Rab5 is involved in budding of clathrin-coated vesicles from the plasma membrane (McLauchlan et al., 1998) and later promotes fusion of these vesicles with early endosomes (Bucci et al., 1992, Morrison et al., 2008). In addition, Rab5 regulates fusion of early endosomes with each other or so called homotypic fusion (Gorvel et al., 1991). Early endosomes are characterized by high phosphatidylinositol-3phosphate $(\mathrm{PI}(3) \mathrm{P})$ content due to Rab5-mediated recruitment of the class III phosphatidylinositol-3-kinase (PI(3)K) (Christoforidis et al., 1999, Murray et al., 2002). $\mathrm{PI}(3) \mathrm{P}$ is specifically found in early endosomes and on internal membranes of late endosomes (Gillooly et al., 2000; Gillooly et al., 2001). High PI(3)P concentration on early endosomes leads to recruitment of several proteins that contain FYVE domains - lipid binding domains with high specificity towards PI(3)P (Burd and Emr, 1998; Gaullier et al., 1998; Patki et al., 1998; Stenmark et al., 1996). One of such proteins is Hrs, a protein that is involved in multivesicular body formation and protein segregation of proteins that are targeted for degradation (Bache et al., 2003; Lloyd et al., 2002; Pons et al., 2008). Hrs also has been proposed to inhibit homotypic fusion of early endosomes (Sun et al., 2003).

\section{Recycling endosomes}

Recycling endosomes are compartments that mediate delivery of endocytosed molecules back to the plasma membrane. While constitutive recycling from early endosomes is mediated by a transport directly to the plasma membrane, regulated recycling of molecules takes place via recycling endosomes (Sheff et al., 1999). Recycling endosomes are thought to form by pinching of tubular structures off from early endosomes (Mellman 1996). Proteins are then delivered from the recycling endosome to the plasma membrane with small transport vesicles. Rab11 serves as a marker of recycling endosomes and regulates trafficking through recycling endosomes (Ullrich et al., 1996; Trischler et al., 1999). Rab11 has also been found on the trans-Golgi network (TGN) and regulates transport between TGN and recycling endosomes (Chen et al., 1998; Lock and Stow, 2005). 


\section{Late endosomes}

Late endosomes or MVBs deliver molecules for degradation in lysosomes. Proteins that are destined for degradation become monoubiquitinated and are sorted by Hrs and ESCRT (endosomal complexes required for transport) proteins in microdomains on the endosome membrane (Lloyd et al., 2002; Pons et al., 2008). This leads to a sequential recruitment of three ESCRT complexes - ESCRT-I, ESCRT-II and ESCRT-III (Babst et al., 2002a; Babst et al., 2002b; Katzmann et al., 2001). These complexes are necessary for invagination and budding off of these domains inside of the late endosome. This leads to formation of small intraluminal vesicles, hence the term MVBs. Proteins and lipids that are sorted in intraluminal vesicles as well as the soluble cargo are then degraded upon fusion with lysosomes. Both lysosomes and late endosomes have acidic intraluminal $\mathrm{pH}$, which promotes the activity of hydrolases (Bond and Butler, 1987). Late endosomes can be distinguished from lysosomes by the presence of Rab7 (Chavrier et al., 1990).

The mechanism of transition between early and late endosomes is still not completely clear. Two models have been proposed: first - transport of material from early to late endosomes by small endosomal carrier vesicles (Vonderheit and Helenius, 2005); second formation of late endosomes by early endosome maturation (Rink et al., 2005). Although the debate is still ongoing, the model of endosome maturation has received substantial experimental support over the last years (Lakadamyali et al., 2006; Rink et al., 2005). According to this model, Rab7 becomes loaded on early endosomes as they undergo the maturation process to late endosomes (Del Conte-Zerial et al., 2008; Rink et al., 2005). Active Rab5 is able to bind Rab7 guanine nucleotide exchange factor (GEF) and could thus promote activation of Rab7 and transition to the late endosome (Rink et al., 2005).

The function of Rab7 in endocytosis is still under discussion, with some observations indicating its function in transition from early to late endosomes (Vonderheit and Helenius, 2005), while other results point towards a role of Rab7 in fusion of late endosomes to lysosomes (Vanlandingham and Ceresa, 2009).

\subsubsection{Rab GTPase cycle}

Rab proteins play a central role in endocytosis and other major vesicle trafficking pathways. $33 \mathrm{Rab}$ genes are encoded in Drosophila genome, while more than $60 \mathrm{Rab}$ genes are present in human cells (Zhang et al., 2007). Main functions of Rabs are in vesicle budding, transport and fusion (Grosshans et al., 2006; Zerial and McBride, 2001). Rabs are 
small GTPases of the Ras superfamily and cycle between a GTP bound active state and a GDP bound inactive state. Conversion between these two conformations is driven by action of several Rab interacting proteins (Fig. 1-2). Rabs are converted to an active state by a guanine nucleotide exchange factor (GEF) that catalyzes GDP exchange to GTP. In the active state Rabs are bound to membranes with their geranygeranyl anchor and interact with their effector proteins, thus exerting their functions. Inactivation of Rabs by GTP hydrolysis is facilitated by a GTPase activating protein (GAP). In the GDP bound state Rabs are removed from the membrane by binding to a GDP dissociation inhibitor (GDI) and reside in the cytosol.

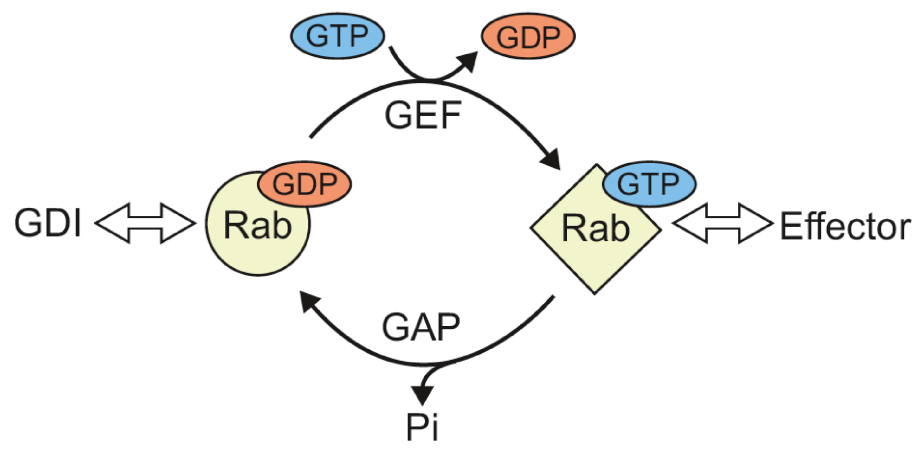

Figure 1-2. The Rab GTPase cycle. Inactive GDP bound Rab is converted to the active form by nucleotide exchange, catalyzed by GEF. Inactivation of Rab takes place by GAP-catalyzed hydrolysis of GTP. In the active form Rab is bound to a membrane and interacts with its effector proteins, while inactive Rab associates with GDI and is cytosolic. Adapted from Stenmark and Olkkonen, 2001.

Rabs have a highly specific localization to membranes of different cell compartments. To achieve this, GDI has to be able to deliver inactive Rab to the specific target membrane, where it can be activated and exert its function. It has been proposed that GDI is recruited to target membranes by a GDI displacement factor (GDF), which promotes release of otherwise tightly bound Rab from GDI (Dirac-Svejstrup et al., 1997; Hutt et al., 2000; Sivars et al., 2003). So far only two GDF factors with a distinct subcellular localization, PRA and PRA2, have been described in detail (Abdul-Ghani et al., 2001), although 16 PRA family proteins are found in humans (Pfeffer and Aivazian, 2004). As the number of putative GDF factors is smaller than that of Rab proteins, it has been proposed that GDF factor mediates delivery of Rab on a membrane close to its target site. Then Rab would diffuse freely in the membrane system until Rab encounters its GEF or effector proteins 
and therefore becomes stabilized in a respective membrane microdomain (Grosshans et al., 2006; Pfeffer and Aivazian, 2004).

\subsection{Cell polarity}

Cell polarity is an essential feature of a variety of cell types and is necessary for diverse functions like growth, chemotaxis, directed molecule transport across the cell and tissue development in multicellular organisms. Polarization of a cell is initiated by an external or internal signal or polarity cue. This signal is recognized by receptors and propagated by signaling cascades in a polarized fashion. The signaling activated by the polarity cue results in changes in the structure of the cytoskeleton, directed transport of proteins and membrane components or changes in the localization of organelles. The polarity cue can be, for example, contact with another cell or with the extracellular matrix, which causes an epithelial cell to assemble specific junction complexes and form epithelial tissue (Drubin and Nelson, 1996).

\subsubsection{Epithelial cell polarity}

Epithelial cells are among the most extensively investigated types of polarized cells. Polarity in an epithelial cell is established on one hand by protein complexes that regulate formation of distinct membrane domains, and, on the other hand, by polarized endocytosis and exocytosis of these polarity complexes (Leibfried and Bellaiche, 2007). Processes that lead to polarity establishment and regulation in epithelial cells are highly conserved and have been widely studied in Drosophila melanogaster.

Epithelial cells function as a barrier between the tissue and the external environment and separate tissues in compartments. To be able to perform these functions epithelial cells have an elaborate junction system, which separates the plasma membrane of epithelial cells in the apical and the basolateral domain. The basolateral plasma membrane is in contact with other cells or extracellular matrix, while the apical domain faces the external environment. These plasma membrane domains differ in their protein and lipid composition. Intercellular junctions and membrane domains of epithelial cells in Drosophila and vertebrates are shown in Fig. 1-3. 


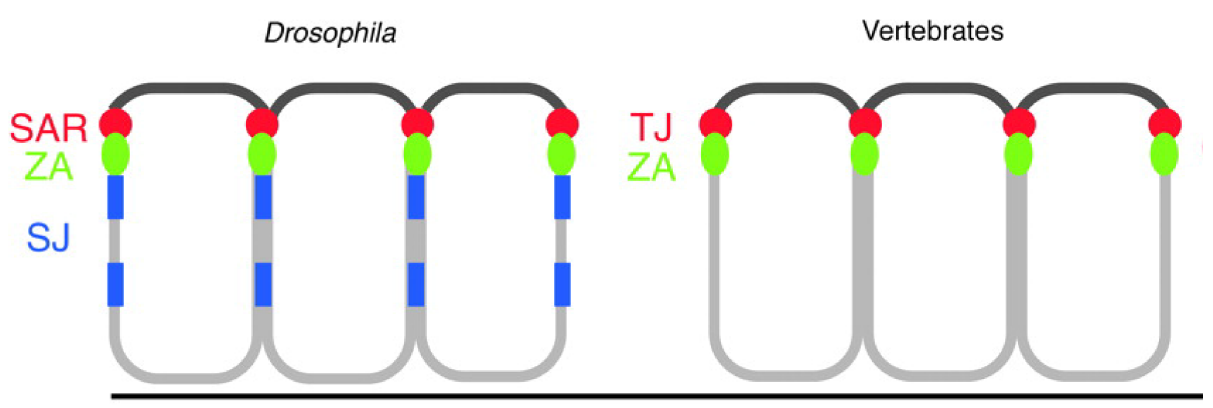

Figure 1-3. Comparison of epithelial cell membrane domains in Drosophila and vertebrates. Abbreviations: SAR - subapical region, ZA - zonula adherens, SJ - septate junction, TJ - tight junction. Similar colors indicate similar protein composition in the regions (see Table 1-1). Apical membrane is indicated in black, basolateral membrane - in grey. Adapted from Knust and Bossinger, 2002.

Drosophila epithelial cells possess adherens junctions that form a belt-like structure, named zonula adherens (ZA), and septate junctions, which are located basally from the ZA along the basolateral membrane (Knust, 2000). Adherens junctions are formed by Ecadherin mediated homophilic contacts between neighboring cells. E-cadherin itself is linked to actin filaments via interaction with $\alpha$-, $\beta$ - and $\gamma$-catenins, thereby strengthening the tissue (Yap et al., 1997). Epithelial cells in Drosophila do not possess tight junctions, but the homologs of vertebrate tight junction components are found apically from adherens junctions in the subapical region (Müller, 2000; Knust and Bossinger, 2002; Johnson and Wodarz, 2003).

Table 1-1. Localization of evolutionarily conserved proteins in epithelial junctions of Drosophila and vertebrates (adapted from Knust and Bossinger, 2002).

\begin{tabular}{l|l|l|l}
\hline \multicolumn{2}{c|}{ Drosophila } & \multicolumn{2}{c}{ Vertebrates } \\
\hline & Bazooka & & Par3 \\
& DmPar6 & & Par6 \\
& DaPKC & Tight junction: & Cdc42 \\
Subapical region: & Cdc42 & & CRB \\
& Crumbs & & Pals1 \\
& Stardust & PATJ \\
\hline
\end{tabular}




\begin{tabular}{|c|c|c|c|}
\hline Adherens junction: & $\begin{array}{l}\text { Shotgun (DE- } \\
\text { Cadherin) } \\
\text { Armadillo ( } \beta \text {-catenin ) } \\
\alpha \text {-catenin }\end{array}$ & Adherens junction: & $\begin{array}{l}\text { E-Cadherin } \\
\beta \text {-catenin } \\
\alpha \text {-catenin }\end{array}$ \\
\hline $\begin{array}{l}\text { Basolateral membrane, } \\
\text { septate junction: }\end{array}$ & $\begin{array}{l}\text { Scribble } \\
\text { Discs large }\end{array}$ & Basolateral membrane: & $\begin{array}{l}\text { SCRIB } \\
\text { hDLG }\end{array}$ \\
\hline
\end{tabular}

On a morphological level cell-cell junctions are one of the first landmarks of polarized epithelial cells. However, formation and proper localization of these junctions depends on a concerted action of many proteins (Table 1-1; Cox et al., 1996; Müller and Wieschaus, 1996). These proteins are evolutionarily conserved and assemble in so called polarity complexes (Margolis and Borg, 2005). Two protein complexes, the Par/aPKC complex and the Crumbs complex, are localized to the subapical region and apical plasma membrane. The Par/aPKC complex consists of Bazooka (Baz), atypical protein kinase C (aPKC), Par6 and the small GTPase Cdc42 (Suzuki and Ohno, 2006). Baz and Par6 are PDZ (PSD95, Discs large, Zona occludens-1) domain-containing scaffold proteins, while aPKC is a serine-threonine kinase. The Crumbs complex is formed by Crumbs (Crb), Stardust (Sdt) and PATJ (Bachmann et al., 2001; Hong et al., 2001). Crb is a transmembrane protein with a large extracellular part and a short cytoplasmic region, which is crucial for the function of Crb. Sdt is a MAGUK (membrane-associated guanylate kinase) protein that contains a PDZ domain, a SH3 (Src homology 3) domain and a GUK (guanylate kinase like) domain. PATJ is a PDZ domain scaffold protein. These two protein complexes confer apical characteristics to the plasma membrane (Hutterer et al., 2004; Petronczki and Knoblich, 2001; Wodarz et al., 2000; Wodarz et al., 1995). 


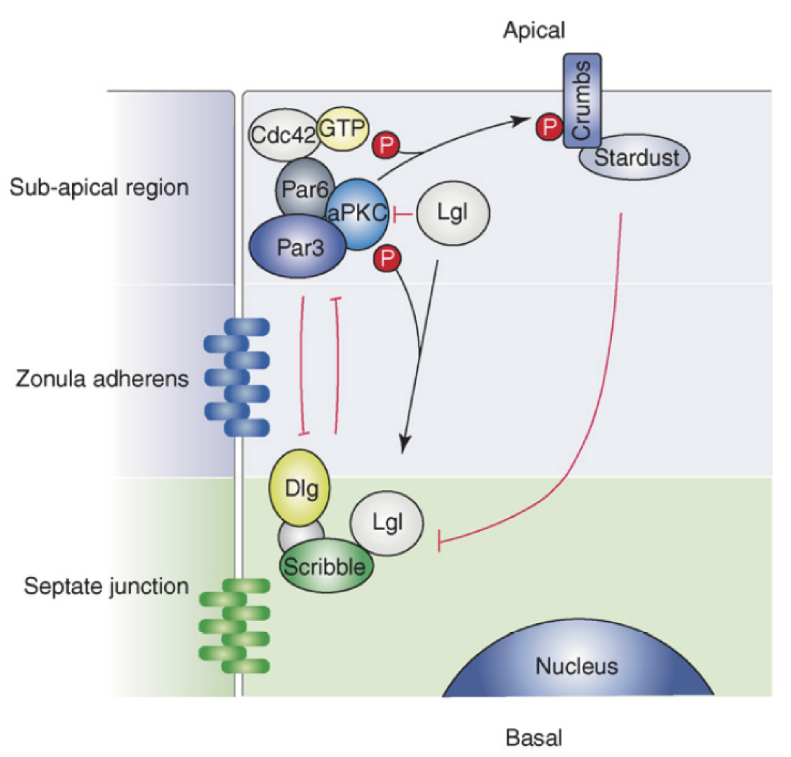

Figure 1-4. Interactions between Par/aPKC, Crb and Scrib complexes in Drosophila epithelial cells. Red lines indicate antagonistic interaction between complexes (Humbert et al., 2006).

Another polarity complex localizes to the basolateral plasma membrane and consists of Scribble (Scrib), Discs large (Dlg) and Lethal giant larvae (Lgl) proteins (Bilder et al., 2000). Scrib is a cytosolic protein that contains four PDZ domains and 16 leucine-rich repeats that are implicated in localization of Scrib to the plasma membrane (Navarro et al., 2005). Both Dlg and Lgl are cytoplasmic; Dlg is a MAGUK protein, while Lgl contains several WD40 repeats. Apical and basolateral protein complexes are mutually antagonistic in regulation of apical and basolateral membrane formation, and mutations in any of them lead to defects in epithelial polarity (Fig. 1-4; Bilder et al., 2003; Tanentzapf and Tepass, 2003). The Par/aPKC complex initiates the assembly of adherens junctions and polarization of epithelia (Harris and Peifer, 2005). The Scrib complex counteracts the Par/aPKC complex to allow formation of the basolateral membrane domain, while phosphorylation of $\mathrm{Lgl}$ by aPKC restricts its activity to the basolateral membrane (Fig. 1-4; Betschinger et al., 2003; Bilder and Perrimon, 2000; Hutterer et al., 2004). In addition, the Crb complex is necessary to maintain the apical membrane domain by inhibition of the Scrib complex (Bilder et al., 2003; Tanentzapf and Tepass, 2003).

In addition to differences in the protein composition apical and basolateral membrane domains have a distinct lipid composition. The apical membrane is enriched in $\mathrm{PI}(4,5) \mathrm{P}_{2}$, while $\mathrm{PI}(3,4,5) \mathrm{P}_{3}$ is more abundant at the basolateral plasma membrane (Gassama-Diagne et al., 2006; Martin-Belmonte et al., 2007). PI(4,5) $\mathrm{P}_{2}$ in turn recruits Cdc42 via Annexin II to the apical plasma membrane and therefore promotes establishment of apical plasma 
membrane domain (Martin-Belmonte et al., 2007).

\subsubsection{Endocytosis in regulation of cell polarity}

The balance between the apical and basolateral polarity complexes is essential to maintain proper epithelial polarity. This balance is regulated on one hand by delivery of newly synthesized proteins to the cell membrane, and on the other hand by endocytosis of excess of proteins from the plasma membrane (Leibfried and Bellaiche, 2007).

Adherens junctions are crucial for the function of epithelial cells and maintenance of their polarity. E-cadherin is a core component of adherens junctions and ensures interaction between two epithelial cells by homophilic binding between two E-cadherin molecules. Regulation of E-cadherin by endocytosis has been widely investigated in mammalian cells. E-cadherin trafficking is important in regulation of cell-cell contact dynamics (Le et al., 1999). After uptake in early endosomes E-cadherin can follow two routes through the endocytic pathway (Delva and Kowalzcyk, 2009). E-cadherin can be delivered back to the plasma membrane via the recycling endosome. This results in reinforcement of cell-cell contacts at tight junctions. Rab11 activity is necessary for efficient E-cadherin recycling. If Rab11 is mutated, E-cadherin is lost from the plasma membrane and polarity of the cells is disrupted (Desclozeaux et al., 2008). Alternatively, E-cadherin can be sent for degradation in lysosomes, thus decreasing the number of E-cadherin molecules at the cell surface. As a result, cell-cell contacts become weaker. Upon excessive removal of E-cadherin from plasma membranes the cells loose adherens junctions and finally undergo epithelialmesenchymal transition (Lu et al., 2003; Palacios et al., 2005).

In the Drosophila embryo, uptake of E-cadherin from adherens junctions by endocytosis is especially active during embryonic development, when rapid cell movement and tissue remodeling takes place (Emery and Knoblich, 2006). Expression of dominant negative Rab11 leads to defects in the recycling of E-cadherin and $\mathrm{Crb}$ and their loss from the plasma membrane (Roeth et al., 2009). Interestingly, Crb becomes mislocalized first, suggesting that $\mathrm{Crb}$ might be either more sensitive towards defects in recycling, or mislocalization of E-cadherin might be caused by loss of Crb.

Defects in early endocytosis can also lead to loss of cell polarity. Deletion of Rab5 or avalanche, a protein involved in early endosome formation, leads to accumulation of $\mathrm{Crb}$ at the apical membrane ( $\mathrm{Lu}$ and Bilder, 2005). Upon defects in early steps of endocytosis excess of $\mathrm{Crb}$ cannot be removed from the plasma membrane. The epithelial cells lose their 
polarity, and begin to overproliferate, leading to tumorous overgrowths. Also defects in later steps of endocytosis can affect cell polarity. Erupted (Ept) and Vps25 are components of the ESCRT machinery and are needed for the transition from early to late endosome. Loss of ept and vps25 leads to defects in Crb localization, apicobasal polarity of epithelial cells and tissue overgrowth (Moberg et al., 2005; Thompson et al., 2005; Vaccari et al., 2005). In addition, mutations in Scrib complex genes also lead to expansion of the apical membrane domain and tumors, indicating that defects in polarity can promote tissue overproliferation (Bilder et al., 2000).

Investigations in both mammalian and Drosophila systems indicate that endocytosis is an important mechanism in regulation of cell polarity. The regulation of cell polarity via endocytosis depends on degradation and recycling of the polarity complexes. Disruption of any of the steps along the endocytic pathway results in overaccumulation or loss of polarity proteins and ultimately to defects in the polarity and function of epithelial cells.

\subsubsection{The Par/aPKC complex in regulation of endocytosis}

As discussed in the previous chapter, endocytosis is involved in regulation of cell polarity complexes. Recent discoveries show that some of the polarity proteins also participate in regulation of endocytosis. In a genetic screen in C.elegans the Par/aPKC complex was found to regulate endocytosis (Balklava et al., 2007). According to the results of the screen, Par/aPKC complex proteins seem to act on several steps in endocytosis - they promote clathrin-dependent endocytosis and maintain functional recycling endosomes. It is still unknown which effector proteins mediate the function of the Par/aPKC complex in endocytosis in C.elegans.

In Drosophila, the Par/aPKC complex regulates the uptake of adherens junction proteins like E-cadherin and of apical markers like Crb in early endosomes (Gerogiou et al. 2008; Harris and Tepass 2008; Leibfried et al. 2008). Interestingly, the localization of basolateral proteins was not affected by mutations of the Par/aPKC complex proteins, indicating that different mechanisms regulate their turnover (Harris and Tepass, 2008; Leibfried et al., 2008). In Drosophila pupal epithelium, Cdc42 promotes endocytosis of E-cadherin. When Cdc42, Par6 or aPKC is lost, E-cadherin cannot be efficiently endocytosed, leading to destabilization of adherens junctions (Gerogiou et al. 2008; Leibfried et al. 2008). The effect of the Par/aPKC complex on early steps of endocytosis is mediated by the Cdc42 effector Cip4 (Leibfried et al., 2008). Cip4 binds to dynamin and promotes vesicle 
formation and scission (Leibfried et al., 2008). Cip4 also interacts with the Arp $2 / 3$ complex, which initiates actin polymerization and thus links vesicle fission and transport (Leibfried et al., 2008; Fricke et al., 2009). In contrast, studies in Drosophila embryonic ectoderm show that dominant negative Cdc42 leads to loss of E-cadherin and Crb from the plasma membrane, suggesting that active Cdc42 slows down endocytosis of these proteins (Harris and Tepass, 2008). Also studies in mammalian cells provide contradictory data about the role of $\mathrm{Cdc} 42$ in early endocytosis. Active $\mathrm{Cdc} 42$ has been proposed to inhibit uptake of dimeric E-cadherin at adherens junctions (Izumi et al., 2004), while another study shows that active Cdc42 is involved in ubiquitination and lysosome targeting of Ecadherin (Shen et al., 2008). In line with the latter observation that active Cdc42 promotes endocytosis, a Cdc42 GAP has been shown to reduce uptake of apical proteins by inactivating Cdc42 (Wells et al., 2006).

Par/aPKC complex proteins also regulate delivery of apical proteins to late endosomes via an unknown mechanism (Harris and Tepass, 2008). Dominant negative Cdc42 induces loss of $\mathrm{Crb}$ and Par/aPKC complex proteins from the plasma membrane and accumulation in Hrs positive endosomes. Similarly, deletion of the ESCRT protein Ept impairs transition to late endosomes and causes accumulation of Crb in early endosomes (Gilbert et al., 2009; Moberg et al., 2005). The role of other members of the Par/aPKC complex in late endosome formation is not clear so far. Although the phenotypes of ept loss of function and Cdc42 dominant negative flies are similar with regard to Crb trafficking, the effect of aPKC in these two genetic backgrounds was cardinally different. While constitutively active aPKC rescued the dominant negative Cdc42 phenotype (Harris and Tepass, 2008), dominant negative aPKC was able to rescue the Crb mislocalization phenotype caused by loss of ept (Gilbert et al., 2009). 


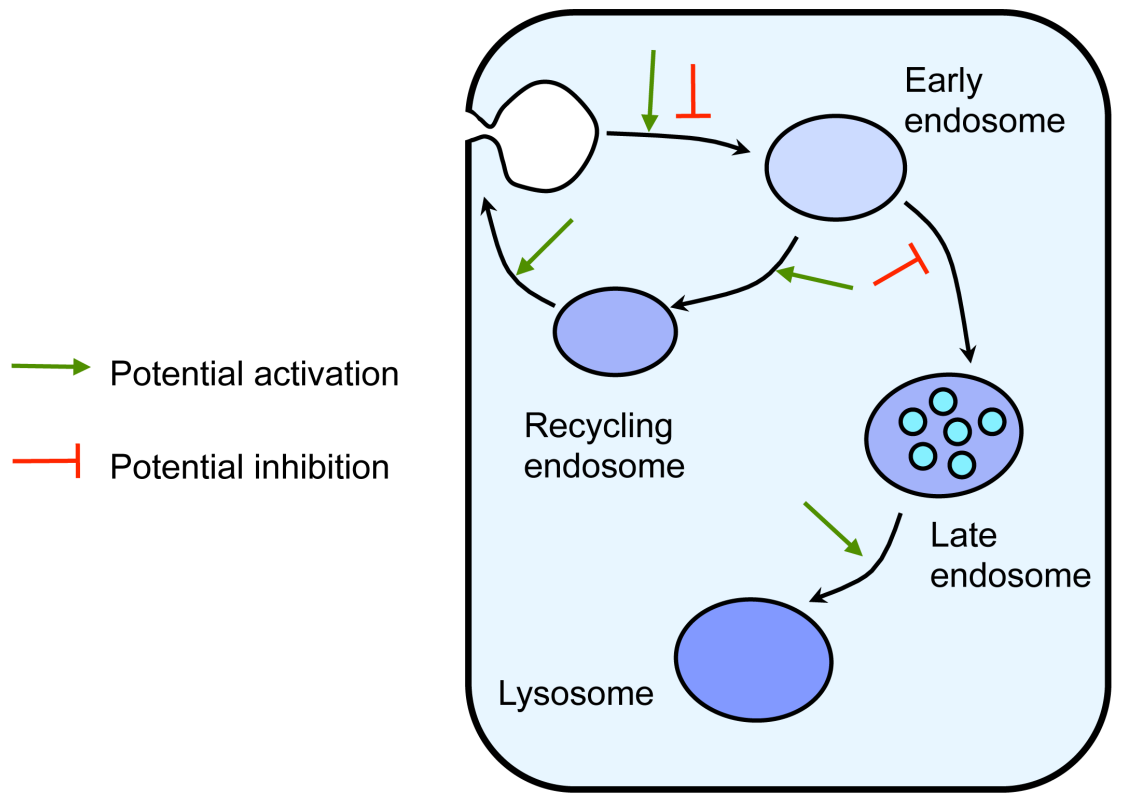

Figure 1-5. Possible effects of the Par/aPKC complex on endocytosis of Crb and E-cadherin. Endocytosed $\mathrm{Crb}$ and E-cadherin can be either recycled back to the plasma membrane or degraded in lysosomes. The places at which the Par/aPKC complex proteins may affect the trafficking are indicated with arrows.

Analysis of the role of Par/aPKC complex proteins in trafficking in Drosophila epithelia has revealed a complex picture. The effect of $\mathrm{Cdc} 42$ is so far best characterized. It seems that $\mathrm{Cdc} 42$ and other Par/aPKC complex members can act on different steps of endocytosis, and often the results show opposing effects (Fig. 1-5). Therefore further research will be needed to clarify the role of the Par/aPKC complex in endocytosis.

\subsection{Rush - a new endosomal protein}

Although the role of Par/aPKC complex proteins in regulation of endocytosis has been shown in a number of studies, the observed effects have been contradictory. In addition effectors of the Par/aPKC complex in endocytosis, especially at later stages, are largely unknown. In order to gain further insight in the function of the Par/aPKC complex, a yeast two-hybrid screen was conducted using the N-terminus of Baz as a bait. One of the isolated potential interaction partners of Baz was the product of the predicted gene CG14782 (Egger-Adam, 2005). CG14782 encodes a so far uncharacterized Drosophila protein with high sequence similarity along the full sequence length with homologs in other organisms from $C$. elegans to vertebrates $(74,6 \%$ sequence identity between $D$. melanogaster and Homo sapiens). We named the gene rush hour (rush) due to its 
phenotype, which is described in the Results chapter. Rush consists mainly of two domains that are implicated in interaction with phosphoinositides - a PH (pleckstrin homology) domain and a FYVE (Fablp, YOTB, Vac1p, EEA1) domain (Fig. 1-6). The FYVE domains have been described to bind exclusively to $\mathrm{PI}(3) \mathrm{P}$, while $\mathrm{PH}$ domains can interact with a broader set of phosphoinositides (Kavran et al., 1998; Lemmon, 2008). Most of FYVE domain containing proteins localize to endosomes (Gillooly et al., 2001), suggesting that Rush might be involved in endocytosis.

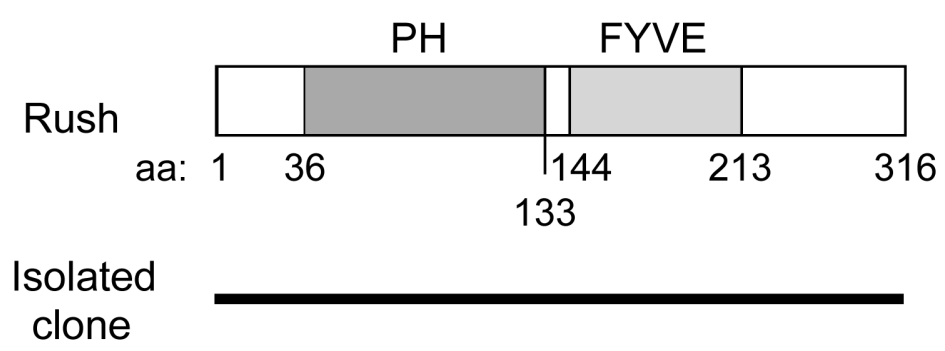

Figure 1-6. Protein structure of Rush. PH and FYVE domains are indicated. The black box depicts the cDNA clone, isolated in the yeast two-hybrid experiment. Adapted from Egger-Adam, 2005.

Rush has two human homologs, Phafin1 and Phafin2, with the highest similarity to Phafin2. The role of these proteins in human cells is poorly characterized. Both Phafin1 and Phafin2 were proposed to promote TNF $\alpha$-induced apoptosis (Chen et al., 2005, Li et al., 2007, Li et al., 2008). Upon apoptosis-inducing stimulus, Phafin1 translocates to lysosomes and promotes permeabilization of lysosomal membranes (Chen et al., 2005, Li et al., 2008), while Phafin2 promotes endoplasmic reticulum-mediated apoptotic response (Li et al., 2007). In contrast to these results, a recent study proposed a role of Phafin2 in endocytosis (Lin et al., 2010). Expression of Phafin2 in the HepG2 human liver cancer cell line resulted in formation of enlarged endosomes, possibly due to activation of Rab5. Interestingly, Phafin2 is overexpressed in several cancer types like human hepatocellular carcinoma and breast cancer (Chen et al., 2002; Lin et al., 2010; Weisz et al., 2004).

The aim of this work was to investigate the role and function of Rush in Drosophila development. To this end I generated a Rush null allele and analyzed effects of Rush loss and overexpression in different epithelial systems. According to the domain structure of Rush and the function of the human homolog (Lin et al., 2010), Rush could act in regulation of endocytosis. To investigate this possibility colocalization of Rush with markers of the endosomal pathway as well as the effect of Rush deletion and 
overexpression on endocytosis was analyzed. It was especially intriguing to determine whether Rush plays a role in endocytosis of polarity proteins or Par/aPKC-regulated endocytosis. For this purpose I performed genetic interaction experiments in a $\mathrm{Cdc} 42$ dominant negative background. The effect of dominant negative Cdc42 on endocytosis has been previously described (Harris and Tepass, 2008). Finally I used pulldown experiments with putative interaction partners deduced from genome-wide screens in yeast and mammals to gain an insight in the mechanism of Rush function. 


\section{Materials and Methods}

\subsection{Materials}

\subsubsection{Chemicals and enzymes}

All chemicals were of analytical grade and purchased from following companies: Biomol (Hamburg, Germany), Bio-Rad (Munich, Germany), Biozym (Oldendorf, Germany), Difco (Detroit, USA), Fluka (Buchs, Switzerland), Gibco/BRL Life Technologies (Karlsruhe, Germany), Merck (Darmstadt, Germany), Polysciences (Eppelheim, Germany), Roth (Karlsruhe, Germany), Serva (Heidelberg, Germany), Sigma-Aldrich (Steinheim, Germany), Macherey-Nagel (Düren, Germany).

Solutions were prepared in distilled water and sterilized by autoclaving or sterile filtration. Enzymes for molecular biology methods were purchased from Bioline (Luckenwalde, Germany), Fermentas (St. Leon-Rot, Germany), Genecraft (Lüdingshausen, Germany), Promega (Madison, USA), Roche (Mannheim, Germany).

\subsubsection{Primers}

Primers were designed using DNA-Star Lasergene V6 program (DNASTAR Inc., Madison, USA). Primer synthesis was done by companies Biotez (Berlin, Germany) and Metabion (Martinsried, Germany). Primers used in this work are listed in Table 2-1.

Table 2-1. List of oligonucleotides

\begin{tabular}{l|l|l}
\hline Name & Sequence 5' ->, & Description \\
\hline EG-N-for & CACCGTGGACCGTCTGGTCAACTCG & $\begin{array}{l}\text { Cloning of } r \text { s } h \text { in } \\
\text { pENTR }\end{array}$ \\
\hline EG-N-rev & TCAACAGTGGCTGCCCGTCGTCG & $\begin{array}{l}\text { Cloning of rus } h \text { in } \\
\text { pENTR }\end{array}$ \\
\hline EG-C-for & CACCATGGTGGACCGTCTGGTCAACTCG & $\begin{array}{l}\text { Cloning of } r u s h \text { in } \\
\text { pENTR }\end{array}$ \\
\hline EG-C-rev & ACAGTGGCTGCCCGTCGTCG & $\begin{array}{l}\text { Cloning of rus } h \text { in } \\
\text { pENTR }\end{array}$ \\
\hline
\end{tabular}




\begin{tabular}{|c|c|c|}
\hline $\begin{array}{l}\text { CG1418 } \\
\text { Ngatefor }\end{array}$ & CACCGCACACACTGGCGGGAACC & $\begin{array}{l}\text { Cloning of } C G 1418 \text { in } \\
\text { pENTR }\end{array}$ \\
\hline $\begin{array}{l}\text { CG1418 } \\
\text { Ngaterev }\end{array}$ & TCAGACAACCTGGGCGAGGAAACC & $\begin{array}{l}\text { Cloning of } C G 1418 \text { in } \\
\text { pENTR }\end{array}$ \\
\hline $\begin{array}{l}\text { GDI } \\
\text { Ngatefor }\end{array}$ & CACCAATGAGGAATACGATGCGATTG & $\begin{array}{l}\text { Cloning of GDI in } \\
\text { pENTR }\end{array}$ \\
\hline $\begin{array}{l}\text { GDI } \\
\text { Ngaterev }\end{array}$ & TTACTGCTCCTCGTCACCCAACTCG & $\begin{array}{l}\text { Cloning of } G D I \text { in } \\
\text { pENTR }\end{array}$ \\
\hline M13 for & GTAAAACGACGGCCAG & $\begin{array}{l}\text { Sequencing of inserts in } \\
\text { pENTR vector }\end{array}$ \\
\hline M13 rev & CAGGAAACAGCTATGAC & $\begin{array}{l}\text { Sequencing of inserts in } \\
\text { pENTR vector }\end{array}$ \\
\hline $\begin{array}{l}\text { EGFP-C- } \\
\text { for }\end{array}$ & CAAAGACCCCAACGAGAAG & $\begin{array}{l}\text { Sequencing of destination } \\
\text { vectors }\end{array}$ \\
\hline $\begin{array}{l}\text { EGFP-N- } \\
\text { rev }\end{array}$ & CGGACACGCTGAACTTGTG & $\begin{array}{l}\text { Sequencing of destination } \\
\text { vectors }\end{array}$ \\
\hline GST for & CAGCAAGTATATAGCATGGC & $\begin{array}{l}\text { Sequencing of destination } \\
\text { vectors }\end{array}$ \\
\hline MBP for & GCGTGCTGAGCGCAGGTATTAACGCCGC & $\begin{array}{l}\text { Sequencing of destination } \\
\text { vectors }\end{array}$ \\
\hline UASPf & GGCAAGGGTCGAGTCGATAG & $\begin{array}{l}\text { Sequencing of destination } \\
\text { vectors }\end{array}$ \\
\hline CG gst for & CAGGATCCGTGGACCGTCTGGTCAACTCG & $\begin{array}{l}\text { Cloning of rush in } \\
\text { pGEX-4T-1 }\end{array}$ \\
\hline CG gst rev & GAGAATTCTCAACAGTGGCTGCCCGTCG & $\begin{array}{l}\text { Cloning of rush in } \\
\text { pGEX-4T-1 }\end{array}$ \\
\hline $\begin{array}{l}\text { FYVE gst } \\
\text { for }\end{array}$ & CTGGATCCAACCACGCCGCCGTTTGGG & $\begin{array}{l}\text { Cloning of Rush FYVE } \\
\text { domain in pGEX-4T-1 }\end{array}$ \\
\hline $\begin{array}{l}\text { FYVE gst } \\
\text { rev }\end{array}$ & GTGAATTCTCAGTGCTTCAAGCGCTCGTAGC & $\begin{array}{l}\text { Cloning of Rush FYVE } \\
\text { domain in pGEX-4T-1 }\end{array}$ \\
\hline
\end{tabular}


Materials and Methods

\begin{tabular}{l|l|l}
\hline PH gst for & GAGGATCCCTGGTGGGCGAGGGC & $\begin{array}{l}\text { Cloning of Rush PH } \\
\text { domain in pGEX-4T-1 }\end{array}$ \\
\hline PH gst rev & GAGAATTCTCACAGGTCCTCCACGCAC & $\begin{array}{l}\text { Cloning of Rush PH } \\
\text { domain in pGEX-4T-1 }\end{array}$ \\
\hline FYR176Gf & GCATCACTGCGGCAACTGCGGCGCTGTTG & $\begin{array}{l}\text { Point mutation R176G in } \\
\text { Rush FYVE domain }\end{array}$ \\
\hline FYR176Gr & CAACAGCGCCGCAGTTGCCGCAGTGATGC & $\begin{array}{l}\text { Point mutation R176G in } \\
\text { Rush FYVE domain }\end{array}$ \\
\hline PH DN for & CCAAGATGTGTCGCGAGCGGCCCAAGTCG & $\begin{array}{l}\text { Point mutation K48E in } \\
\text { Rush PH domain }\end{array}$ \\
\hline PH DN rev & CGACTTGGGCCGCTCGCGACACATCTTGG & $\begin{array}{l}\text { Point mutation K48E in } \\
\text { Rush PH domain }\end{array}$ \\
\hline CG UTR & GTATTTCTCCAAGTATTGCTGCCAGC & $\begin{array}{l}\text { Verification of } r u s h \\
\text { deletion }\end{array}$ \\
\hline Sta rev & GTACATTGTTGTGGTAGTTACAGATGG & $\begin{array}{l}\text { Verification of } r u s h \\
\text { deletion }\end{array}$ \\
\hline
\end{tabular}

\subsubsection{Vectors}

Table 2-2. List of vectors

\begin{tabular}{l|l|l}
\hline Plasmid & Description & Reference or source \\
\hline pHSI-65 & cDNA clone, containing Rush sequence & Egger-Adam, 2005 \\
\hline pENTR/D-TOPO & $\begin{array}{l}\text { Entry vector for Gateway cloning, } \\
\text { kanamycin resistance }\end{array}$ & Invitrogen, Carlsbad, Germany \\
\hline pTGW & $\begin{array}{l}\text { Expression vector, UASt promoter, N- } \\
\text { terminal GFP tag, ampicilin resistance }\end{array}$ & Murphy lab, Baltimore, USA \\
\hline pTWG & $\begin{array}{l}\text { Expression vector, UASt promoter, C- } \\
\text { terminal GFP tag, ampicilin resistance }\end{array}$ & Murphy lab, Baltimore, USA \\
\hline pPWR & $\begin{array}{l}\text { Expression vector, UASp promoter, C- } \\
\text { terminal RFP tag, ampicilin resistance }\end{array}$ & Murphy lab, Baltimore, USA \\
\hline
\end{tabular}




\begin{tabular}{|c|c|c|}
\hline pAHW & $\begin{array}{l}\text { Expression vector, Actin5C promoter, N- } \\
\text { terminal 3x HA tag, ampicilin resistance }\end{array}$ & Murphy lab, Baltimore, USA \\
\hline pAWH & $\begin{array}{l}\text { Expression vector, Actin5C promoter, } \mathrm{C} \text { - } \\
\text { terminal 3x HA tag, ampicilin resistance }\end{array}$ & Murphy lab, Baltimore, USA \\
\hline pAGW & $\begin{array}{l}\text { Expression vector, Actin5C promoter, N- } \\
\text { terminal GFP tag, ampicilin resistance }\end{array}$ & Murphy lab, Baltimore, USA \\
\hline pAWG & $\begin{array}{l}\text { Expression vector, Actin5C promoter, C- } \\
\text { terminal GFP tag, ampicilin resistance }\end{array}$ & Murphy lab, Baltimore, USA \\
\hline pWAGAL4 & GAL4 expression vector, Actin promoter & Y. Hiromi, unpublished \\
\hline pGGWA & $\begin{array}{l}\text { Destination vector for expression of GST } \\
\text { fusion proteins in } E \text {. coli, ampicilin } \\
\text { resistance }\end{array}$ & Murphy lab, Baltimore, USA \\
\hline pMGWA & $\begin{array}{l}\text { Destination vector for expression of MBP } \\
\text { fusion proteins in } E \text {. coli, ampicilin } \\
\text { resistance }\end{array}$ & Murphy lab, Baltimore, USA \\
\hline pGEX-4T-1 & $\begin{array}{l}\text { Vector for expression of GST fusion } \\
\text { proteins in E. coli, ampicilin resistance }\end{array}$ & $\begin{array}{l}\text { Amersham Pharmacia Biotech, } \\
\text { Buckinghamshire, England }\end{array}$ \\
\hline
\end{tabular}

\subsubsection{Bacterial strains}

Table 2-3. List of bacterial strains

\begin{tabular}{|c|c|c|c|}
\hline Strain & Genotype & Application & Source \\
\hline $\mathrm{DH} 5 \alpha$ & 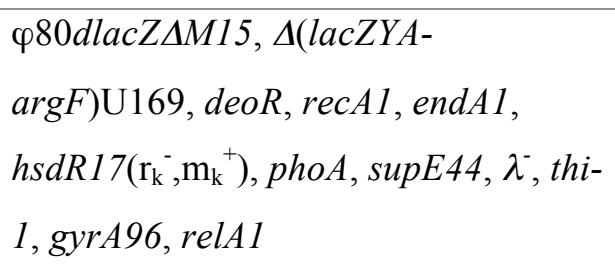 & $\begin{array}{l}\text { Amplification of plasmid } \\
\text { DNA }\end{array}$ & Invitrogen \\
\hline BL21 & $\begin{array}{l}\mathrm{F}-, o m p \mathrm{~T}, h s d S_{B}\left(\mathrm{r}_{\mathrm{B}^{-}}, \mathrm{m}_{\mathrm{B}^{-}}\right), d c m, g a l, \\
\lambda(\mathrm{DE} 3)\end{array}$ & $\begin{array}{l}\text { Expression of recombinant } \\
\text { proteins }\end{array}$ & Invitrogen \\
\hline TOP10 & $\begin{array}{l}\mathrm{F}-, m c r A, \Delta(m r r-h s d \mathrm{RMS}-m c r \mathrm{BC}), \\
\varphi 80 d l a c Z \Delta M 15, \Delta l a c X 74, \text { deo } \mathrm{R}, \\
\operatorname{rec} \mathrm{A} 1, \operatorname{ara\mathrm {D}} 139, \Delta(\text { ara }, \text { leu }) 7697, \\
\text { galK, rpsL(strr), endA } 1, \text { nup } \mathrm{G}\end{array}$ & $\begin{array}{l}\text { Cloning of PCR fragments in } \\
\text { pENTR vector }\end{array}$ & Invitrogen \\
\hline $\begin{array}{l}\text { XL1- } \\
\text { Blue }\end{array}$ & $\begin{array}{l}\text { endA1, gyrA96 }\left(\text { nal }^{\mathrm{R}}\right) \text {, thi-1, } \operatorname{rec} A 1, \\
\text { relA1, lac, glnV44, F'[ ::Tn10 proAB } \\
\left.\text { lacI }^{\mathrm{q}} \Delta(\mathrm{lacZ}) \mathrm{M} 15\right], \text { hsdR } 17\left(\mathrm{r}_{\mathrm{K}}^{-} \mathrm{m}_{\mathrm{K}}^{+}\right)\end{array}$ & Site-directed mutagenesis & Stratagene \\
\hline
\end{tabular}




\subsubsection{Antibodies}

Table 2-4. List of primary antibodies

\begin{tabular}{|c|c|c|c|c|}
\hline Epitope & Animal & Dilution & Designation & Reference, source \\
\hline Actin & Rabbit & $1: 1000$ & A2066 & Sigma \\
\hline Bazooka & Rabbit & $1: 1000$ & DE99646-2 & Wodarz et al., 2000 \\
\hline Bazooka & Rat & $1: 1000$ & DE99647-1 & Wodarz et al., 1999 \\
\hline $\begin{array}{l}\text { Rush C- } \\
\text { term }\end{array}$ & Rabbit & $1: 1000$ & $\begin{array}{l}\text { DE03410, affinity } \\
\text { purified, EP033850 }\end{array}$ & Egger-Adam, 2005 \\
\hline $\mathrm{Crb}$ & Mouse & $1: 50$ & $\mathrm{Cq} 4$ & $\begin{array}{l}\text { Developmental Studies Hybridoma } \\
\text { Bank, University of Iowa, USA }\end{array}$ \\
\hline $\begin{array}{l}\text { DE- } \\
\text { Cadherin }\end{array}$ & Rat & $1: 2$ & DCAD 2 & $\begin{array}{l}\text { Developmental Studies Hybridoma } \\
\text { Bank, University of Iowa, USA }\end{array}$ \\
\hline FasIII & Mouse & $1: 20$ & $7 \mathrm{G} 10$ & $\begin{array}{l}\text { Developmental Studies Hybridoma } \\
\text { Bank, University of Iowa, USA }\end{array}$ \\
\hline GDI2 & Rabbit & $1: 1000$ & AV13037 & Sigma-Aldrich \\
\hline GFP & Mouse & $1: 1000$ & \# 11814460001 & Roche \\
\hline GFP & Mouse & $1: 1000$ & \# A11120 & Invitrogen \\
\hline GFP & Rabbit & $1: 1000$ & \# A11122 & Invitrogen \\
\hline GST & Rabbit & $1: 20000$ & G7781 & Sigma-Aldrich \\
\hline HA & Mouse & $1: 1000$ & \#11 583816001 & Roche \\
\hline HA & Rat & $1: 1000$ & \# 11867423001 & Roche \\
\hline Hrs & Guinea pig & $1: 1000$ & & Lloyd et al., 2002 \\
\hline Lva & Rabbit & $1: 1000$ & & Sisson et al., 2000 \\
\hline Orb & Mouse & $1: 20$ & $4 \mathrm{H} 8$ & $\begin{array}{l}\text { Developmental Studies Hybridoma } \\
\text { Bank, University of Iowa, USA }\end{array}$ \\
\hline Par6 & Guinea pig & $1: 1000$ & DE02639 SA172 & Kim et al., 2009 \\
\hline Rab5 & Rabbit & $1: 1000$ & & Tanaka and Nakamura, 2008 \\
\hline Rab7 & Rabbit & $1: 1000$ & & Tanaka and Nakamura, 2008 \\
\hline Rab11 & Rabbit & $1: 1000$ & & Tanaka and Nakamura, 2008 \\
\hline
\end{tabular}


Table 2-5. List of secondary antibodies

\begin{tabular}{l|l|l|l|l}
\hline Epitope & Animal & Tag & Dilution & Source \\
\hline Mouse IgG & Goat & HRP & $1: 10000$ & Dianova \\
\hline Rabbit IgG & Goat & HRP & $1: 10000$ & Dianova \\
\hline Rat IgG & Goat & HRP & $1: 10000$ & Dianova \\
\hline Guinea pig IgG & Donkey & Cy3 & $1: 200$ & Dianova \\
\hline Guinea pig IgG & Donkey & Cy5 & $1: 200$ & Dianova \\
\hline Mouse IgG & Donkey & Cy2 & $1: 200$ & Dianova \\
\hline Mouse IgG & Donkey & Cy3 & $1: 200$ & Dianova \\
\hline Rabbit IgG & Goat & Cy2 & $1: 200$ & Dianova \\
\hline Rabbit IgG & Donkey & Cy3 & $1: 200$ & Dianova \\
\hline Rabbit IgG & Goat & Cy5 & $1: 200$ & Dianova \\
\hline Rat IgG & Goat & Cy5 & $1: 200$ & Dianova \\
\hline
\end{tabular}

\subsection{Molecular biology methods}

\subsubsection{Polymerase chain reaction (PCR)}

Amplification of DNA fragments was done with the PCR method (Mullis and Faloona, 1987) according to a standard procedure (Sambrook and Russel, 2001). PCR reactions were done in $50 \mu \mathrm{l}$ total reaction volume. Per reaction 20-50 ng of plasmid DNA or $200 \mathrm{ng}$ of fly genomic DNA were mixed with $200 \mathrm{nM}$ of forward/reverse primer (Table 2-1), 250 $\mu \mathrm{M}$ of each dNTP (Bioline, Luckenwalde, Germany) and $1 \mathrm{U}$ of polymerase in the corresponding reaction buffer. Depending on the aim of DNA amplification, Taq polymerase (Genecraft, Lüdingshausen, Germany) or Pfu polymerase (Bioline, Luckenwalde, Germany) were used. Pfu polymerase was used to amplify DNA fragments for cloning due to its higher proof-reading activity.

A standard PCR program is shown in Table 2-6. PCR programs were run on Master Cycler Personal (Eppendorf, Hamburg, Germany). PCR products were purified either directly from the PCR reaction mixture or after agarose gel electrophoresis (see 2.2.3.) by cutting out of the gel the DNA band of correct size. In both cases NucleoSpin Extract II kit (Macherey-Nagel, Düren, Germany) was used according to manufacturer's instructions. PCR products were eluted in $30 \mu$ d distilled $\mathrm{H}_{2} \mathrm{O}$. 
Table 2-6. Standard PCR program

\begin{tabular}{|c|c|c|}
\hline Step & Temperature & Duration \\
\hline 1) Initial denaturation & $95^{\circ} \mathrm{C}$ & $5 \min$ \\
\hline 2) Denaturation & $95^{\circ} \mathrm{C}$ & $30 \mathrm{sec}$ \\
\hline 3) Annealing & $\begin{array}{l}50-70{ }^{\circ} \mathrm{C} \text { depending on } \\
\text { primer pair }\end{array}$ & $30 \mathrm{sec}$ \\
\hline 4) Elongation & $72^{\circ} \mathrm{C}$ & $\begin{array}{l}\text { Depending on } \\
\text { construct length } \\
(1 \mathrm{~min} / \mathrm{kb})\end{array}$ \\
\hline \multicolumn{3}{|c|}{ Repeat steps 2-4 34 times } \\
\hline 5) Final elongation & $72{ }^{\circ} \mathrm{C}$ & $5 \mathrm{~min}$ \\
\hline 6) End of the reaction & $4{ }^{\circ} \mathrm{C}$ & $\infty$ \\
\hline
\end{tabular}

\subsubsection{Long template PCR}

Expand Long Template PCR System (Roche, Mannheim, Germany) was used to amplify PCR fragments longer than $3 \mathrm{~kb}$. To verify deletion of Rush genomic region in flies, long template PCR reactions were set up according to manufacturer's instructions. The PCR reaction mix used to amplify Rush genomic region is shown in Table 2-7. PCR program for long template PCR is shown in Table 2-8.

Table 2-7. PCR mix for verification of Rush deletion.

\begin{tabular}{c|c} 
Component & Volume $(\boldsymbol{\mu l})$ \\
\hline Template genomic DNA & $1-2 \mu \mathrm{l}(300 \mathrm{ng})$ \\
\hline 10x Buffer 2 & $5 \mu \mathrm{l}$ \\
\hline Long template enzyme mix & $0,75 \mu \mathrm{l}$ \\
\hline dNTP $(25 \mathrm{mM}$ each $)$ & $1 \mu \mathrm{l}$ \\
\hline CG UTR down primer $(50 \mu \mathrm{M})$ & $0,3 \mu \mathrm{l}$ \\
\hline Sta rev primer $(50 \mu \mathrm{M})$ & $0,3 \mu \mathrm{l}$ \\
\hline Water & Fill up to $50 \mu \mathrm{l}$
\end{tabular}


Table 2-8. PCR program for long template PCR.

\begin{tabular}{l|l|l}
\hline Step & Temperature & Duration \\
\hline 1) Initial denaturation & $94{ }^{\circ} \mathrm{C}$ & $2 \mathrm{~min}$ \\
\hline 2) Denaturation & $94{ }^{\circ} \mathrm{C}$ & $10 \mathrm{sec}$ \\
\hline 3) Annealing & $60{ }^{\circ} \mathrm{C}$ & $30 \mathrm{sec}$ \\
\hline 4) Elongation & $68^{\circ} \mathrm{C}$ & $4 \mathrm{~min}$ \\
\hline \multicolumn{3}{|l|}{ Repeat steps 2-4 10 times } \\
\hline 5) Denaturation & $94{ }^{\circ} \mathrm{C}$ & $15 \mathrm{sec}$ \\
\hline 6) Annealing & $60{ }^{\circ} \mathrm{C}$ & $30 \mathrm{sec}$ \\
\hline 7) Elongation & $68^{\circ} \mathrm{C}$ & $4 \mathrm{~min}+20 \mathrm{sec}$ for each cycle \\
\hline & \multicolumn{1}{|c}{ Repeat steps 5-7 10 times } \\
\hline 8) Final elongation & $68^{\circ} \mathrm{C}$ & $7 \mathrm{~min}$ \\
\hline 9) End of the reaction & $4{ }^{\circ} \mathrm{C}$ & $\infty$ \\
\hline
\end{tabular}

\subsubsection{Agarose gel electrophoresis}

To analyze DNA fragments produced in PCR or enzymatic digestion of DNA, horizontal agarose gel electrophoresis system Power Pac Basic (Bio-Rad, Munich, Germany) was used. $1 \%$ agarose gels were used (1\% w/v agarose, $40 \mathrm{mM}$ Tris, $10 \mathrm{mM}$ EDTA). Ethidium bromide $(0,5 \mu \mathrm{g} / \mathrm{ml})$ was added to the solution before pouring the gel. Ethidium bromide intercalates between the base pairs of a DNA molecule. Illumination with UV light $(\lambda=302$ $\mathrm{nm}$ ) causes fluorescence of ethidium bromide and thereby visualizes DNA.

The samples were mixed with 1/6 volume of loading dye solution (Fermentas, St. LeonRot, Germany) and loaded in the pockets of the gel. To determine the size of separated DNA fragments, $5 \mu 1$ of GeneRuler 1kb DNA Ladder (Fermentas, St. Leon-Rot, Germany) were loaded in a separate pocket. Gels were run at $100 \mathrm{~V}$ for 20-30 $\mathrm{min}$ in TAE buffer (40 $\mathrm{mM}$ Tris, $10 \mathrm{mM}$ EDTA). The DNA bands were visualized and photographed with BioDoc-It UV transilluminator (Ultra Violet Products, Upland, USA).

\subsubsection{Estimation of DNA concentration}

Concentration of DNA was determined by the absorption at 260/280 nm with BioPhotometer spectrophotometer (Eppendorf, Hamburg, Germany). Double-stranded DNA has an absorption maximum at $260 \mathrm{~nm}$, while contamination of the sample with 
proteins can be determined by absorption at $280 \mathrm{~nm}$. Absorption quotient $\mathrm{A}_{260 / 280}=1,8$ corresponds to a pure DNA solution.

\subsubsection{Gateway cloning technology}

The Gateway cloning method allows fast cloning of the gene of interest from the entry vector into diverse destination vectors. A wide range of destination vectors is available that allow expression of the protein of interest under control of different promoters and with different N-terminal and C-terminal tags. Gateway cloning employs sequence-specific recombination, done by DNA recombination enzymes from $\lambda$ phage.

\section{TOPO cloning}

Rush was amplified with primers EG-N-for/EG-N-rev (without Start codon to generate Nterminally tagged protein) or EG-C-for/EG-C-rev (without Stop codon to generate Cterminally tagged protein) from plasmid pHSI65 (Table 2-2). GDI and CG1418 were amplified from wild type fly cDNA (prepared by Gang Zhang) with primers GDI Ngatefor/GDI Ngaterev and CG1418 Ngatefor/CG1418 Ngaterev accordingly (Table 1). Purified PCR products were introduced into the pENTR/D-TOPO vector using the pENTR/D-TOPO Cloning kit (Invitrogen, Carlsbad, Germany) according to the manufacturer's protocol. During the reaction the Topoisomerase I cleaves the vector DNA, leaving a 5' overhang, complementary to the CACC sequence in the 5' end of the forward primers, used for amplification of the gene (Table 2-1). These sequences anneal and lead to the cloning of the gene into the vector in the correct orientation. $1 \mu$ of the cloning reaction was used to transform $E$. coli cells. The success of transformation was determined with a treatment with restriction nucleases (Fermentas, St. Leon-Rot, Germany) according to manufacturer's instructions. The sequence of the insert was verified by sequencing using the M13 for and M13 rev primers (Table 2-1).

\section{Gateway LR recombination into expression vectors}

Rush, GDI and CG1418 were transferred from the pENTR/D-TOPO vector into destination vectors (Table 2-2) in the LR recombination reaction. $\lambda$ phage recombination enzymes recognize attL1 and attL2 sequences in the entry vector, cut the gene out and ligate it into 
the destination vector between attR1 and attR2 sequences, forming the expression clone (Fig. 2-1). Due to sequence differences between attL1 and attL2 as well as between attR1 and $\operatorname{attR2}$, the gene is inserted in a correct orientation. Gene $\operatorname{ccdB}$, coding for a toxic protein, is transferred in the same way from the destination vector to the entry vector, forming a by-product of the reaction. The LR recombination reaction was performed with LR Clonase Enzyme Mix (Invitrogen, Carlsbad, Germany) according to the manufacturer's protocol, using $100 \mathrm{ng}$ of pENTR vector and $150 \mathrm{ng}$ of the destination vector. $1 \mu \mathrm{l}$ of the reaction mix was used for transformation of $E$. coli cells. As $c c d B$ codes for a toxic compound, the cells that are transformed with the destination vector or the by-product plasmid do not form colonies. E. coli cells that contain the expression clone were selected by their resistance to ampicilin.
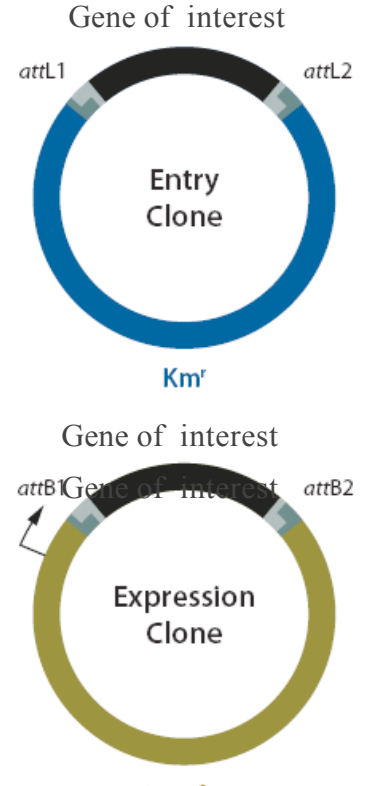

$\mathrm{Ap}^{r}$

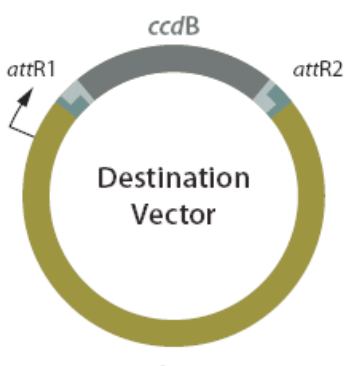

$\mathrm{Ap}^{r}$

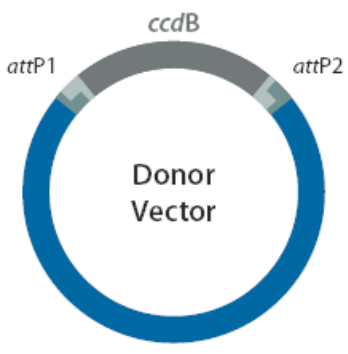

$\mathrm{Km}^{r}$

Figure 2-1. Gateway recombination reaction. $\lambda$ phage recombination enzymes recognize attL1 and attL2 sequences in the entry vector, cut the gene of interest out from the entry clone and ligate it into the destination vector between attR1 and attR2 sequences. The obtained expression clone contains the gene of interest fused to the selected tag. The product of $\operatorname{ccdB}$ is toxic and eliminates cells, transformed with the byproduct of the recombination reaction (Adapted from Invitrogen).

\subsubsection{Cloning of inserts into pGEX-4T-1 vector}

To express GST-tagged proteins in E.coli cells, full Rush sequence or its PH and FYVE domains alone were amplified with primers that contain EcoRI and BamHI recognition 
sites (Table 2-1). Purified PCR products and pGEX-4T-1 vector were digested with EcoRI and BamHI. pGEX-4T-1 vector was dephosphorylated with Shrimp Alkaline Phosphatase (Roche, Mannheim, Germany). PCR products were ligated with the dephosphorylated pGEX-4T-1 vector using T4 DNA Ligase (Fermentas, St. Leon-Rot, Germany). $2 \mu 1$ of ligation reactions were transformed into $E$. coli cells. Success of cloning was verified by sequencing of clones.

\subsubsection{Transformation of chemically competent $E$. coli cells}

E. coli strains used in this work are listed in Table 2-3. In brief, chemically competent $E$. coli cells were transformed as follows: cells were thawn on ice, approx. $100 \mathrm{ng}$ of plasmid DNA was added, gently mixed and incubated on ice for $15 \mathrm{~min}$. Then the cells were heatshocked at $42{ }^{\circ} \mathrm{C}$ for $30 \mathrm{sec}$ in a water bath. The cells were briefly cooled down on ice, 250 $\mathrm{ml}$ of room temperature SOC medium ( $2 \%$ tryptone, $0,5 \%$ yeast extract, $10 \mathrm{mM} \mathrm{NaCl}$, 2,5mM KCl, $10 \mathrm{mM} \mathrm{MgCl} 2,10 \mathrm{mM} \mathrm{MgSO}_{4}, 20 \mathrm{mM}$ glucose) was added and the cells were incubated at $37{ }^{\circ} \mathrm{C}$ for $1 \mathrm{~h}$ with shaking at $200 \mathrm{rpm}$. Then the cells were plated on LB agar plates ( $1 \%$ tryptone, $0,5 \%$ yeast extract, $1 \% \mathrm{NaCl}, 1 \%$ agar) with an appropriate antibiotic (kanamycin $50 \mu \mathrm{g} / \mathrm{ml}$ or ampicilin $100 \mu \mathrm{g} / \mathrm{ml}$ ) for selection of transformed cells.

\subsubsection{Purification of plasmid DNA}

To purify plasmid DNA from E. coli cells in smaller amounts, plasmid DNA was purified according to a modified plasmid purification method from Qiagen, Hilden, Germany. Briefly, a single colony of transformed E. coli cells was inoculated in $1 \mathrm{ml} \mathrm{LB}$ medium and incubated overnight at $37{ }^{\circ} \mathrm{C}$ at $200 \mathrm{rpm}$. Then cells were pelleted by centrifugation for 1 min at $13000 \mathrm{rpm}$. The pellet was resuspended in $200 \mu \mathrm{l}$ of buffer P1 $(50 \mathrm{mM}$ Tris-HCl, $\mathrm{pH}$ 8,0. 10mM EDTA, $100 \mu \mathrm{g} / \mathrm{ml}$ RNase A). Afterwards $200 \mu \mathrm{l}$ of buffer P2 $(200 \mathrm{mM} \mathrm{NaOH}$, $1 \%$ SDS) was added, the mixture was mixed by inverting 5-6 times and incubated for 5 min at room temperature. After addition of $200 \mu \mathrm{l}$ of buffer P3 (3M K acetate, $\mathrm{pH} 5,5)$ the mixture was inverted 5-6 times and centrifuged for $20 \mathrm{~min}$ at $13000 \mathrm{rpm}, 4{ }^{\circ} \mathrm{C}$. The supernatant was transferred to a fresh centrifuge tube. Then $400 \mu 1$ of isopropanol were added and the mixture was centrifuged for $30 \mathrm{~min}$ at $13000 \mathrm{rpm}, 4^{\circ} \mathrm{C}$. The supernatant was discarded and the pellet was washed with $500 \mu \mathrm{l}$ ice-cold $70 \%$ ethanol. The sample was centrifuged for $5 \mathrm{~min}$ at $13000 \mathrm{rpm}$, the supernatant was discarded and the pellet was air- 
dried at room temperature. Then purified plasmid DNA was dissolved in $20 \mu 1 \mathrm{H}_{2} \mathrm{O}$.

To obtain large amounts of pure DNA for cloning and transformation, plasmid DNA was purified with Nucleobond X100 kit (Macherey-Nagel) according to the manufacturer's procedure.

\subsubsection{Site-directed mutagenesis}

To create point mutations in Rush sequence, QuikChange II Site-Directed Mutagenesis kit (Stratagene) was used according to manufacturer's instructions. In brief, pENTR vector containing Rush was amplified with primers $\mathrm{PH}$ DN for/PH DN rev for K48E mutation or FYR176Gf/FYR176Gr for R176G mutation (Table 2-1), using $20 \mathrm{ng}$ of an entry clone and $125 \mathrm{ng}$ of each of primers. The PCR program used for site directed mutagenesis is shown in Table 2-9. Methylated template DNA was removed by digestion with $1 \mu 1 \mathrm{DpnI}$ for $1 \mathrm{~h}$ at $37{ }^{\circ} \mathrm{C}$. XL1-Blue E. coli cells were transformed with $2 \mu 1$ of the reaction solution. Cells were incubated on ice for $30 \mathrm{~min}$, heat-shocked for $45 \mathrm{sec}$ at $42{ }^{\circ} \mathrm{C}$ and afterwards cooled down on ice for $2 \mathrm{~min}$. $500 \mu \mathrm{l}$ of $\mathrm{NZY}^{+}$broth (1\% casein hydrolysate, $0,5 \%$ yeast extract, $0,5 \% \mathrm{NaCl}, 20 \mathrm{mM}$ glucose, $12,5 \mathrm{mM} \mathrm{MgCl}_{2}, 12,5 \mathrm{mM} \mathrm{MgSO}_{4}$ ) preheated to $42{ }^{\circ} \mathrm{C}$ was added to each transformation reaction. Cells were incubated for $1 \mathrm{~h}$ at $37{ }^{\circ} \mathrm{C}$ with shaking at $200 \mathrm{rpm}$ and plated on LB agar plates.

Table 2-9. PCR program for site-directed mutagenesis reaction

\begin{tabular}{l|l|l}
\hline Step & Temperature & Duration \\
\hline 1) Initial denaturation & $95^{\circ} \mathrm{C}$ & $30 \mathrm{sec}$ \\
\hline 2) Denaturation & $95^{\circ} \mathrm{C}$ & $30 \mathrm{sec}$ \\
\hline 3) Annealing & $55^{\circ} \mathrm{C}$ & $1 \mathrm{~min}$ \\
\hline 4) Elongation & $68^{\circ} \mathrm{C}$ & $3,5 \mathrm{~min}$ \\
\hline \multicolumn{2}{c}{$\mathrm{Repeat} \mathrm{steps} \mathrm{2-4} 16$ times } \\
\hline 5) End of the reaction & $37^{\circ} \mathrm{C}$ & $\infty$ \\
\hline
\end{tabular}

\subsubsection{Sequencing of DNA}

Sequencing reaction was set up as follows: to sequence insert in a plasmid, $300 \mathrm{ng}$ of plasmid DNA were mixed with 8 pmol of corresponding primer, 1,5 $\mu 1$ sequencing buffer 
and 1,5 $\mu 1$ sequencing mix and filled up to $10 \mu 1$ with sterile water. To sequence a PCR product, 20-30 ng of PCR product was mixed with 8 pmol of the sequencing primer, $1 \mu 1$ of sequencing buffer and $1 \mu 1$ sequencing mix and filled up to $10 \mu \mathrm{l}$ with sterile water. PCR program for sequencing reactions is shown in Table 2-10. After completion of PCR program the mixture was transferred to a new tube. After addition of $1 \mu l$ of $125 \mathrm{mM}$ EDTA, $1 \mu \mathrm{l}$ of $3 \mathrm{M} \mathrm{NaAc}$ and $50 \mu \mathrm{l}$ of $100 \%$ ethanol the sample was incubated for $5 \mathrm{~min}$ at room temperature. Then the sample was centrifuged for $15 \mathrm{~min}$ at $13000 \mathrm{rpm}$, the supernatant was removed and the pellet washed once with $70 \%$ ethanol. After centrifugation for $5 \mathrm{~min}$ at $13000 \mathrm{rpm}$ the supernatant was removed and the pellet was airdried. Afterwards the pellet was dissolved in $15 \mu \mathrm{l}$ of HiDi (Applied Biosystems, Darmstadt, Germany). Analysis of sequencing reactions was done by in-house sequencing service in the Department of Developmental Biochemistry, Ernst-Caspari-Haus, GZMB, Göttingen.

Table 2-10. PCR program for sequencing reaction

\begin{tabular}{l|l|l} 
Step & Temperature & Duration \\
\hline 1) Initial denaturation & $96{ }^{\circ} \mathrm{C}$ & $2 \mathrm{~min}$ \\
\hline 2) Denaturation & $96{ }^{\circ} \mathrm{C}$ & $20 \mathrm{sec}$ \\
\hline 3) Annealing & $55^{\circ} \mathrm{C}$ & $30 \mathrm{sec}$ \\
\hline 4) Elongation & $60{ }^{\circ} \mathrm{C}$ & $4 \mathrm{~min}$ \\
\hline \multicolumn{2}{c}{ Repeat steps 2-4 26 times } \\
\hline 5) End of the reaction & $12{ }^{\circ} \mathrm{C}$ & $\infty$ \\
\hline
\end{tabular}

\subsubsection{Isolation of genomic DNA from flies}

To purify genomic DNA from flies, 30 flies (preferably male) were shock frozen in liquid nitrogen. Frozen flies were disrupted with a biovortexer in $400 \mu$ l of homogenization buffer (100mM HCl, pH 7,5, $100 \mathrm{mM}$ EDTA, pH 8,0, $100 \mathrm{mM} \mathrm{NaCl}, 0,5 \%$ SDS) and incubated for $15-30 \mathrm{~min}$ at $65^{\circ} \mathrm{C}$. Then $228,4 \mu \mathrm{l}$ of $5 \mathrm{M} \mathrm{KAc}$ and $571,6 \mu 1$ of $6 \mathrm{M} \mathrm{LiCl}$ were added and the mixture was incubated on ice for $15 \mathrm{~min}$. The mixture was centrifuged at $13000 \mathrm{rpm}$ for $15 \mathrm{~min}$, and $1 \mathrm{ml}$ of the supernatant was transferred to a new tube. After addition of $600 \mu \mathrm{l}$ of isopropanol the mixture was centrifuged again at $13000 \mathrm{rpm}$ for 15 min. The supernatant was discarded and the DNA pellet was washed once with ice cold 
$70 \%$ ethanol. After centrifugation at $13000 \mathrm{rpm}$ for $10 \mathrm{~min}$ the supernatant was discarded and DNA pellet was air dried. Purified genomic DNA was solubilized in $150 \mu 1$ of sterile water and stored at $4{ }^{\circ} \mathrm{C}$.

\subsubsection{Culture and transfection of Schneider 2 cells}

Schneider 2 (S2) cells, an immortalized culture of Drosophila embryonic cells (Schneider, 1972), were used for experiments in the cell culture system. The cells were grown at $25{ }^{\circ} \mathrm{C}$ in Drosophila S2 medium (Invitrogen, Carlsbad, Germany) supplemented with serum and antibiotics. S2 cells were transfected with FuGENE HD Transfection Reagent (Roche, Mannheim, Germany). $1 \times 10^{6}$ cells were used for each transfection reaction. The cells were harvested with centrifugation at $1000 \mathrm{rpm}$ for $10 \mathrm{~min}$, resuspended in S2 cell medium and transferred to a 6 well plate. $2 \mu \mathrm{g}$ of plasmid DNA were diluted in $100 \mu 1$ of sterile water. 4 $\mu 1$ of FuGENE transfection reagent was added in the solution and incubated for $15 \mathrm{~min}$ at room temperature. Afterwards the solution was added to the wells with cell suspension. After transfection cells were incubated at $25^{\circ} \mathrm{C}$ for $2-3$ days.

\subsection{Biochemical methods}

\subsubsection{Protein extraction from embryos}

Embryos were collected from apple juice plates in small amount of water with a paintbrush. To remove the chorion, 5\% sodium hypochlorite $(\mathrm{NaOCl})$ was added and embryos were incubated for 4-5 min. Then embryos were collected on a metal sieve with a vacuum pump, washed extensively with $\mathrm{H}_{2} \mathrm{O}$, transferred into a centrifuge tube and used immediately or shock-frozen at $-70{ }^{\circ} \mathrm{C}$.

Embryos were homogenized for $3 \mathrm{~min}$ on ice with a biovortexer (Roth, Karlsruhe, Germany) in five-fold volume of TNT lysis buffer $(150 \mathrm{mM} \mathrm{NaCl}, 50 \mathrm{mM}$ Tris, $\mathrm{pH} 8,0,1 \%$ Triton X-100) (Willert et al., 1997). Protease inhibitors were freshly added to the lysis buffer before use (Pefabloc $200 \mu \mathrm{g} / \mathrm{ml}$, Pepstatin $2 \mu \mathrm{g} / \mathrm{ml}$, Aprotinin $2 \mu \mathrm{g} / \mathrm{ml}$, Leupeptin 2 $\mu \mathrm{g} / \mathrm{ml}$ (Roche, Mannheim, Germany)). After incubation on ice for $30 \mathrm{~min}$ the sample was centrifuged for $10 \mathrm{~min}$ at $13000 \mathrm{rpm}, 4{ }^{\circ} \mathrm{C}$. The supernatant was transferred to a new tube and protein content was determined (see 2.3.3.). 


\subsubsection{Protein extraction from $S 2$ cells}

S2 cells were harvested by a centrifugation at $1000 \mathrm{rpm}$ for $5 \mathrm{~min}$ and washed 3 times with ice-cold PBS (130 mM NaCl, $270 \mathrm{mM} \mathrm{KCl,} \mathrm{0,7} \mathrm{mM} \mathrm{Na} 2 \mathrm{HPO}_{4}, 0,3 \mathrm{mM} \mathrm{KH}_{2} \mathrm{PO}_{4}, \mathrm{pH}$ 7,4). The pellet was resuspended in $200 \mu 1$ of TNT lysis buffer containing protease inhibitors and incubated on ice for $30 \mathrm{~min}$. Afterwards the supernatant was centrifuged for $20 \mathrm{~min}$ at $13000 \mathrm{rpm}, 4{ }^{\circ} \mathrm{C}$. The supernatant was transferred to a clean tube and the protein content was measured (see 2.3.3.)

\subsubsection{Determination of protein concentration}

Protein concentration in samples was determined according to Bradford method with RotiQuant reagent (Roth, Karlsruhe, Germany). $800 \mu 1 \mathrm{H}_{2} \mathrm{O}$ were mixed with $200 \mu \mathrm{l}$ of the reagent and $2 \mu \mathrm{l}$ of the protein solution was added. $2 \mu 1$ of the lysis buffer were used as a blank. The absorption was measured at $600 \mathrm{~nm}$ with BioPhotometer spectrophotometer (Eppendorf, Hamburg, Germany). $\mathrm{OD}_{600}=1$ corresponds to approximately $1 \mathrm{mg} / \mathrm{ml}$ of total protein.

\subsubsection{SDS-polyacrylamide gel electrophoresis}

Protein samples were separated electrophoretically by means of denaturing discontinuous SDS-polyacrylamide gel electrophoresis (SDS-PAGE) essentially as described (Wodarz, 2008). $10 \%$ polyacrylamide gels were used (2,5 $\mathrm{ml} \mathrm{30 \%}$ acrylamide/BIS (29:1), 2,8 $\mathrm{ml} 1 \mathrm{M}$ Tris, $\mathrm{pH}$ 8,0, $38 \mu \mathrm{l} 20 \%$ SDS, 2,1 ml $\mathrm{H}_{2} \mathrm{O}, 30 \mu 1$ 10\% APS, $8 \mu 1$ TEMED) with a stacking gel of following composition: $310 \mu 130 \%$ acrylamide/BIS (29:1), $235 \mu 11 \mathrm{M}$ Tris, pH 6,8, $10 \mu 120 \%$ SDS, $1,3 \mathrm{ml} \mathrm{H} \mathrm{H}_{2}, 10 \mu 1$ 10\% APS, $5 \mu 1$ TEMED. Mini Protean system 3 (BioRad, Munich, Germany) was used for pouring and running of gels.

Protein samples were mixed 1:1 with 2X SDS Loading buffer (100mM Tris, $\mathrm{pH}$ 6,8, 4\% SDS, $0,2 \%$ Bromphenolblue, $20 \%$ glycerol, $100 \mathrm{mM} \beta$-mercaptoethanol) and boiled for 5 min. Afterwards the samples were loaded in the pockets of the gel. $5 \mu 1$ of PageRuler Prestained Protein Ladder (Fermentas, St. Leon-Rot, Germany) were loaded as a size marker. Proteins were separated at $200 \mathrm{~V}$ for 1 hour in SDS buffer (192 mM glycine, 2,5 $\mathrm{mM}$ Tris, $0,1 \% \mathrm{SDS}$ ). 


\subsubsection{Western blot}

Proteins separated by SDS-PAGE (1.3.4.) were transferred onto a nitrocellulose membrane (Schleicher and Schuell, Dassel, Germany) with Mini Trans-Blot system (Bio-Rad, Munich, Germany) according to the manufacturer's instructions. Protein transfer was done in transfer buffer (192 mM glycine, 2,5 mM Tris, 20\% methanol) at $100 \mathrm{~V}$ for $1 \mathrm{~h}$ at $4{ }^{\circ} \mathrm{C}$. Afterwards the transfer of proteins was tested by staining with Ponceau S solution. The staining was removed by washing in TBST (20mM Tris, pH8,0, $150 \mathrm{mM} \mathrm{NaCl}, 0,2 \%$ Tween 20). Sites of unspecific antibody binding were blocked by incubating the membrane for $1 \mathrm{~h}$ in the blocking buffer (1\% bovine serum albumin, 3\% skim milk powder in TBST). Then the membrane was incubated with a primary antibody (diluted accordingly in the blocking buffer) overnight at $4{ }^{\circ} \mathrm{C}$. The membrane was washed with TBST three times for $20 \mathrm{~min}$ and then incubated with a secondary antibody (coupled to horseradish peroxidase (HRP), dilution 1:10000 in the blocking buffer) for $1 \mathrm{~h}$ at room temperature. Primary and secondary antibodies used for Western blot are listed in Tables 2-4 and 2-5. After incubation with secondary antibody the membrane was washed again three times for 20 min with TBST and incubated for 1 min with BM chemiluminescence blotting substrate (Roche, Mannheim, Germany). HRP activity was visualized by exposing the membrane to an X-ray film Fuji SuperRX (Fuji, Tokyo, Japan). The film was developed and fixed with Optimax X-ray film processor (Protec Medizintehnik, Oberstenfeld, Germany).

\subsubsection{Coomassie staining}

Polyacrylamide gels were fixed wit $12 \% \mathrm{w} / \mathrm{v}$ trichloroacetic acid for 1 hour at room temperature. Afterwards gels were stained with colloidal Coomassie staining solution (10 $\% \mathrm{v} / \mathrm{v}$ phosphoric acid, $10 \% \mathrm{w} / \mathrm{v}$ ammonium sulfate, $0,12 \% \mathrm{w} / \mathrm{v}$ Coomassie Brilliant Blue G250, 20\% v/v methanol) overnight at room temperature (Candiano et al., 2004). Destaining was done by consecutive washes in water.

\subsubsection{GST and MBP fusion protein purification}

$50 \mathrm{ml}$ of $2 \mathrm{xYTA}$ medium (16 g/l tryptone, $10 \mathrm{~g} / \mathrm{l}$ yeast extract, $5 \mathrm{~g} / \mathrm{l} \mathrm{NaCl}, \mathrm{pH} \mathrm{8,0)}$ was inoculated with $2 \mathrm{ml}$ overnight culture of bacteria transformed with target plasmid and incubated at $37{ }^{\circ} \mathrm{C}$ till the culture reached mid log phase (OD $\left.550=0,5-1,0\right)$. IPTG was added to a final concentration of $0,5 \mathrm{mM}$ to induce the expression of recombinant protein. After 
incubation with IPTG for 2 - 4 hours at $30^{\circ} \mathrm{C}$ bacteria were harvested by centrifugation at $8000 \mathrm{rpm}$ at $4{ }^{\circ} \mathrm{C}$. The pellet was resuspended in $2,5 \mathrm{ml} 1 \mathrm{x}$ PBS with protease inhibitors. Bacteria were disrupted either by sonication or freeze-thawing at $-20{ }^{\circ} \mathrm{C}$. Triton-X100 was added to the lysate to a final concentration of $2 \%$ and the mixture was gently mixed for 20 $\min$ at $4{ }^{\circ} \mathrm{C}$. The lysates was cleared by centrifugation at $10000 \mathrm{rpm}$ for $10 \mathrm{~min}$ at $4{ }^{\circ} \mathrm{C}$.

To purify GST fusion proteins $40 \mu \mathrm{l}$ of Gluthatione Sepharose beads (GE Healthcare) were added to the lysate. After incubation for $30 \mathrm{~min}$ at room temperature beads were washed three times in PBS. Bound protein was eluted with elution buffer containing $20 \mathrm{mM}$ reduced glutathione in 50mM Tris $\mathrm{HCl}, \mathrm{pH} 8,0$.

For purification of MBP fusion proteins $40 \mu \mathrm{l}$ of Amylose resin (New England Biolabs, Schwalbach/Taunus, Germany) was added to the lysates. After three washing steps in PBS, MBP fusion protein was either left bound on beads or eluted with buffer containing $10 \mathrm{mM}$ Tris $\mathrm{HCl}, 10 \mathrm{mM}$ maltose, $\mathrm{pH}$ 7,2.

\subsubsection{MBP fusion protein pulldown}

To analyze direct interactions between proteins, MBP fusion protein pulldown was used. 2 $\mu \mathrm{l}$ of amylose resin with bound MBP fusion protein or MBP alone was washed three times with pulldown buffer (150 mM NaCl, $10 \mathrm{mM} \mathrm{MgCl}_{2}, 20 \mathrm{mM}$ HEPES (4-(2-hydroxyethyl)1-piperazineethanesulfonic acid), 1 mM EDTA, 1\% Triton X-100, 5 mM DTT). The resin was then incubated with $1 \mu \mathrm{g}$ of GST fusion protein in pulldown buffer for 1 hour at room temperature. $1 \mu \mathrm{g}$ of GST alone was used as a negative control. The resin with bound GST fusion protein was washed three times with pulldown buffer. Then $30 \mu 1$ of $2 x$ SDS loading buffer was added and the sample was analyzed by Western blot.

\subsubsection{Lipid overlay assay}

To determine lipid binding specificity of Rush and its separate domains, PIP Strips (Echelon Biosciences, Salt Lake City, UT) were used according to the manufacturer's protocol. In brief, the membrane was blocked in blocking buffer (1xTBS, 0,1\% Tween, $3 \% \mathrm{BSA}$ ) for 1 hour. After blocking, the membrane was incubated for 1 hour with 0,2 $\mu \mathrm{g} / \mathrm{ml}$ GST fusion protein in blocking buffer. $0,25 \mu \mathrm{g} / \mathrm{ml}$ of PIP2 Grip ${ }^{\mathrm{TM}}$ protein (Echelon Biosciences, Salt Lake City, UT) or GST alone were used as a control. The membrane was washed three times in TBS with $0,1 \%$ Tween and incubated with anti-GST antibody for 30 
min. Afterwards the membrane was washed as previously and incubated for 1 hour with HRP-coupled secondary antibody. The membrane was washed three times and bound protein detected by a chemiluminescence reaction.

\subsubsection{Endosome fractionation assay}

Early and late endosomes were separated from S2 cell or embryo protein extracts by a sucrose gradient as described in Torres et al. (2008). S2 cells were harvested by centrifugation at $1000 \mathrm{rpm}, 4{ }^{\circ} \mathrm{C}$, washed once in $10 \mathrm{ml}$ of ice cold PBS and resuspended 1:4 in homogenization buffer. Cells were homogenized by passing 10 times through a 26gauge needle in a $1 \mathrm{ml}$ syringe. Post nuclear supernatant (PNS) was separated by centrifugation for $15 \mathrm{~min}$ at $3500 \mathrm{rpm}, 4{ }^{\circ} \mathrm{C}$. PNS was diluted 2:3 with $60 \%$ sucrose in homogenization buffer $(250 \mathrm{mM}$ sucrose, $3 \mathrm{mM}$ imidazole, $\mathrm{pH} 7,5)$ to achieve final sucrose concentration of $40,6 \%$. A sucrose gradient was prepared by sequentially overlaying $1 \mathrm{ml}$

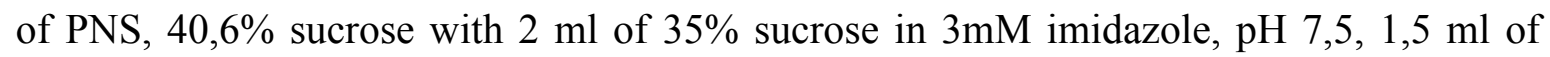
$25 \%$ sucrose in $3 \mathrm{mM}$ imidazole, $\mathrm{pH} 7,5$ and $400 \mu \mathrm{l}$ of homogenization buffer ( $8 \%$ sucrose) in a Beckman $5 \mathrm{ml}$ centrifuge tube. Gradient was centrifuged at $40000 \mathrm{rpm}(125.000 \mathrm{x} \mathrm{g})$ at $4{ }^{\circ} \mathrm{C}$ in Optima MAX ultracentrifuge (Beckman Coulter, Fullerton, USA). Early endosomes were collected at the $35 / 25 \%$ sucrose interface and late endosomes at the $8 / 25 \%$ sucrose interface. Protein distribution in endosomal fractions was analyzed by Western blot.

To prepare endosome fractions from fly embryos, embryos were devitellinized as described in 2.3.1., homogenized for $3 \mathrm{~min}$ on ice with a biovortexer (Roth, Karlsruhe, Germany) and resuspended 1:4 in homogenization buffer. The embryo lysate was further prepared similarly as described for S2 cells.

\subsection{Immunohistochemistry}

\subsubsection{Fixation of embryos}

Embryos from overnight egg collection cages were used for staining with antibodies. Before the staining embryos were fixed to permeabilize the tissue and make it accessible for antibodies as well as to preserve the tissue and inhibit protease activity.

Embryos were collected like described before (see 2.3.1.) and after washing with $\mathrm{H}_{2} \mathrm{O}$ transferred into scintillation glasses with 1:1 mixture of fixation solution and heptane. For 
most stainings $4 \%$ formaldehyde in PBS was used as a fixation solution. Steffanini solution (440 $\mu 1$ 37\% formaldehyde, $660 \mu 1$ pikric acid, $660 \mu 1$ 0,5M PIPES (piperazine1,4-bis-2-ethanesulfoic acid), $\mathrm{pH} \mathrm{7,5,2,34} \mathrm{ml}$ sterile water) was used as a fixation solution for stainings with antibody against Rush. Embryos were fixed for 20 min with shaking. Afterwards the lower aqueous phase that contains formaldehyde was discarded and 1 volume of methanol was added. Embryos were strongly shaken for approx. $30 \mathrm{sec}$ to remove the vitelline envelope. Devitellinized embryos were transferred into a fresh tube, washed two times with methanol and stored at $-20{ }^{\circ} \mathrm{C}$ or stained immediately.

\subsubsection{Immunostaining of embryos}

Fixed embryos were washed 3x 20 min with PBT (1x PBS, 0,1\% Tween 20) on a shaker. Unspecific binding sites were blocked by incubation in a blocking solution (5\% normal horse serum (NHS) in PBT) for $1 \mathrm{~h}$. Embryos were incubated with a primary antibody diluted in blocking solution overnight at $4{ }^{\circ} \mathrm{C}$ or $2 \mathrm{~h}$ at room temperature. Then embryos were washed 3x 20 min with PBT, incubated with a dilution of secondary antibody in blocking solution for $2 \mathrm{~h}$ at room temperature. Used antibodies are listed in Tables 2-4 and 2-5. After a repeated washing step with PBT (3x $20 \mathrm{~min}$ ) embryos were transferred to a microscopy slide and embedded in Mowiol/DABCO.

Mowiol: 5 g Elvanol/Mowiol (Höchst, Frankfurt, Germany) were dissolved in $20 \mathrm{ml}$ PBS, $\mathrm{pH} 7,4.10 \mathrm{ml}$ of glycerol were added and mixed for $16 \mathrm{~h}$. The solution was centrifuged for $15 \mathrm{~min}$ at $12000 \mathrm{rpm}$ and the supernatant stored at $-20{ }^{\circ} \mathrm{C}$. Few flakes of DABCO (Diazabicyclo(2.2.2)octane) were added $30 \mathrm{~min}$ before embedding and mixed with overhead rotor.

\subsubsection{Fixation and immunostaining of ovaries}

Wild type flies were put on apple juice agar plates three to four days before preparation of ovaries to stimulate egg development. Ovaries were prepared in PBS. Egg chambers were separated from each other by pipetting up and down with a pipette, saturated in NHS. Then ovaries were transferred to a centrifuge tube and fixed for $20 \mathrm{~min}$ in fixation solution (see 2.4.1.). After washing 3x 10 min with PBT ovaries were blocked in PTX (5\% NHS, 0,5\% Triton X-100 in PBS) for $3 \mathrm{~h}$ at room temperature or overnight at $4{ }^{\circ} \mathrm{C}$. Staining with 
antibodies was done as described in 2.4.2.

\subsubsection{Fixation and immunostaining of $S 2$ cells}

S2 cells were fixed in chamber slides coated with $0,01 \%$ L-polylysine. Cells were allowed to adhere to the slide for $2 \mathrm{~h}$ at $25{ }^{\circ} \mathrm{C}$ and washed once with PBS. Fixation solution containing $4 \%$ formaldehyde in PBS was added for $10 \mathrm{~min}$ at room temperature. Fixed cells were washed twice with PBS.

For immunostaining the cells were incubated for $1 \mathrm{~h}$ in the blocking solution containing 5\% NHS in PBT. Subsequently the cells were incubated for $1 \mathrm{~h}$ with primary antibody (see Table 2-4 for a list of used primary antibodies) diluted in blocking solution. The cells were washed three times with PBT and incubated for $1 \mathrm{~h}$ with the secondary antibody (Table 25) diluted in blocking solution. Afterwards the cells were washed three times with PBT and embedded in Mowiol/DABCO.

\subsubsection{Staining of DNA}

Staining of DNA in fixed preparations was done with DAPI (Dianova). DAPI was added in 1:2000 dilution in PBT during the first washing step after incubation with secondary antibody.

\subsubsection{Staining of lysosomes with LysoTracker}

Staining of lysosomes was done essentially as described in Hou et al. (2008). Ovaries were dissected in PBS and incubated with $50 \mu \mathrm{M}$ LysoTracker DND-99 (Invitrogen, Carlsbad, Germany) in PBS for $3 \mathrm{~min}$ in the dark. Then the ovaries were washed three times for 5 min each in PBS and fixed for $10 \mathrm{~min}$ in $4 \%$ formaldehyde in PBS. The ovaries were washed again three times for $5 \mathrm{~min}$ in PBS and mounted on microscope slides in Mowiol/DABCO.

\subsubsection{Staining of actin microfilaments}

To stain actin microfilaments, Cy3-conjugated phalloidin (Invitrogen, Carlsbad, Germany) was used. $5 \mu \mathrm{l}$ of phalloidin were vacuum-dried, resuspended in $10 \mu \mathrm{l}$ of PBT and added to the sample during the incubation with secondary antibodies. 


\subsubsection{Dextran uptake assay}

Third instar larval wing discs were dissected in serum free S2 medium and incubated with $1 \mathrm{mg} / \mathrm{ml}$ Alexa Fluor 594 conjugated dextran (lysine fixable, MW10000; Invitrogen Molecular Probes) for 10 minutes. After three washing steps in ice cold S2 medium for 10 min each, discs were fixed for 20 min with $4 \%$ formaldehyde in PBS. Then discs were washed three times for 20 min in PBT and incubated with blocking solution (10\% NHS in PBT) for 2 hours in room temperature. Discs were incubated with first antibody in blocking solution overnight at $4{ }^{\circ} \mathrm{C}$ and washed three times with PBT for $20 \mathrm{~min}$. Secondary antibody was added for 2 hours at room temperature, and after three washing steps in PBT imaginal discs were mounted on microscope slides in Mowiol/DABCO.

\subsubsection{Confocal microscopy, image acquisition and statistical analysis}

Images of immunohistochemistry stainings were acquired with LSM 510 Meta confocal laser scanning microscope (Carl Zeiss, Jena, Germany) with 45x 0,8 NA Plan Neofluar and 63x 1,4 NA Plan Apochromat objectives using LSM 510 software (Carl Zeiss, Jena, Germany). Single images were processed with Adobe Photoshop CS2 (Adobe Systems, San Jose, USA) software.

For measurements of the size and number of vesicles images were analyzed with ImageJ software (National Institutes of Health, Bethesda, USA). Images were first converted to 8bit grayscale, inverted and processed with automatic thresholding. Mean particle size and particle number of each image were measured with the analyze particles function. Statistical significance was calculated with Student's t-test.

\subsection{Fly genetics}

\subsubsection{Fly breeding}

The fly stocks used in the work were kept at $18{ }^{\circ} \mathrm{C}$, room temperature or $25{ }^{\circ} \mathrm{C}$ on standard medium (Ashburner, 1989). For collection of embryos, flies were kept in egg collection 
cages on apple juice plates. To stimulate egg laying, small amount of yeast paste was applied at the center of the apple juice plate.

Standard medium: $712 \mathrm{~g}$ cornmeal, $95 \mathrm{~g}$ soya flour, $168 \mathrm{~g}$ dry yeast, $450 \mathrm{~g}$ malt extract, $150 \mathrm{ml} \mathrm{10 \%} \mathrm{Nipagin} \mathrm{(700} \mathrm{ml} \mathrm{99 \%} \mathrm{ethanol,} 300 \mathrm{ml} \mathrm{H} \mathrm{H}_{2} \mathrm{O}, 100 \mathrm{~g}$ Nipagin $\left(\mathrm{C}_{8} \mathrm{H}_{8} \mathrm{O}_{3}\right)$ ), $45 \mathrm{ml}$ propionic acid, $50 \mathrm{~g}$ agar, $400 \mathrm{~g}$ sugar beet sirup, add 9,75 $1 \mathrm{H}_{2} \mathrm{O}$

Apple juice plates: $40 \mathrm{~g}$ agar, $11 \mathrm{H}_{2} \mathrm{O}, 340 \mathrm{ml}$ apple juice, $17 \mathrm{~g}$ sugar, $20 \mathrm{ml}$ 10\% nipagin

\subsubsection{Fly stocks}

Table 2-11. List of fly stocks.

\begin{tabular}{|c|c|c|c|}
\hline Stock & Genotype & Description & Reference \\
\hline $\begin{array}{l}\text { Wild type Oregon } \\
\text { R }\end{array}$ & wild type & Red eyes & $\begin{array}{l}\text { A. Wodarz lab } \\
\text { stock collection }\end{array}$ \\
\hline white & $w^{1118}$ & White eyes & Bloomington \#5905 \\
\hline $\mathrm{P}(\mathrm{EP}) r u s h$ & $y^{l} \mathrm{P}\{\mathrm{EPgy} 2\} r u s h^{\mathrm{EY} 04997} w^{67 c 23}$ & $\begin{array}{l}\mathrm{P}\{\mathrm{EP}\} \text { element } \\
\text { insertion in } 5, \mathrm{UTR} \text { of } \\
\text { rush gene, UAS } \\
\text { reporter line. }\end{array}$ & $\begin{array}{l}\text { Bloomington } \\
\# 19697\end{array}$ \\
\hline P(XP)d03799 & $\mathrm{P}\{\mathrm{XP}\} r u s h^{\mathrm{d} 03799}$ & $\begin{array}{l}\text { P-element insertion } \\
\text { upstream of rush }\end{array}$ & $\begin{array}{l}\text { Exelixis Collection, } \\
\text { Harward }\end{array}$ \\
\hline PBac(WH)f03712 & PBac $\{W H\}$ f03712 & $\begin{array}{l}\text { PiggyBac insertion } \\
\text { downstream of } s t a\end{array}$ & $\begin{array}{l}\text { Exelixis Collection, } \\
\text { Harward }\end{array}$ \\
\hline rush & rush $^{4} ; \operatorname{Tr} 1$ & rush null allele & This work \\
\hline arm-Gal4 & $w^{*} ; \mathrm{P}\{\mathrm{GAL} 4-a r m . \mathrm{S}\} 11$ & $\begin{array}{l}\text { GAL4 driver line, } \\
\text { ubiquitous expression } \\
\text { in armadillo gene } \\
\text { pattern, } 2 \text { nd } \\
\text { chromosome }\end{array}$ & Bloomington $\# 1560$ \\
\hline act-Gal4 & $\begin{array}{l}y^{l} w^{*} ; \mathrm{P}\{A c t 5 C- \\
\text { Gal4 }\} 25 \mathrm{FO} 1 / \mathrm{CyO}, \mathrm{y}^{+}\end{array}$ & $\begin{array}{l}\text { GAL4 driver line, } \\
\text { ubiquitous expression, } \\
\text { 2nd chromosome }\end{array}$ & Bloomington \#4414 \\
\hline
\end{tabular}




\begin{tabular}{|c|c|c|c|}
\hline Cu2-Gal4 & $\mathrm{P}\{\mathrm{Ga} 14-\mathrm{Cu} 2\}$ & $\begin{array}{l}\text { Gal4 driver line, } \\
\text { expression in follicle } \\
\text { cells from stage } 8,2 \text { nd } \\
\text { chromosome }\end{array}$ & Trudi Schüpbach \\
\hline$d a-\mathrm{Gal} 4$ & $w^{*} ; \mathrm{P}\{\mathrm{GAL} 4-d a . \mathrm{G} 32\} \mathrm{UH} 1$ & $\begin{array}{l}\text { Gal4 driver line, } \\
\text { ubiquitous expression } \\
\text { in daughterless gene } \\
\text { pattern, 3rd } \\
\text { chromosome }\end{array}$ & $\begin{array}{l}\text { Bloomington } \\
\# 5460\end{array}$ \\
\hline pnr-Gal4 & $\begin{array}{l}y^{I} w^{1118} ; \\
\mathrm{P}\{\mathrm{GawB}\} p n r^{M D 237} / \mathrm{TM} 3, \\
\mathrm{P}\{\mathrm{UAS}-\mathrm{y} . \mathrm{C}\} \mathrm{MC} 2, \mathrm{Ser}^{I}\end{array}$ & $\begin{array}{l}\text { Gal4 driver line, } \\
\text { expression in pannier } \\
\text { gene pattern, 3rd } \\
\text { chromosome }\end{array}$ & $\begin{array}{l}\text { Bloomington } \\
\# 3039\end{array}$ \\
\hline $\mathrm{P}\{\mathrm{GawB}\} 109 \mathrm{C} 1$ & $\mathrm{P}\{\mathrm{GawB}\} 109 \mathrm{C} 1, y^{l} w^{*}$ & $\begin{array}{l}\text { Gal4 driver line, } \\
\text { expression in polar } \\
\text { cells and follicle } \\
\text { epithelium, 1st } \\
\text { chromosome }\end{array}$ & $\begin{array}{l}\text { Bloomington } \\
\# 7020\end{array}$ \\
\hline $\mathrm{Cdc} 42 \mathrm{DN}$ & $\mathrm{w}^{*} ; \mathrm{P}\{\mathrm{UAS}-C d c 42 . N 17\} 3$ & $\begin{array}{l}C d c 42 \text { dominant } \\
\text { negative construct }\end{array}$ & Bloomington \#6288 \\
\hline YFP-Rab5 & $\begin{array}{l}\mathrm{y}^{1} \mathrm{w}^{*} ; \mathrm{P}\{\mathrm{UASp}- \\
\text { YFP.Rab5\}02 }\end{array}$ & Wild type Rab5 & $\begin{array}{l}\text { Bloomington } \\
\# 24616\end{array}$ \\
\hline YFP-Rab5CA & $\begin{array}{l}y^{I} w^{*} ; \mathrm{P}\{\mathrm{UASp}- \\
\text { YFP.Rab5.Q88L\}1(2)k16918 } \\
24\end{array}$ & $\begin{array}{l}\text { Rab5 constitutively } \\
\text { active construct }\end{array}$ & Bloomington $\# 9774$ \\
\hline Rab5DN-GFP & $\begin{array}{l}w ; \text { UAS-Rab5S43N- } \\
\text { GFP/TM3, Sb }\end{array}$ & $\begin{array}{l}\text { Rab5 dominant } \\
\text { negative construct }\end{array}$ & Entchev et al., 2000 \\
\hline Rab5DN-GFP & $\begin{array}{l}w ; \text { UAS-Rab5S43N- } \\
\text { GFP/CyO }\end{array}$ & $\begin{array}{l}\text { Rab5 dominant } \\
\text { negative construct }\end{array}$ & Entchev et al., 2000 \\
\hline YFP-Rab7 & $\begin{array}{l}y^{I} w^{*} ; \mathrm{P}\{\mathrm{UASp}- \\
\text { YFP.Rab7\}21/SM5 }\end{array}$ & Wild type $R a b 7$ & $\begin{array}{l}\text { Bloomington } \\
\# 23641\end{array}$ \\
\hline $\operatorname{Tr} 1$ & $\mathrm{C}(1) \mathrm{DX}, y f / s t a^{l t 3} / \mathrm{Y} ; \operatorname{Tr} 1$ & sta rescue construct & Melnick et al., 1993 \\
\hline P(70FLP) & $\begin{array}{l}w^{1118} ; n o c^{S c o} / \mathrm{SM} 6 \mathrm{~b} \\
\mathrm{P}\{70 \mathrm{FLP}\} 7\end{array}$ & $\begin{array}{l}\text { Stock for heat } \\
\text { dependent flipase } \\
\text { expression }\end{array}$ & Bloomington \#6876 \\
\hline
\end{tabular}




\begin{tabular}{|c|c|c|c|}
\hline Binsinscy & $\begin{array}{l}\text { Df(1)Exel8196 } \\
w^{1118} / \text { Binsinscy }\end{array}$ & $\begin{array}{l}\text { First chromosome } \\
\text { balancer line }\end{array}$ & Bloomington \#7769 \\
\hline FM7(Twist GFP) & FM7 $\{t w i-\mathrm{GFP}\}$ & $\begin{array}{l}\text { First chromosome } \\
\text { balancer line, } \\
\text { expresses GFP in } \\
\text { Twist pattern }\end{array}$ & $\begin{array}{l}\text { Benni Shilo, } \\
\text { Weizmann Institute } \\
\text { of Science, } \\
\text { Rehovot, Israel }\end{array}$ \\
\hline $\mathrm{FM7}($ lacZ) & $\begin{array}{l}y^{l} \operatorname{arm}^{4} w^{*} / \mathrm{FM} 7 \mathrm{c}, \\
\mathrm{P}\{f t z / l a c C\} \mathrm{YH} 1\end{array}$ & $\begin{array}{l}\text { First chromosome } \\
\text { balancer line, } \\
\text { ubiquitously expresses } \\
\text { lacZ }\end{array}$ & Bloomington \#616 \\
\hline Gla/CyO & $w^{-} ;$Gla $/$Cyo, P $\{f t z:: 1 \mathrm{acZ}\}$ & $\begin{array}{l}\text { Second chromosome } \\
\text { balancer line, curly } \\
\text { wings }\end{array}$ & $\begin{array}{l}\text { A. Wodarz lab } \\
\text { stock collection }\end{array}$ \\
\hline TM3/TM6B & $\begin{array}{l}w^{*} ; \mathrm{TM} 3, S^{l} \operatorname{Ser}^{l} / \mathrm{TM} 6 \mathrm{~B} \\
T b^{l}\end{array}$ & $\begin{array}{l}\text { Third chromosome } \\
\text { balancer line }\end{array}$ & Bloomington \#2537 \\
\hline
\end{tabular}

\subsubsection{The UAS-GAL4 system}

The UAS-GAL4 system (Brand and Perrimon, 1993) is used to ectopically overexpress the gene of interest in a time and tissue specific manner. The method makes use of a yeast transcription factor GAL4 that binds to an upstream activating sequence (UAS), therefore activating gene expression. In UAS reporter flies the gene of interest is placed under the control of UAS. Another fly stock, so called GAL4 driver line, contains the GAL4 gene under the control of a promoter or enhancer of a gene with a known expression pattern. When the two fly stocks are crossed, GAL4 activates the expression of the gene of interest. By choosing different GAL4 driver lines, the gene can be expressed in a wide variety of tissues and developmental stages. GAL4 driver lines and UAS reporter flies used in this work are described in Table 2-11.

\subsubsection{Generation of transgenic flies}

To generate transgenic flies, transgenic constructs inserted in P-element based vectors were injected into the posterior end of syncytial blastoderm embryos together with a helper plasmid that contains transposase DNA. Transposase activity mediates integration of the Pelement including transgenic construct into genomic DNA. Transgenic flies that have 
undergone successful integration of the P-element can be recognized by red eye color, since vectors used for injection contain the mini-white gene. The protocol for transgenic fly generation was adapted from Bachmann and Knust (2008). In brief, $20 \mu \mathrm{g}$ of plasmid DNA was mixed with $5 \mu \mathrm{g}$ of helper plasmid and $5 \mu \mathrm{l}$ of $10 \mathrm{x}$ injection buffer $(5 \mathrm{mM} \mathrm{KCl}, 0,1$ $\mathrm{mM}$ sodium phosphate, $\mathrm{pH}$ 6,8) in final volume of $50 \mu$ l. Dechorionated white embryos were arranged on coverslips and after 15-20 min of drying covered with 10S Voltalef oil (Prolabo, Paris, France). The plasmid mixture was injected to the posterior ends of the embryos by micromanipulator InjectMan NI2 (Eppendorf, Hamburg, Germany). After injection embryos were kept in $10 \mathrm{~S}$ Voltalef oil at $18^{\circ} \mathrm{C}$ for $48 \mathrm{hr}$ before the hatched larvae were collected. Hatched flies were single-crossed to $w^{-} ; \mathrm{Gla} / \mathrm{CyO}$ flies for the transgenic fly selection and insertion site analysis. A list of transgenic constructs used for injection in flies is shown in Table 2-12.

Table 2-12. Transgenic constructs used for injection in flies.

\begin{tabular}{l|l|l|l}
\hline Gene & Vector & Promoter & Tag \\
\hline$r u s h$ & pTWG & UASt & GFP \\
\hline$r u s h^{K 48 E}$ & pTWG & UASt & GFP \\
\hline$r u s h^{R I 76 G}$ & pTWG & UASt & GFP \\
\hline$r u s h^{K 48 E} R 176 G$ & pTWG & UASt & GFP \\
\hline$C G 1418$ & pTGW & UASt & GFP \\
\hline$G D I$ & pTGW & UASt & GFP \\
\hline
\end{tabular}

\subsubsection{FLP/FRT mediated gene deletion}

To generate a deletion of rush, FLP/FRT mediated gene deletion described in Parks et al. (2004), was used. The method makes use of the ability of FLP recombinase to mediate recombination between two FRT sites located on homologous chromosomes. This way a deletion of a genomic region flanked by two transposons that contain FRT sites can be achieved. In case of rush two transposon insertion lines were available - P(XP)d03799 is located in the 5' UTR of rush, while a piggyBac insertion line pBac(WH)f03712 is located in the 5' UTR of sta, a gene positioned downstream of rush (Fig. 2-2 A). Upon induction of FLP recombinase the genomic region between two FRT sites is deleted, leaving a single transposon at the deletion site. As FLP mediated recombination is more efficient in cis, excision of the UAS sequence of the $\mathrm{P}(\mathrm{XP})$ element takes place before recombination in 
trans. In this case successful recombination between the two FRT sites in trans can be detected by loss of red eye color, since white genes on both transposons are deleted together with the genomic region.

Crosses used to delete the rush gene are shown in Fig. 2-2 B. First, virgin females of the P(XP)d03799 insertion line were crossed with males of a stock carrying a heat-inducible FLP recombinase on the second chromosome. FLP recombinase coding sequence in this stock is inserted in the balancer chromosome SM6b, allowing to select flies that carry FLP recombinase gene by curly wings. Male progeny of this cross that had curly wings were crossed to $\mathrm{pBac}(\mathrm{WH}) \mathrm{f03712}$ virgin females. Progeny of this cross were heat shocked for two hours at $37{ }^{\circ} \mathrm{C}$ for two days in second instar larval stage. Curly winged virgin females heterozygous for $\mathrm{P}(\mathrm{XP}) \mathrm{d} 03799$ and $\mathrm{pBac}(\mathrm{WH}) \mathrm{f03712}$ from this generation were crossed with Binsinscy balancer males and the progeny were screened for white eyes. Recombination caused a simultaneous deletion of the neighboring sta gene, which is essential for Drosophila development (Melnick et al., 1993). Therefore a sta rescue construct $\operatorname{Tr} 1$ was crossed in. Tr1 contains a complete sta sequence, but not rush, and has been shown to fully rescue loss of sta (Melnick et al., 1993). 
A

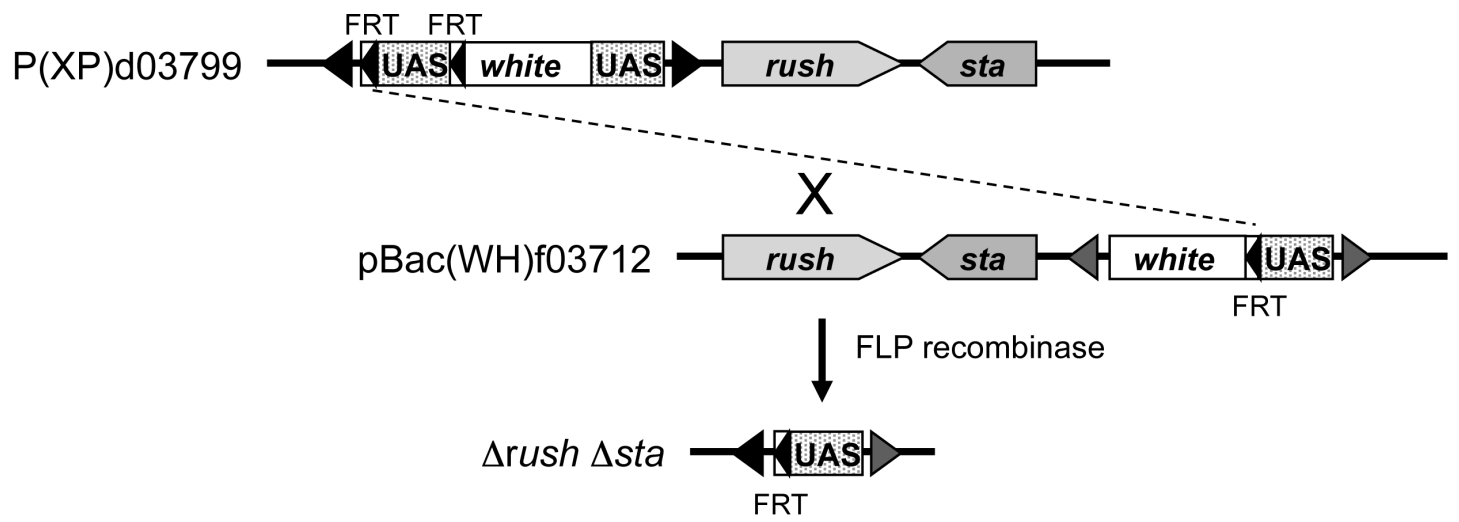

B
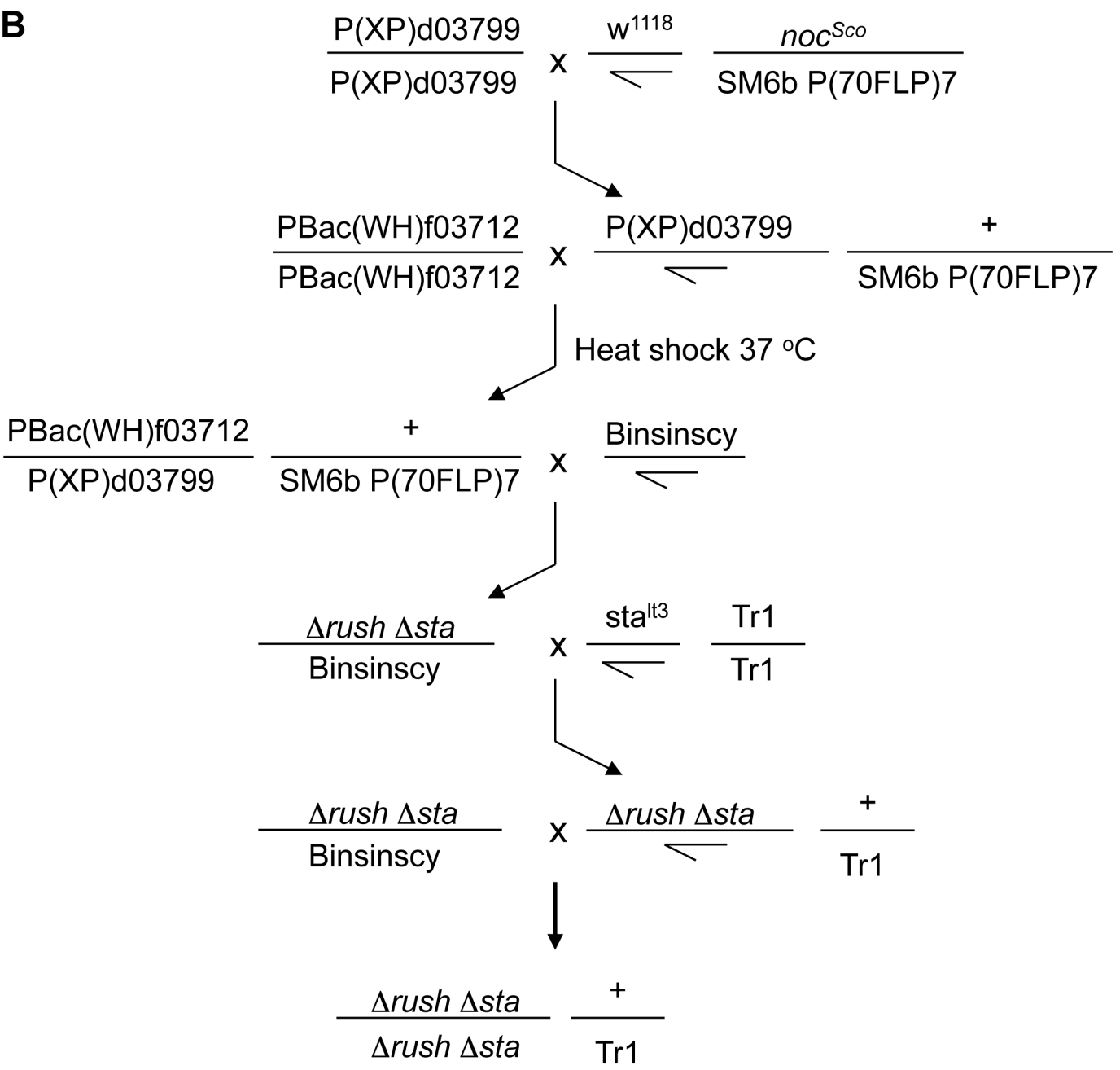

Figure 2-2. FLP/FRT mediated deletion of $\boldsymbol{r}$ ush gene. A - Recombination induced by FLP recombinase can be used to delete genomic region between two transposons that contain FRT sites. In this case, P(XP)d03799 and pBac(WH)f03712 insertion lines were used to delete rush gene. B - Crossing scheme to obtain rush deletion line using FLP/FRT mediated gene deletion method. 


\section{Results}

\subsection{Localization of Rush}

\subsubsection{Colocalization of Rush with polarity markers}

The rush gene is localized on the first chromosome and codes for a protein with a predicted length of 316 amino acids (Fig. 3-1). To determine the expression and subcellular localization of Rush during embryonic development, the embryos were stained with an affinity purified antibody against the C-terminus of Rush. Rush was ubiquitously expressed in embryos (Fig 3-2 A, B). Rush localized to the apical plasma membrane already in the stage 5 embryo (Fig 3-2 A), suggesting that Rush is maternally contributed. To test the specificity of the antibody staining, I overexpressed endogenous Rush by using a UAS sequence-containing P-element $\mathrm{P}(\mathrm{EP}) \mathrm{EY}$ 04997. The $\mathrm{P}(\mathrm{EP})$-element is inserted in the 5' UTR of rush, 632 base pairs before the start codon (Fig. 3-1). Expression of Rush was driven by expression of $p r d$-Gal4. $p r d$ is a pair rule gene and is expressed in seven stripes in alternating segments. Antibody staining showed an increase of Rush signal in prd pattern (Fig. 3-2 C), indicating that the antibody is specific for Rush. As the staining of Rush in wild type embryos was weak, subcellular localization of Rush was analyzed in embryos that overexpress Rush under the control of the $p r d$ promoter ( $p r d>$ Rush). In the prd $>$ Rush embryonic ectoderm Rush was localized at the plasma membrane with accumulations in the cytosol (Fig. 3-2 D). At the plasma membrane Rush colocalized with E-cadherin (Fig 3-2 D"). 


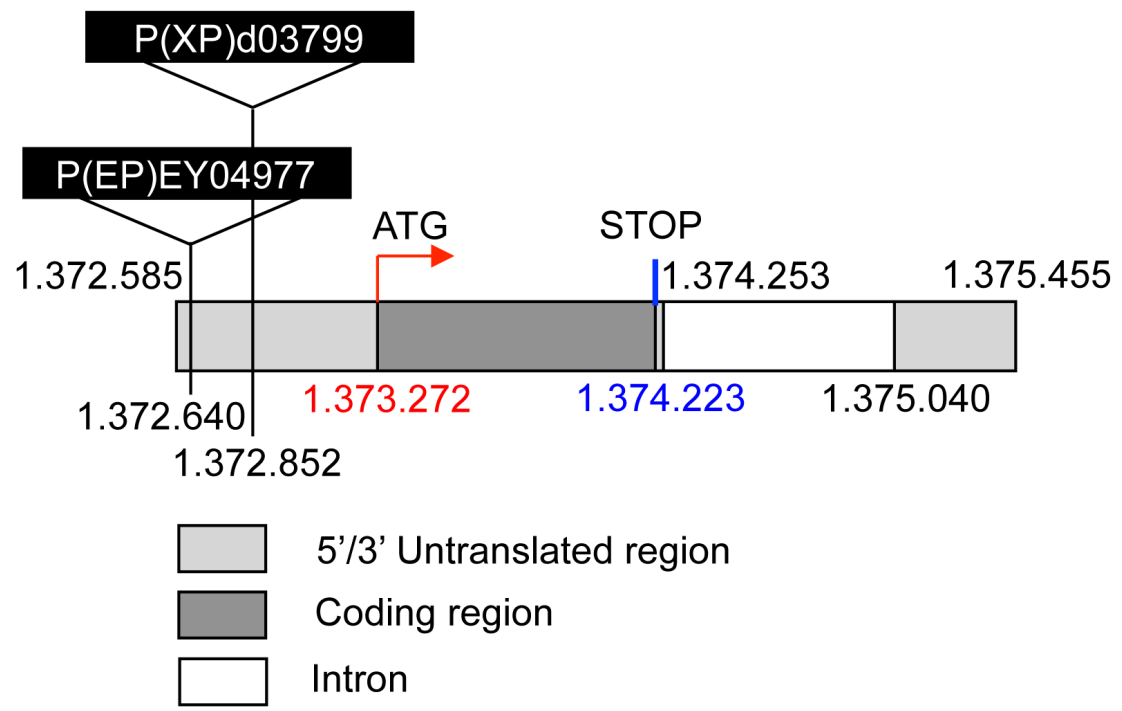

Figure 3-1. The localization and structure of rush. The rush gene is located on the first chromosome and contains two exons (1669 bp and 415 bp long). The coding region is located in the first exon. Positions of start and stop codons are denoted with red and blue letters, respectively. The numbers denote base pairs in the Drosophila genome. Insertion positions of two P-elements in the 5' UTR of rush are shown. P-element size is not shown in scale.

Due to difficulties to analyze localization of wild type Rush in embryos, I stained wild type ovaries with anti-Rush antibody. Rush was expressed both in the germline (Fig. 3-3 A, white arrow in Fig. 3-3 B) and in the follicle epithelium (Fig. 3-3). In the follicle epithelium, similarly as in the embryonic ectoderm, Rush localized to the plasma membrane as well as in cytoplasmic puncta (Fig. 3-3). Rush localized mainly at the lateral domain of the plasma membrane with accumulations at the apical side (Fig. 3-3 A, D, E). Similarly as in the embryonic ectoderm, Rush colocalizes with E-cadherin at the lateral plasma membrane of the follicle epithelium (Fig. 3-3 B, C). We co-stained wild type ovaries with antibodies against Baz and Par6 to determine whether Rush colocalizes with the Par/aPKC complex proteins. Baz and Par6 localize at the subapical region of the lateral plasma membrane (Fig. 3-3 D, E). Rush partially colocalizes with Baz and Par6 at the apical part of the lateral plasma membrane, however, the accumulations of Rush are localized slightly more basally than Baz and Par6 (Fig. 3-3 D, E). 


\section{Results}

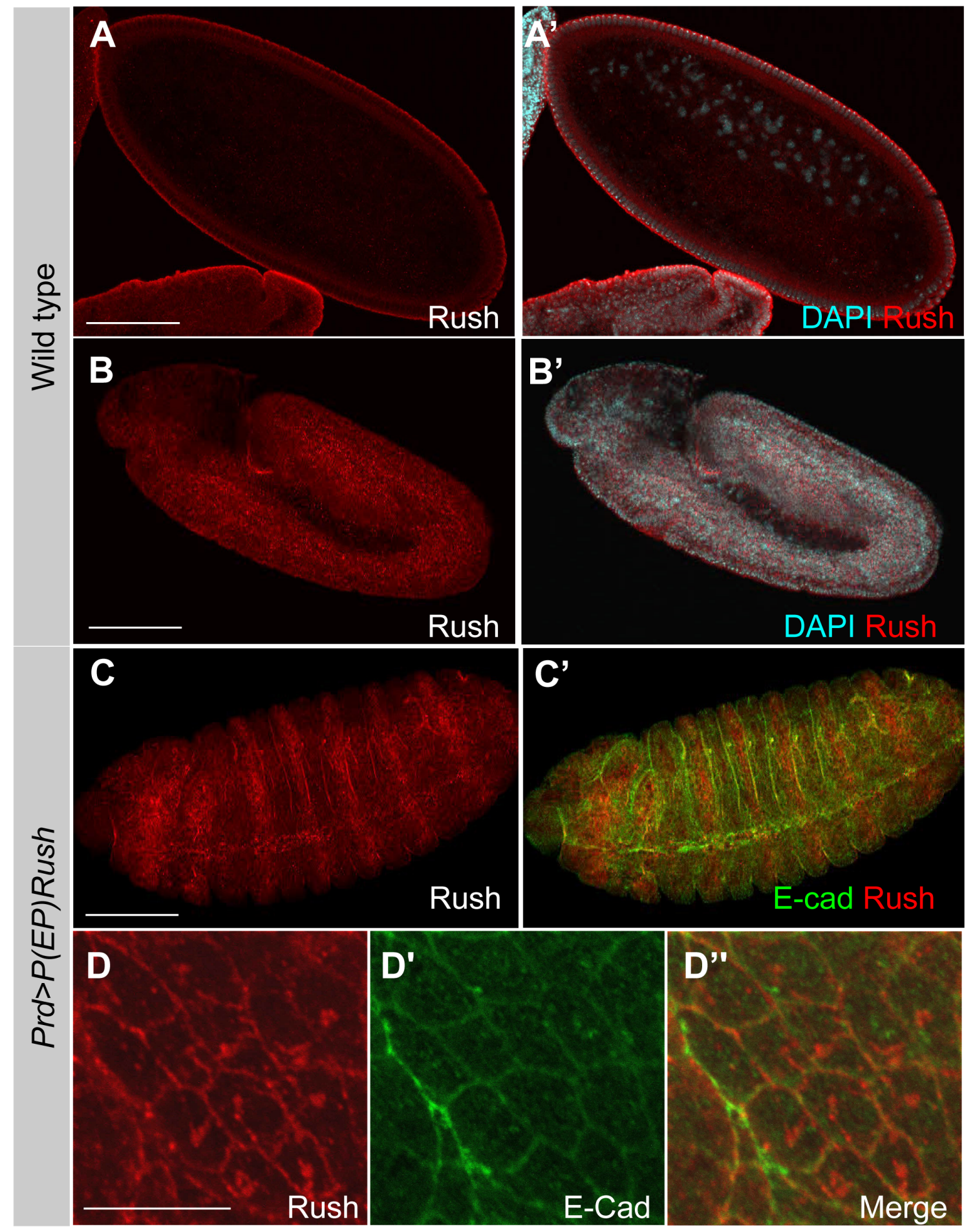

Figure 3-2. Localization of Rush in embryos. A, B - Wild type embryos were stained with an antibody against C-terminus of Rush. A - stage 5 embryo, B - stage 11 embryo. C,D - overexpression of wild type Rush in a prd pattern. C - stage 15 embryo. D - Subcellular localization of Rush in the ectoderm of a stage 15 embryo. Rush colocalizes with E-cadherin at the plasma membrane. to the plasma membrane and forms accumulations in the cytoplasm. Scale bars: A, B, C $=100 \mu \mathrm{m}, \mathrm{D}=10 \mu \mathrm{m}$. In A, B, C anterior is to the left. 


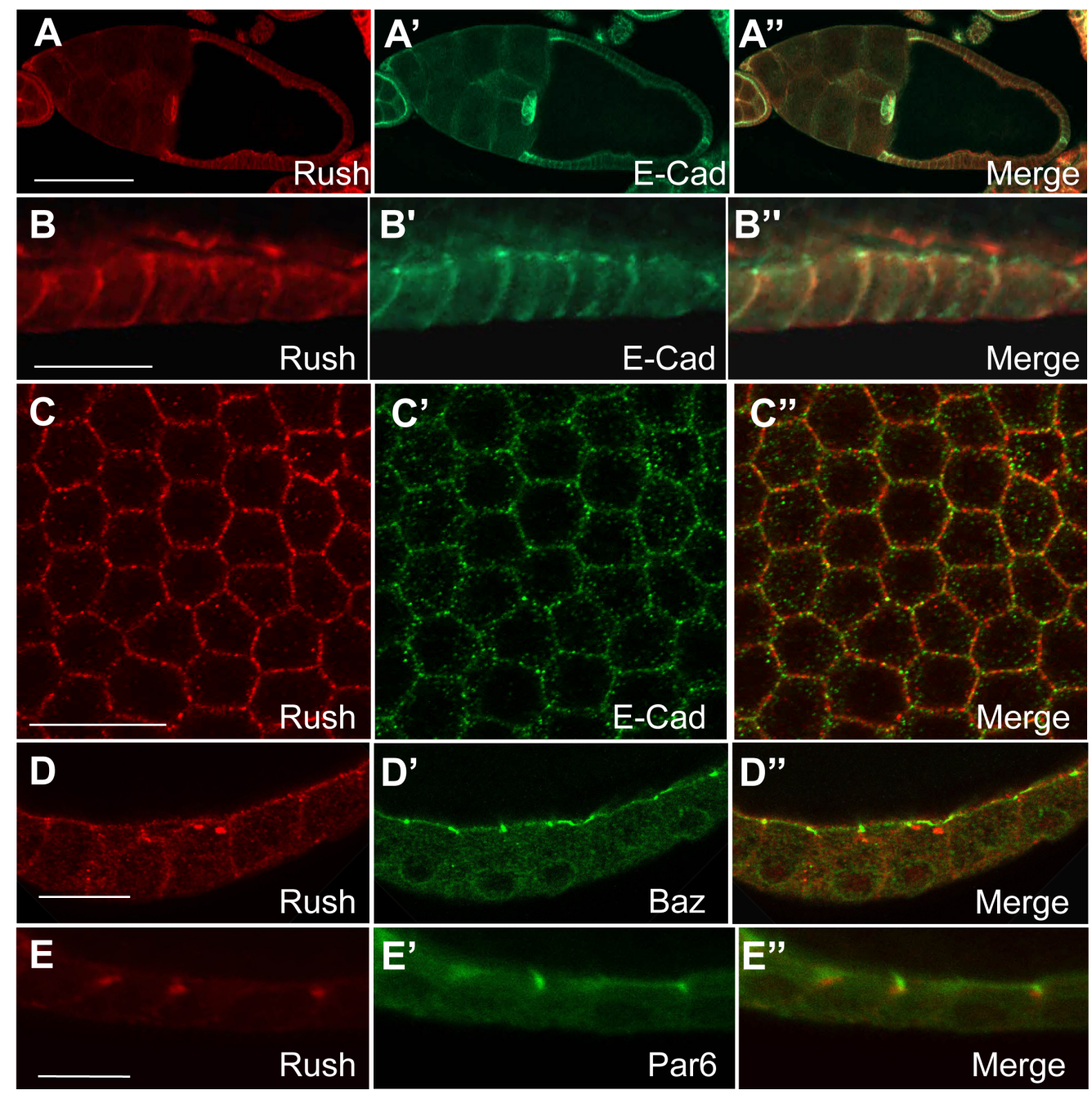

Figure 3-3. Localization of Rush in wild type ovaries. Ovaries were stained with antibodies against Rush and cell polarity markers. All panels show stainings of stage 10 egg chambers. A -Rush is expressed both in the germline and in the follicle epithelium. B - Cross section of the follicle epithelium. Rush localizes to the lateral plasma membrane with apical accumulations and colocalizes with E-cadherin. $\mathbf{C}-$ Tangential view of the follicle epithelium. Rush colocalizes with E-cadherin at the cell-cell contacts. D - Cross section of the follicle epithelium. Rush partially colocalizes with Baz. E - Cross section of the follicle epithelium. Rush partially colocalizes with Par6 at the subapical region. In panel A anterior is to the left. In panels B, D, E apical is to the top. Scale bars: $\mathrm{A}=50 \mu \mathrm{m}, \mathrm{B}, \mathrm{C}, \mathrm{D}, \mathrm{E}=10 \mu \mathrm{m}$.

\subsubsection{Rush associates with endosomes}

Both in the embryonic ectoderm and in the follicle epithelium a fraction of Rush was found in dot-like accumulations in the cytoplasm. Rush contains a FYVE domain (Fig. 1-6), which has been described to localize proteins to endosomal compartments (Gillooly et al., 2001). Therefore these dot-like structures could be endosomes. To investigate this possibility, I analyzed the colocalization of Rush with markers of the endocytic pathway. 
In the wild type follicle epithelium, cytoplasmic puncta of Rush colocalized with Hrs (Fig 3-4 A), a FYVE domain-containing protein that regulates the transition between early and late endosomes (Lloyd et al., 2002). Rab proteins are widely used as markers of different endocytic compartments. As it was not possible to stain simultaneously for Rush and Rabs in wild type tissue, since all available antibodies were generated in rabbits, I expressed YFP-tagged versions of wild type Rab5, Rab7 and a constitutively active mutant of Rab11 (Rab11CA) to mark early, late and recycling endosomes, respectively. Rush showed good colocalization with YFP-Rab7 (Fig. 3-4 B), but colocalized less extensively with YFPRab5 and YFP-Rab11CA (Fig. 3-4 C-D). Therefore Rush seems to associate with the late endosome and/or the transition intermediate between early and late endosomes.

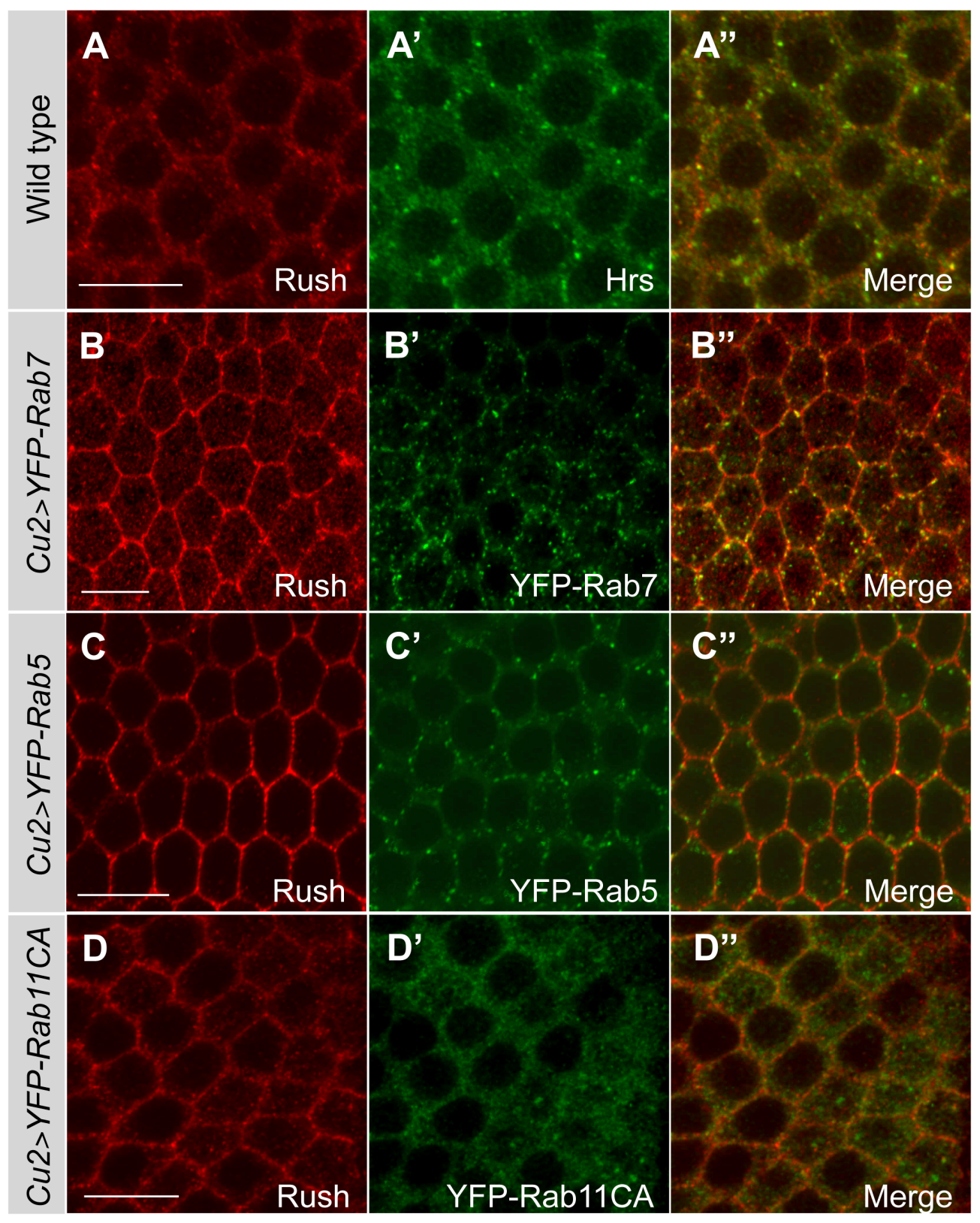


Figure 3-4. Colocalization of Rush with endosome markers. Ovaries of the indicated genotype were stained against Rush and different endosome markers. All panels show tangential sections of stage 8-10 egg chambers. A - Rush colocalizes with Hrs in cytoplasmic puncta. B - Rush colocalizes with YFP-Rab7, a marker of late endosomes. Less colocalization was observed between Rush and YFP-Rab5 (C) and YFPRab11CA (D). Scale bars $=10 \mu \mathrm{m}$.

The oocyte is a cell with highly active endocytic pathways due to the active uptake of yolk protein precursors (DiMario and Mahowald, 1987). Endocytic markers have been described to have a dynamic localization during oocyte maturation (Tanaka and Nakamura, 2008). In stage 7-8 egg chambers Rush accumulated in the centre of the oocytes (Fig. 3-5). Hrs accumulated in the centre of wild type oocytes together with Rush, indicating that these accumulations have an endocytic origin (Fig. 3-5 A). YFP-Rab7, when expressed in the germline under the control of the actin promoter, also accumulates in the centre of the oocyte (Fig. 3-5 B). Rush colocalizes with YFP-Rab7 in these accumulations. A similar localization of endocytic compartments to the centre of the oocyte in stage 7-8 egg chambers has been described before (Januschke et al., 2007; Tanaka and Nakamura, 2008). Thus Rush colocalizes with late endosomes both in the follicle epithelium and in the oocyte.

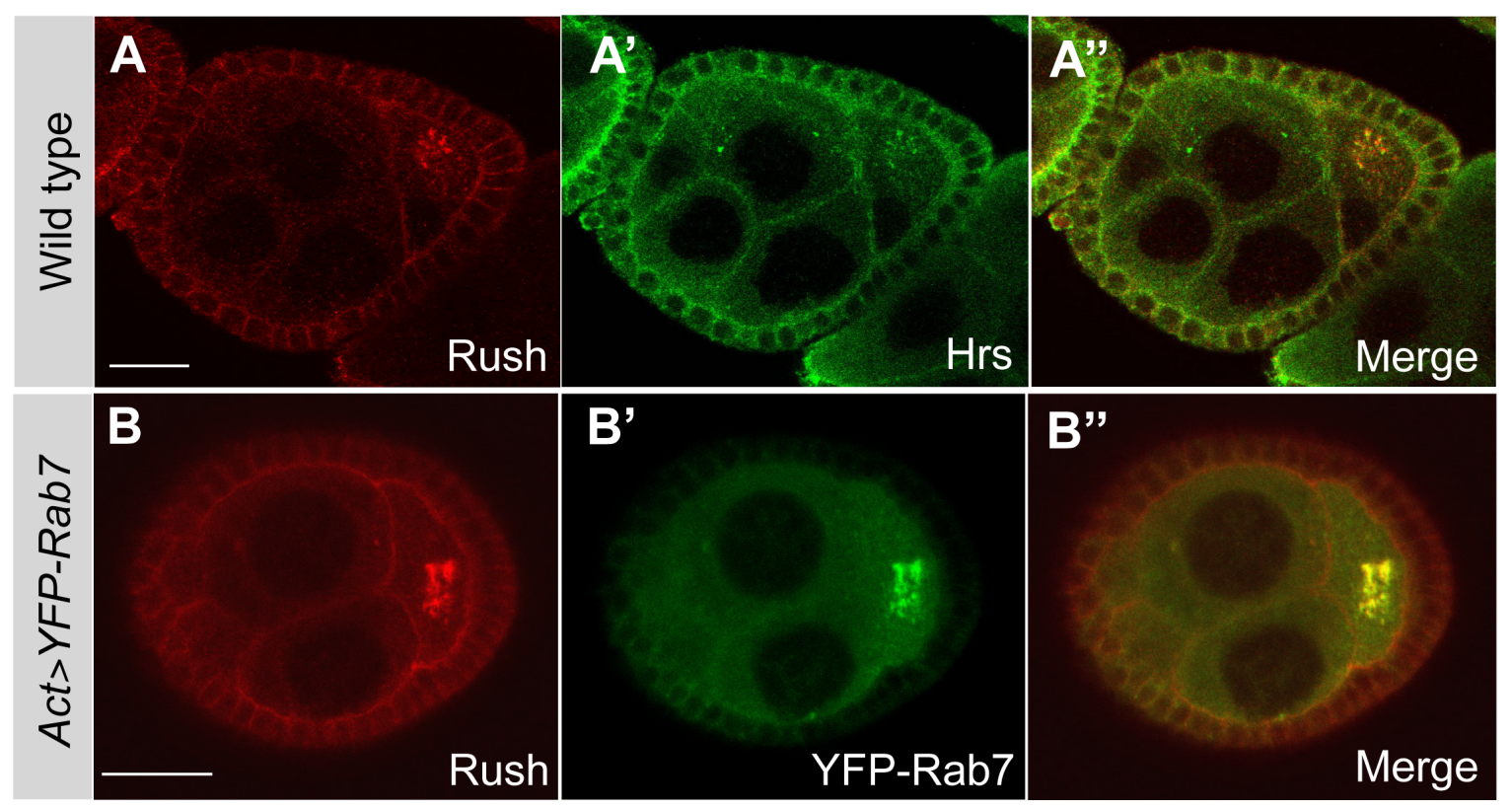

Figure 3-5. Rush colocalizes with endosome markers in the oocyte. A - Rush accumulates and colocalizes with Hrs in the oocyte of a wild type stage 8 egg chamber. B - YFP-Rab7 was overexpressed under the control of an ubiquitous actin promotor. In the stage 7 egg chamber YFP-Rab7 accumulates in the centre of the oocyte and colocalizes with Rush. Scale bars $=20 \mu \mathrm{m}$. 
To verify the association of Rush with endosomes, I performed cell fractionation experiments. Wild type S2 cell lysates were separated on a sucrose gradient and early and late endosome fractions were separated. Rush was found to fractionate together with endosome markers Rab5 and Rab7, but not in the fraction that contains Rab7 alone (Fig. 3$6)$.

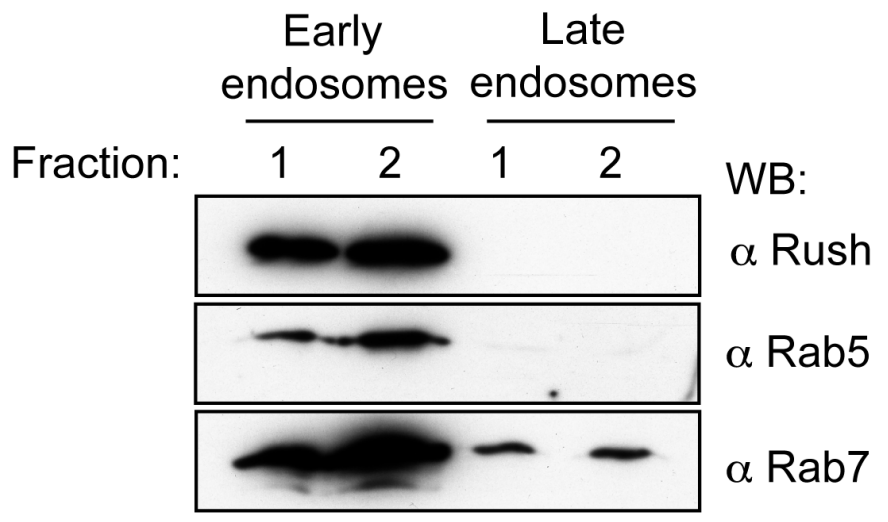

Figure 3-6. Rush cofractionates with endosomal markers. Wild type $\mathrm{S} 2$ cell lysates were fractionated on a sucrose gradient and the fractions corresponding to the early and late endosomes were analyzed with Western blotting. Rush co-fractionated with Rab5 and Rab7, but not Rab7 alone.

\subsubsection{Effect of Rush overexpression on endocytic compartments}

To further analyze association of Rush with endosomes, I generated a Rush fusion protein with a C-terminally attached GFP tag. When overexpressed in the follicle epithelium under

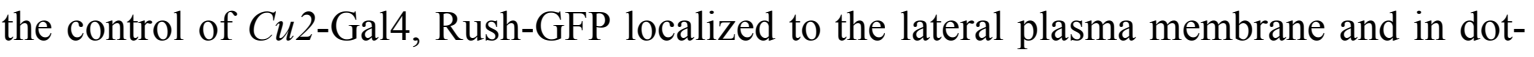
like structures in the cytoplasm (Fig. 3-7 C',), similar to the wild type protein (Fig. 3-4 A). To test whether overexpression of Rush affects polarity of epithelial cells, the $\mathrm{Cu2}>\mathrm{Rush}-$ GFP ovaries were stained against the polarity markers Baz and Par6. The localization of Baz and Par6 to the apical plasma membrane and the subapical region in Cu2>Rush-GFP follicle epithelium cells was similar as in the wild type cells (Fig. 3-7 C). Localization of E-cadherin was not affected either (Fig. 3-7 B, D). Therefore overexpression of Rush does not disrupt follicle cell polarity. 


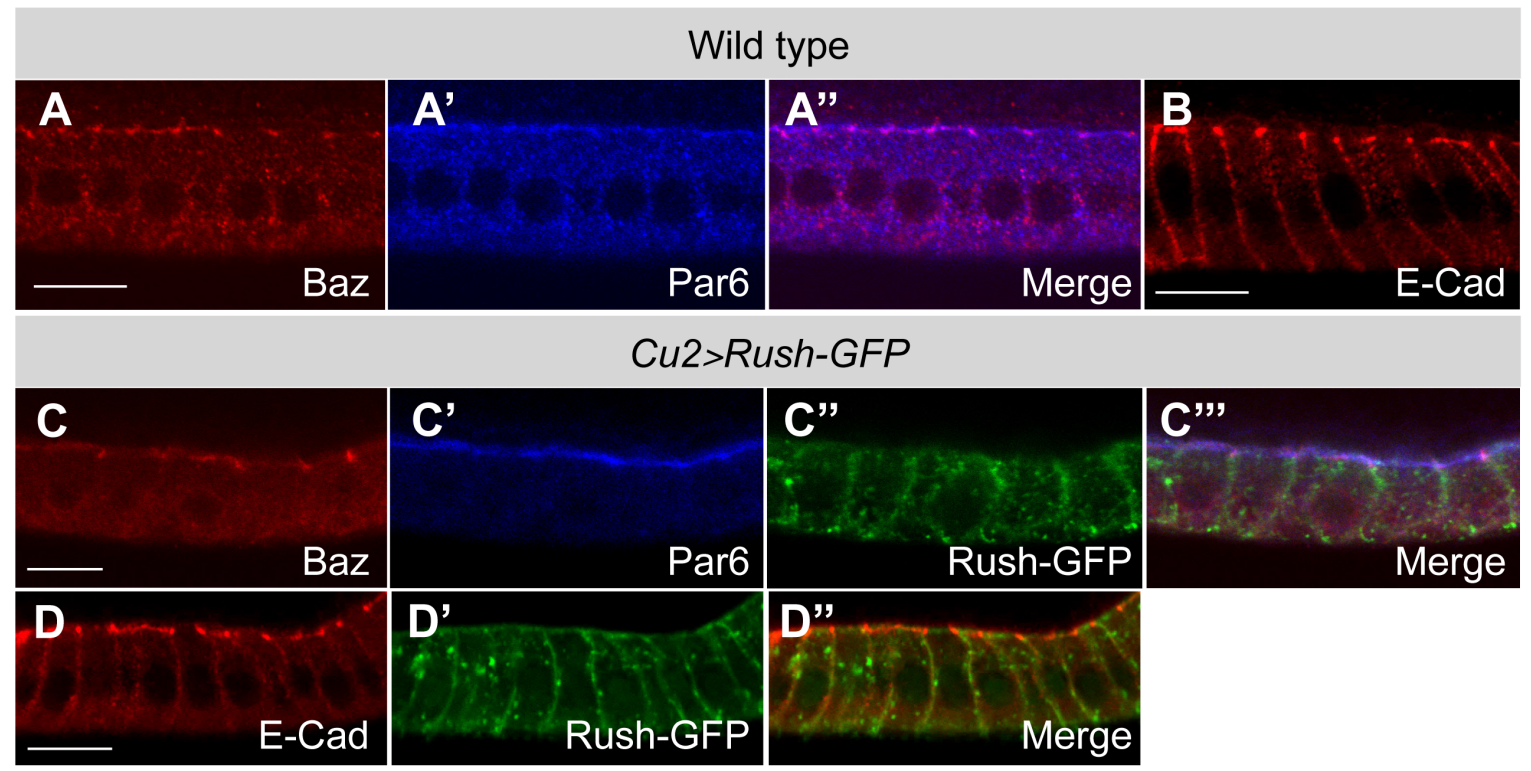

Figure 3-7. Overexpression of Rush-GFP does not affect localization of polarity markers. Expression of

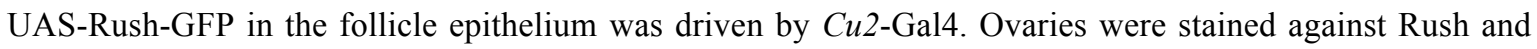
polarity proteins Baz, Par6 and E-cadherin. Cross sections of follicle epithelia of stage 10 egg chambers are depicted. A - In the wild type follicle epithelium Baz and Par6 localize to the apical membrane and the subapical region. B - Localization of E-cadherin in the wild type follicle epithelium. $\mathbf{C}$ - overexpression of Rush-GFP does not change localization of Baz and Par6. D - overexpression of Rush-GFP does not affect localization of E-cadherin. Apical is to the top. Scale bars $=10 \mu \mathrm{m}$.

To investigate whether the cytoplasmic accumulations of Rush-GFP represent endocytic compartments, I stained the ovaries that overexpress Rush-GFP in the follicle epithelium with antibodies against endosomal markers. Similarly as in the wild type tissue, Rush-GFP colocalized with Hrs and Rab7 (Fig. 3-8 A, B). Rush-GFP did not colocalize with Rab5, which localizes to early endosomes (Fig. 3-8 C), or Rab11, the marker of recycling endosomes (Fig. 3-8 D). Interestingly, overexpression of Rush-GFP led to formation of enlarged late endosomes, as marked by Rab7 staining, in comparison with wild type cells (Fig. 3-8 E). The observed large late endosomes could be induced by the activity of Rush, for example, in promoting transition between early and late endosomes or in a blockage of transport to lysosomes. Another possibility would be that the overproduction of Rush causes its increased degradation and leads to an increase in the endosome size. To test whether the cytoplasmic puncta of Rush-GFP represent functional endosomes, I performed dextran uptake experiments. Fluorescent dextran is endocytosed together with the fluid phase and can be used to track the endocytic pathway. Dextran uptake has been analyzed in detail in epithelium of wing discs of wandering third instar larvae (Boekel et al., 2006; $\mathrm{Lu}$ and Bilder, 2005), therefore I used this epithelial tissue for analysis of Rush-GFP 
endosomes.

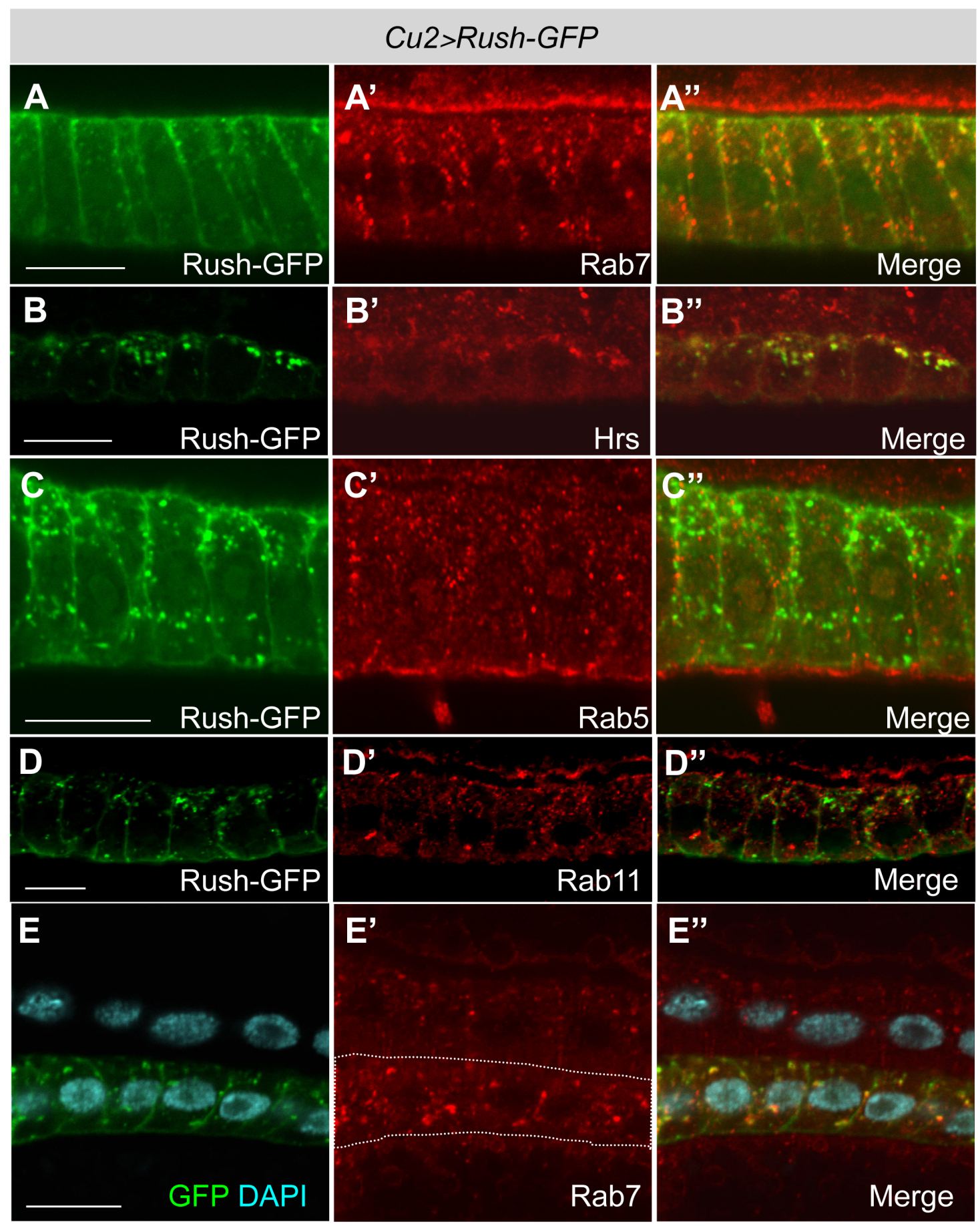

Figure 3-8. Rush-GFP colocalizes with late endosome markers. Ovaries that overexpress Rush-GFP were stained with antibodies against Rab proteins. Cross sections of follicle epithelia of stage 10 egg chambers are shown. Cytoplasmic puncta of Rush-GFP colocalize with Rab7 (A) and Hrs (B), but not with the early endosome marker Rab5 (C) or recycling endosome marker Rab11 (D). E - Rab7 vesicles are enlarged in Rush-GFP expressing follicle epithelium (marked with dotted line) in comparison with the wild type follicle cells. Apical is to the top. Scale bars $=10 \mu \mathrm{m}$. 
Immunofluorescence staining of wing discs with antibodies against Rush and Hrs confirmed that also in this tissue endogenous Rush and Rush-GFP colocalize with Hrs, while Hrs-positive structures are larger in the wing discs that overexpress Rush-GFP (Fig. 3-9 A, B). When incubated with fluorescent dextran, wing disc epithelial cells take up dextran molecules together with the fluid phase. After incubation of wing discs that overexpress Rush-GFP with dextran for $10 \mathrm{~min}$, dextran was found in puncta inside of cells (Fig. 3-9 C'). Endocytosed dextran partially colocalized with Rush-GFP (Fig. 3-9 C), indicating that the endosomes that are marked by Rush-GFP are functional and receive freshly endocytosed material.

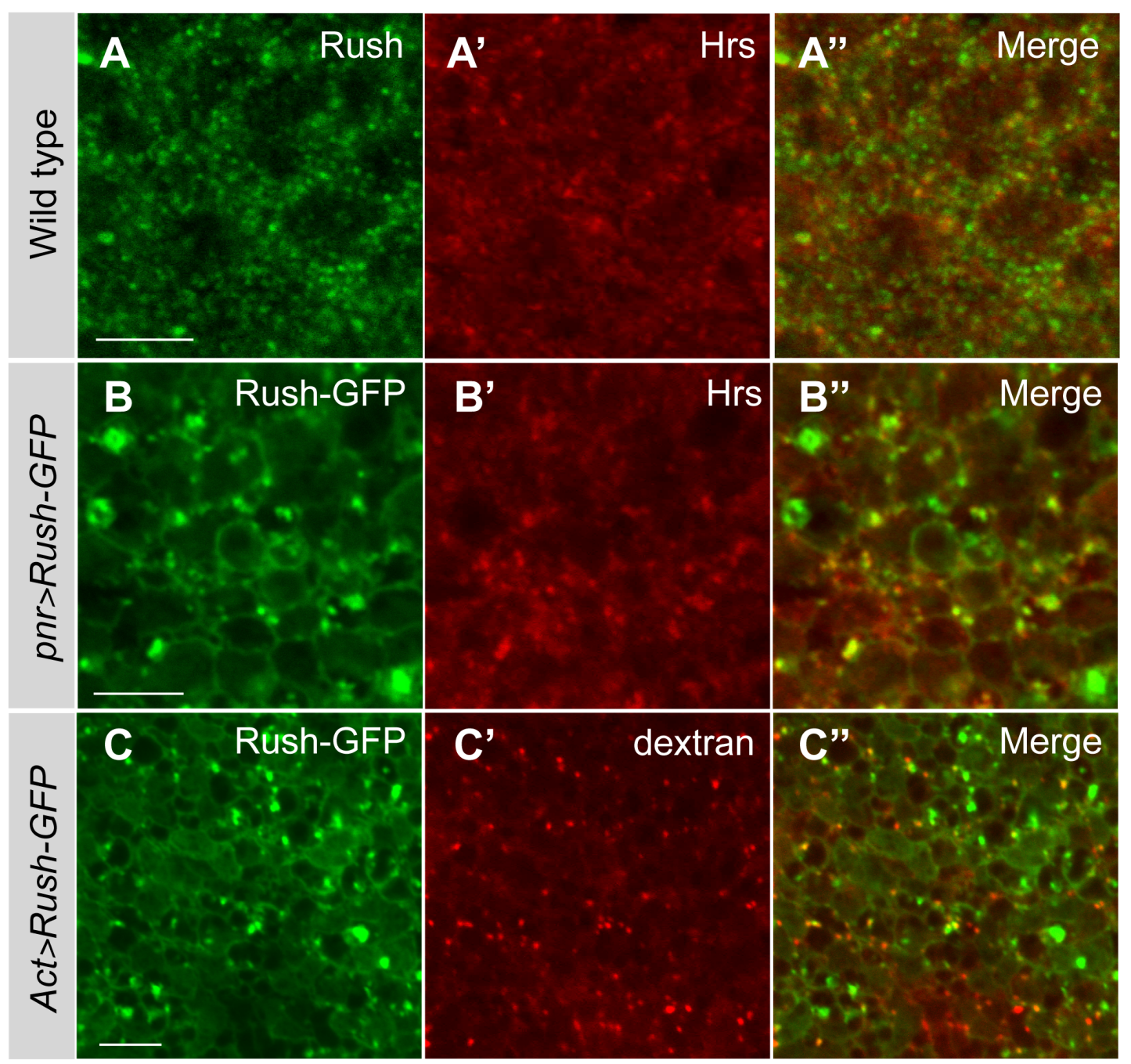

Figure 3-9. Rush colocalizes with Hrs and endocytosed dextran in wing discs. A - endogenous Rush colocalizes with Hrs in wild type wing discs. B - Rush-GFP colocalizes with Hrs in enlarged endocytic compartments. C - Rush-GFP marked endosomes are functional as shown by colocalization of endocytosed dextran. Scale bars $=5 \mu \mathrm{m}$. 
Since Rush overexpression caused formation of enlarged late endosomes, I wondered whether the endocytic pathway downstream of late endosomes was affected. For this purpose I stained wild type egg chambers and egg chambers that overexpress Rush-GFP in the follicle epithelium with LysoTracker (LTR). LTR stains acidic intracellular compartments and especially lysosomes. LTR staining was brighter in wild type follicle epithelium than in the follicle epithelium of Cu2>Rush-GFP ovaries (Fig. 3-10). Therefore it is possible that trafficking from the late endosome to lysosome is slowed down in Rush overexpressing cells, and thus leads to an increase in late endosome size.

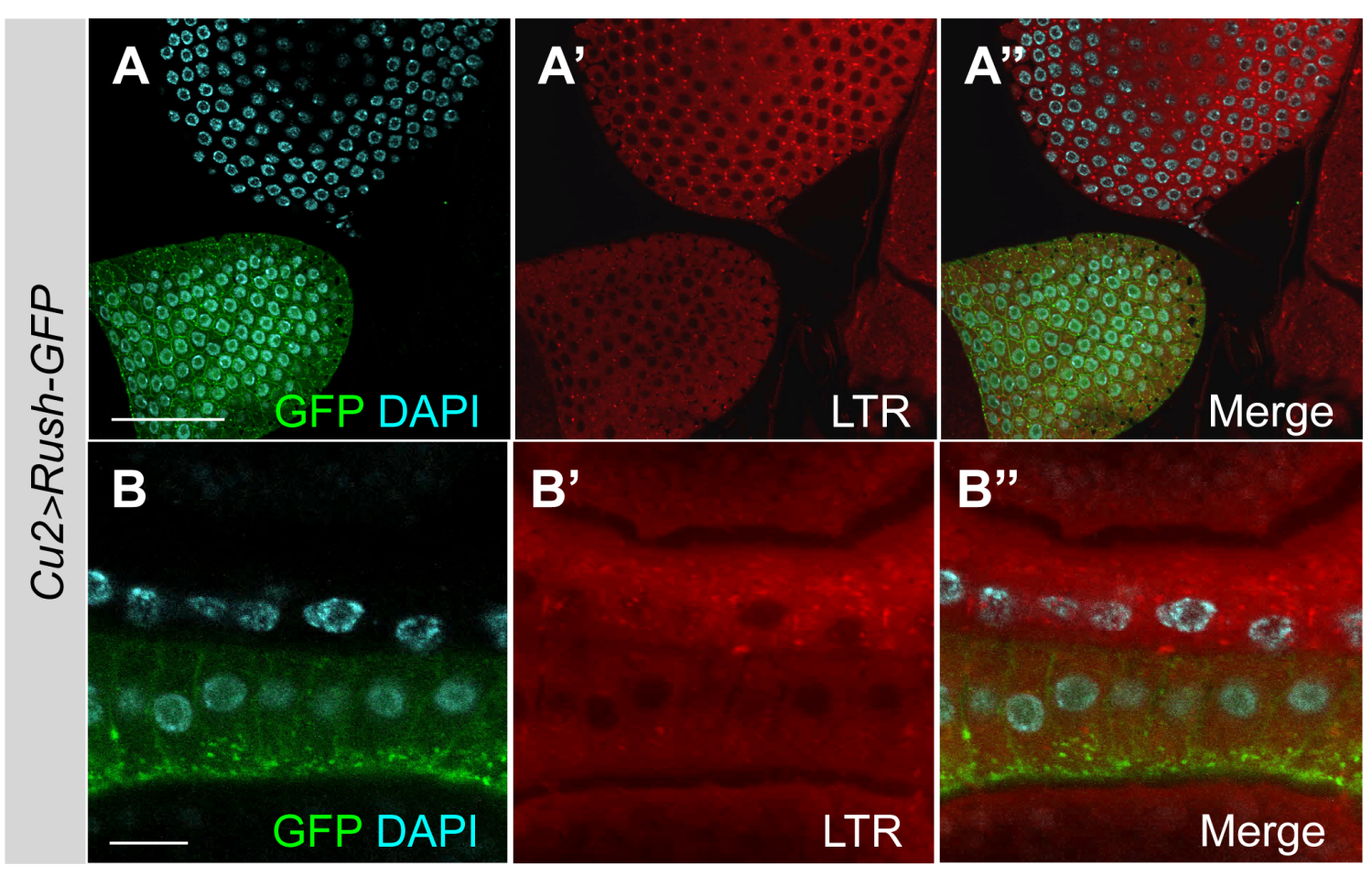

Figure 3-10. LTR staining is decreased in Rush-GFP overexpressing follicle epithelium. Wild type ovaries and ovaries with Rush-GFP expressed in follicle cells under the control of Cu2-Gal4 were incubated with LTR for $3 \mathrm{~min}$. A - Follicle epithelium of stage 10 egg chambers after incubation with LTR. LTR signal is weaker in the Rush-GFP expressing follicle epithelium. B - Higher magnification of wild type and RushGFP follicle epithelium. Scale bars: $\mathrm{A}=50 \mu \mathrm{m}, \mathrm{B}=10 \mu \mathrm{m}$.

Unexpectedly, overexpression of UAS-Rush-GFP in the follicle epithelium under the control of the $\mathrm{Cu} 2$ promoter in some cases induced apoptosis of germline cells (Fig. 3-11 A-C). Germline cells of Cu2>Rush-GFP egg chambers exhibited the hallmarks of apoptosis - condensed and fragmented nuclei. Interestingly, in most cases the follicle cells that express Rush-GFP were not apoptotic (Fig. 3-11 B). Expression of Cu2-Gal4 begins in stage 8 egg chambers. The observed apoptotic egg chambers usually had reached stage 10 
in the oogenesis (Fig. 3-11 A-C), possibly due to higher Rush-GFP levels after a longer expression period. To test whether the cell-non-autonomous apoptotic effect of Rush overexpression is specific to stage 10 chambers, I overexpressed Rush-GFP under the control of the $\mathrm{P}\{\mathrm{GawB}\} 109 \mathrm{C} 1$ enhancer trap line, which drives Gal4 expression in polar cells and follicle cells starting from early stages of oogenesis. Also in this case egg chambers with apoptotic germline cells were observed (Fig. 3-11 D). When Rush-GFP was expressed in the follicle epithelium starting from early stages, egg chambers underwent apoptosis earlier, indicating that the apoptosis is not specific to a stage in oogenesis, but rather to Rush-GFP levels.
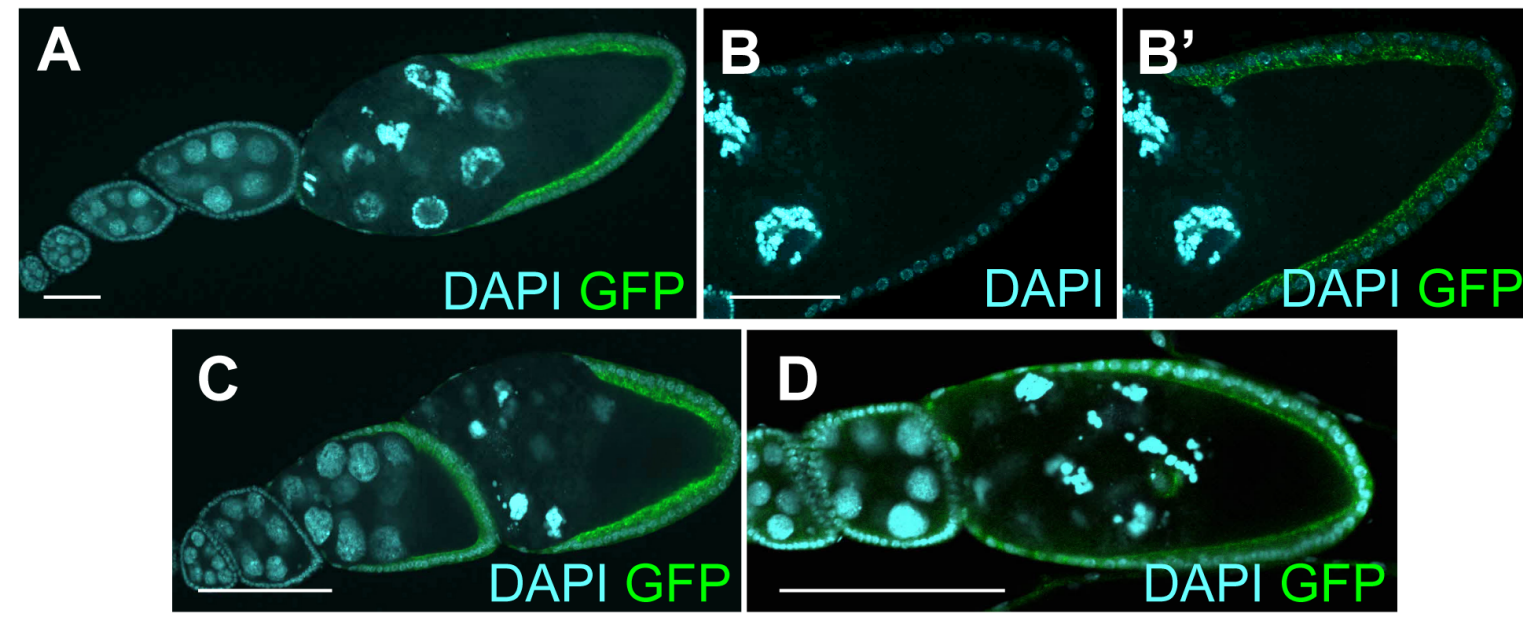

Figure 3-11. Overexpression of Rush-GFP in the follicle epithelium causes germline apoptosis. A, B, C - overexpression of UAS-Rush-GFP in the follicle epithelia under the control of the $\mathrm{Cu}$-Gal4 driver leads to germline apoptosis. B - A magnification of the stage 10 egg chamber shown in A. D - expression of UASRush-GFP under the control of the $\mathrm{P}\{\mathrm{GawB}\} 109 \mathrm{C} 1$ enhancer trap line also induces germline apoptosis. Apoptotic stage 9 egg chamber is shown. Anterior is to the left. Scale bars: A, C, D = $100 \mu \mathrm{m}, \mathrm{B}=50 \mu \mathrm{m}$.

\subsection{Rush modifies the shape of Rab5-induced early endosomes}

As Rush localizes both to the plasma membrane and to late endosomes, we wondered whether Rush associates also with early endosomes. It is possible that I could not observe colocalization between Rab5 and Rush due to weak antibody staining in wild type epithelium. For this purpose I decided to analyze Rush localization in flies that express Rab5Q88L, which is unable to hydrolyze GTP and is therefore constitutively in its active state (Rab5CA). Rab5 in the active state promotes fusion of endocytic vesicles with early endosomes and the homotypic fusion of separate early endosomes (Gorvel et al., 1991; 
Rubino et al., 2000). When expressed alone, Rush-GFP does not significantly colocalize with Rab5 in the follicle epithelium (Fig. 3-12 A). Expression of YFP-Rab5CA in the follicle epithelium led to formation of enlarged early endosomes (Fig. 3-12 B), as described previously (Bucci et al., 1992). Interestingly, Rush colocalized with Rab5CA vesicles (Fig. 3-12 B). Co-expression of Rush-GFP together with YFP-Rab5CA resulted in striking changes of the Rab5-marked endosome morphology. Rab5-induced large endosomes changed their shape and seemed to consist of smaller interconnected vesicles (Fig. 3-12 C, inset in Fig. 3-12 C'"). Rush was also localized to these large vesicle clusters (Fig. 3-12 D).

Rush-GFP-marked vesicles are distributed more or less uniformly in the cytoplasm of follicle cells (Fig. 3-13 A). In contrast, enlarged early endosomes that form in Rab5CAexpressing cells are localized at the apical side of cells (Fig. 3-13 B). Interestingly, when I co-expressed Rush-GFP together with YFP-Rab5CA, Rush changed its localization and was now found only in apical endosomes (Fig. 3-13 C). 


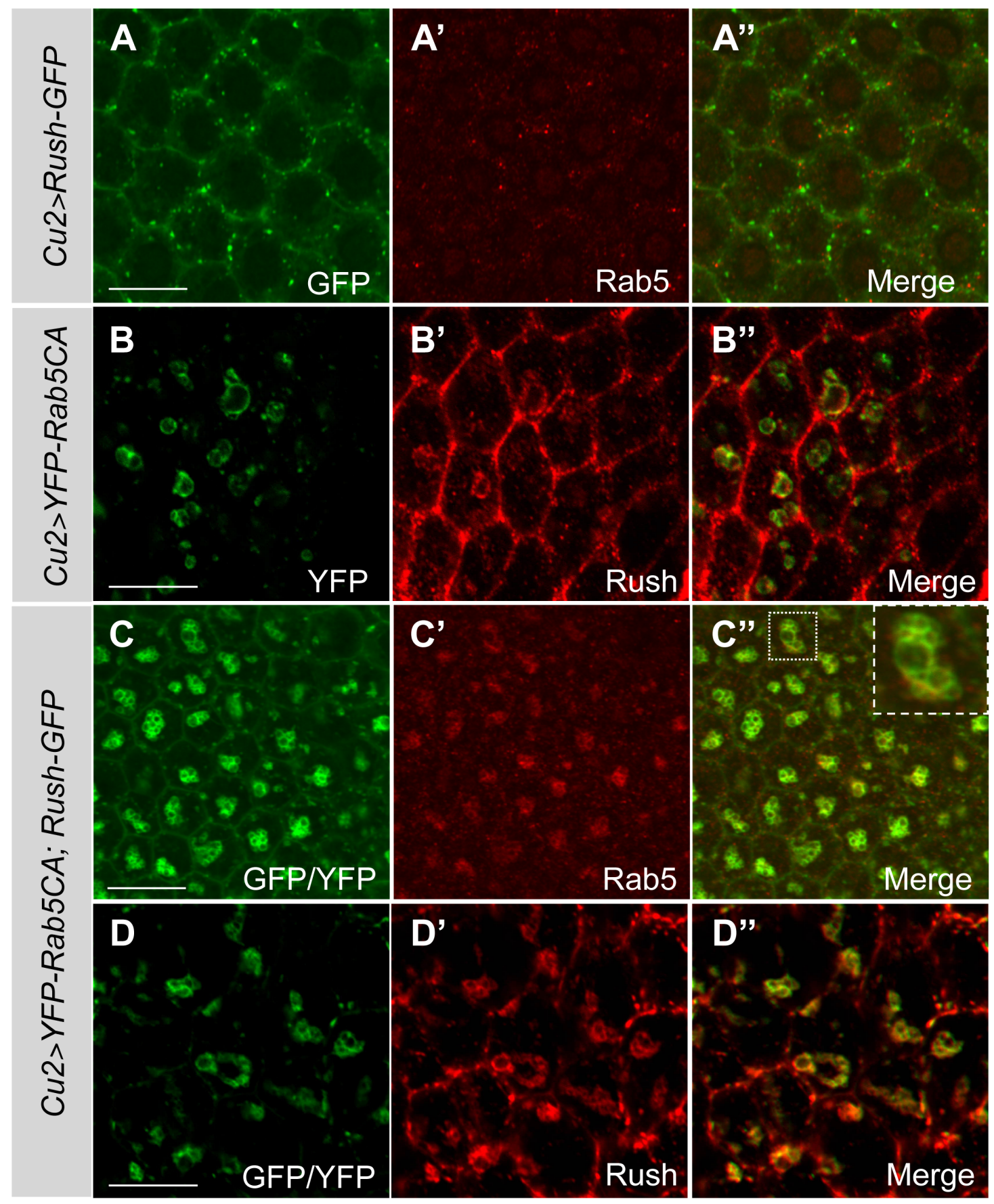

Figure 3-12. Rush-GFP changes the shape of Rab5CA-induced endosomes. Rush-GFP and/or YFPRab5CA were overexpressed in the follicle epithelium with $C u 2>$ Gal4. All panels depict tangential sections of stage 10 egg chamber follicle epithelium. A - Rush-GFP does not colocalize with Rab5. B - Expression of YFP-Rab5CA results in formation of large endosomes that colocalize with Rush. C, D - co-expression of Rush-GFP and YFP-Rab5CA leads to fractionation of the large endosomes. Inset in C" represents the area marked by the white rectangle. Scale bars $=10 \mu \mathrm{m}$. 


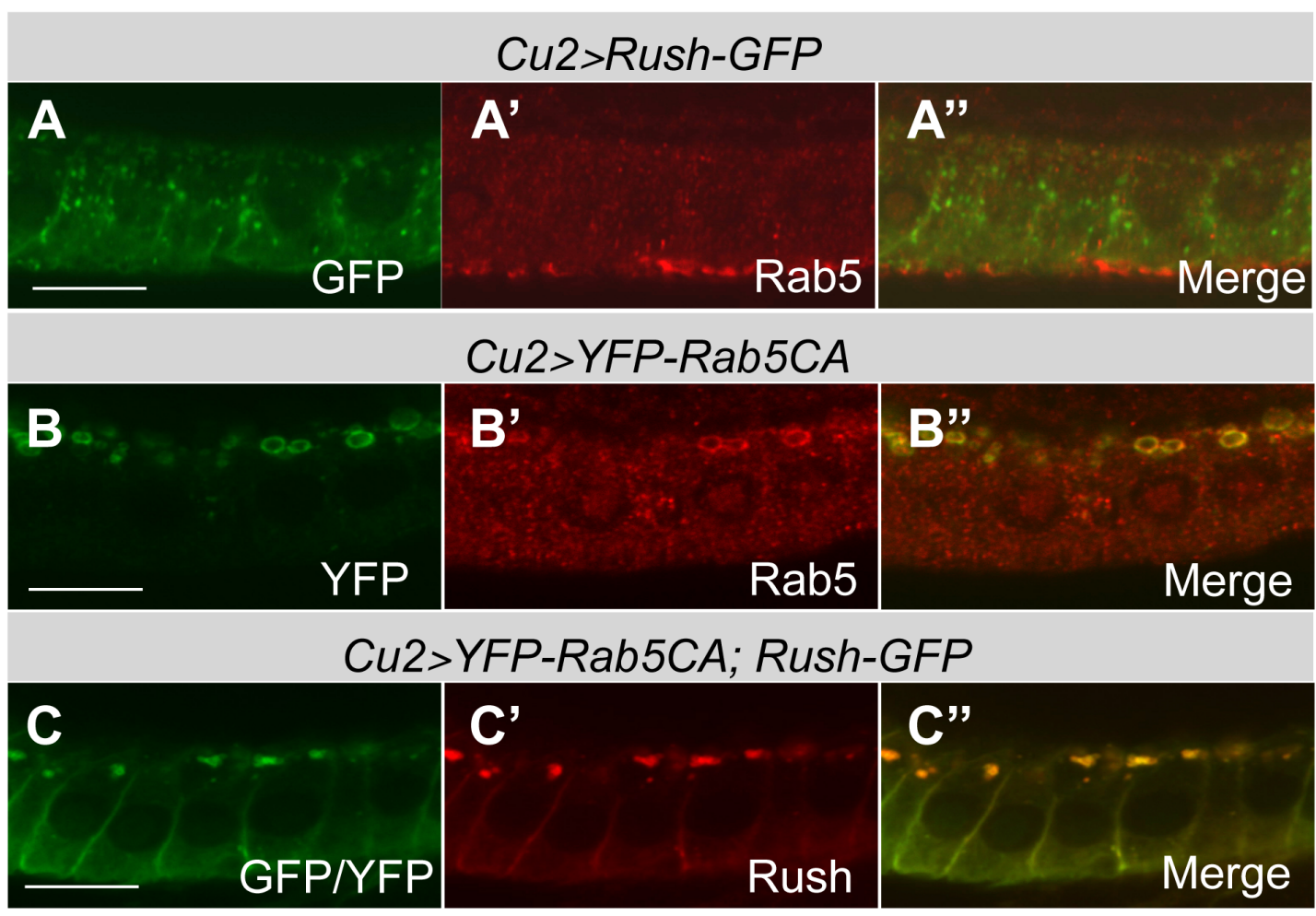

Figure 3-13. Rab5CA expression changes the localization of Rush-GFP. All panels show cross sections of the follicle epithelium of stage 10 egg chambers. A - Rush-GFP localization in follicle epithelium. B Rab5CA causes formation of large apical endosomes. C - When co-expressed with Rab5CA, Rush-GFP changes its localization and localizes apically. Apical is to the top. Scale bars $=10 \mu \mathrm{m}$.

Rush-GFP, when expressed alone, colocalizes with Rab7, a marker for late endosomes (Fig. 3-14 A). As expression of Rab5CA leads to relocalization of Rush to early endosomes, I tested whether Rab5CA affects localization of other late endosomal proteins like Rab7. I found that Rab7 also became associated with Rab5CA-positive large endosomes (Fig. 3-14 B). Rab7 is also recruited to the clusters of endosomes that are formed due to simultaneous overexpression of Rush-GFP and YFP-Rab5CA (Fig. 3-14 C). 


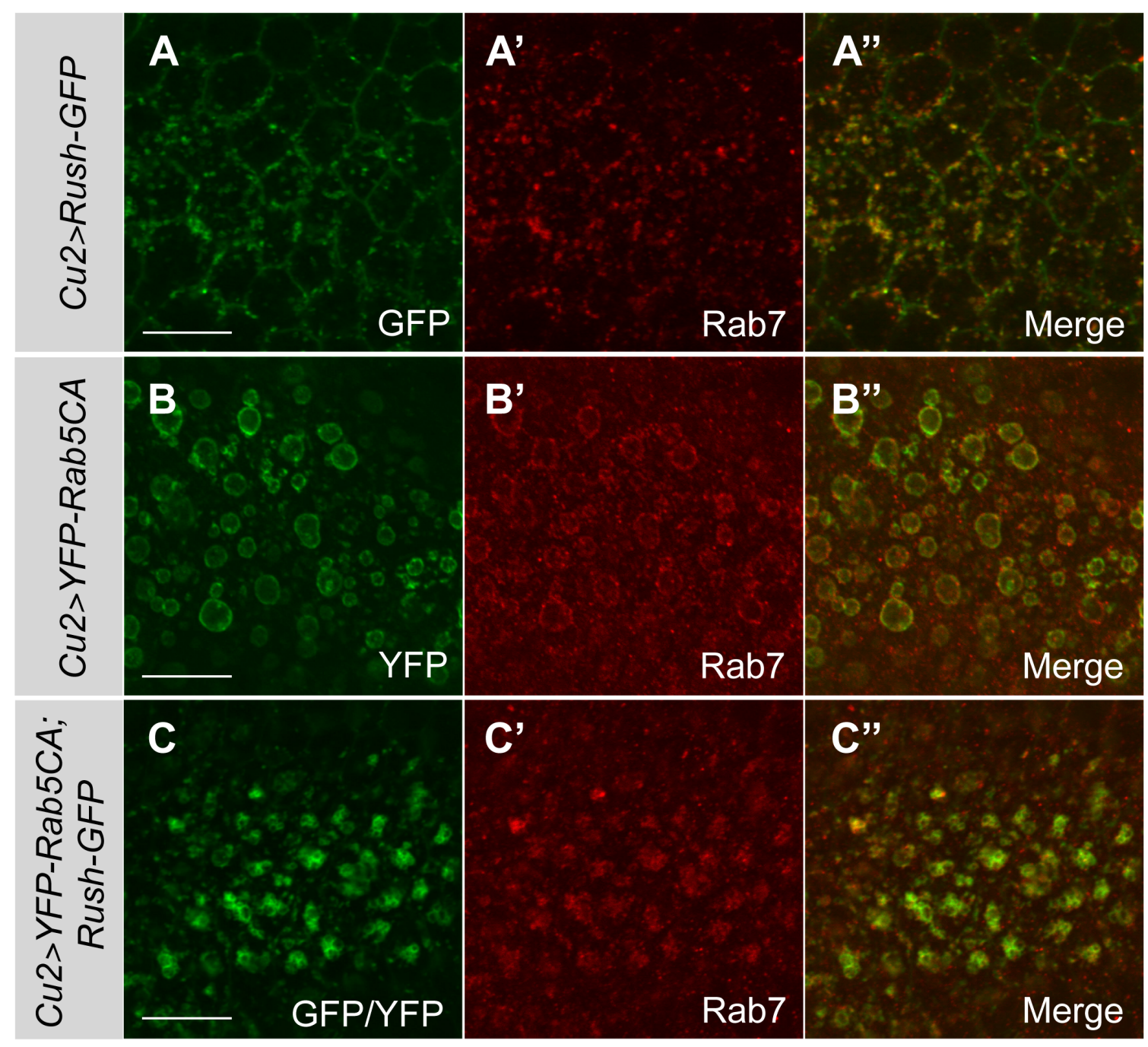

Figure 3-14. Rab7 localizes to Rush-GFP and YFP-Rab5CA vesicles. A - Rush-GFP colocalizes with Rab7. B - Rab7 localizes to Rab5CA-induced large endosomes. C - Rab7 colocalizes with large vesicle clusters in follicle cells that co-express Rush-GFP and YFP-Rab5CA. All panels show tangential sections of stage 10 egg chamber follicle epithelium. Scale bars $=10 \mu \mathrm{m}$.

As Rab5CA caused relocalization of late endosome proteins to the Rab5-positive compartment, I performed stainings against Rab11 to see if the distribution of the recycling endosome proteins is affected. Rab11 does not colocalize with Rush-GFP vesicles (Fig. 315 A) and Rab5CA vesicles (Fig. 3-15 B). In the cells that express Rush-GFP and YFPRab5CA, Rab11 signal is slightly increased in the clustered endosomes (Fig. 3-15 C).

Taken together, expression of Rab5CA leads to association of late endosome proteins and Rush with enlarged early endosomes, most probably due to inability of early endosomes to transit to a late endosome state. Overexpression of Rush together with Rab5CA changed the morphology of the enlarged early endosomes, leading to their fragmentation. 


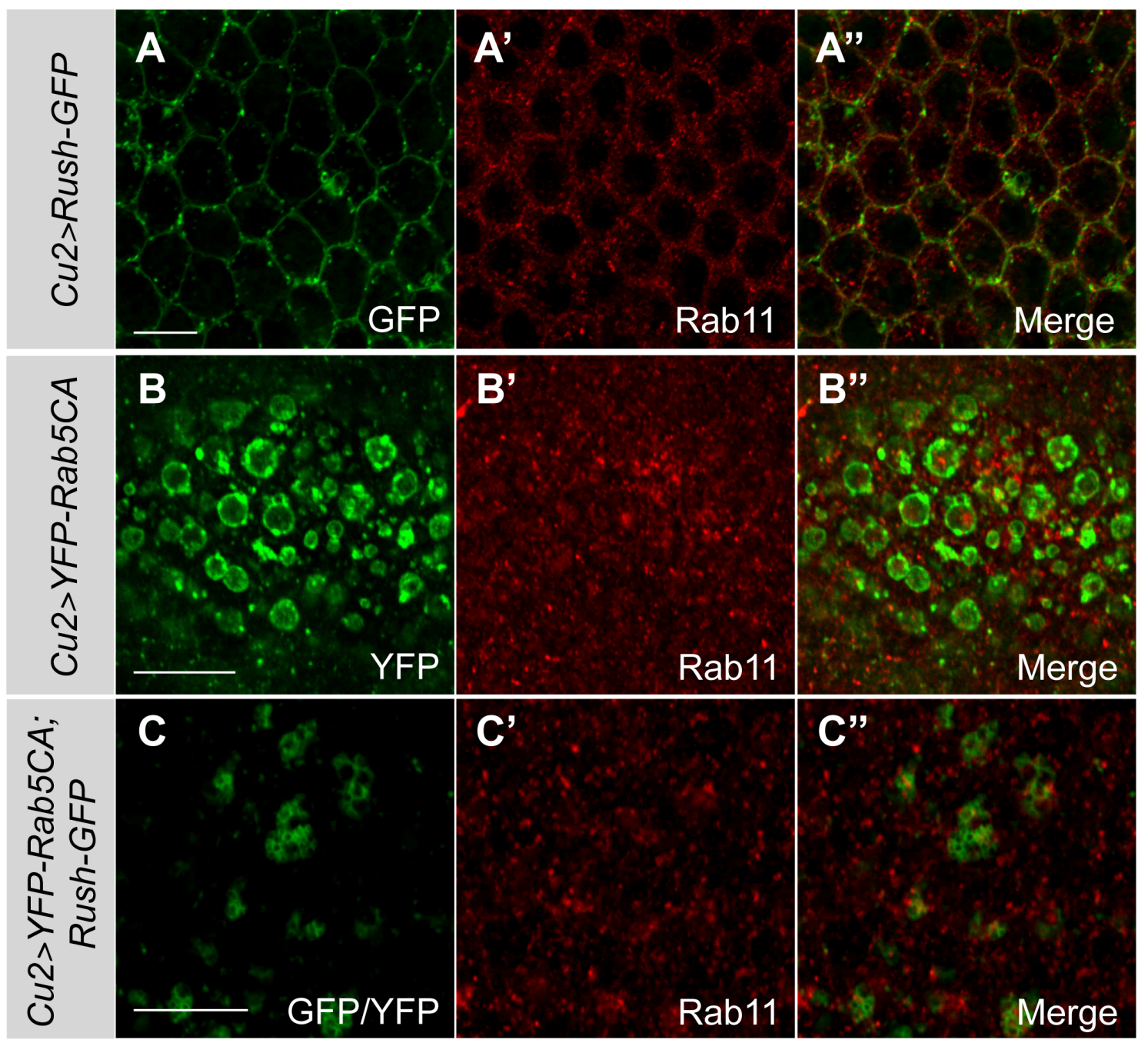

Figure 3-15. Localization of Rab11 in Rush-GFP and/or YFP-Rab5CA expressing follicle epithelium. A

- Rab11 shows very limited colocalization with Rush-GFP. B - Rab11 does not colocalize with Rab5CA. C Rab11 staining is slightly increased at Rush-GFP, Rab5CA-induced clustered endosomes. All panels are tangential sections through the follicle epithelium of stage 10 egg chambers. Scale bars $=10 \mu \mathrm{m}$.

\subsection{Lipid binding properties of Rush}

Rush contains two lipid binding domains, a PH and a FYVE domain (Fig. 1-6, Fig. 3-16 A). Both FYVE and PH domains interact with phosphatidylinositol phosphates (PIPs), but differ in their affinity for PIPs. FYVE domains have been described to bind specifically to PI(3)P, a phosphoinositide found on early endosomes and multivesicular bodies (van Meer et al., 2008). PH domains of different proteins have diverse affinities to PIPs, e.g. the PH domain of phospholipase $\mathrm{C} \delta 1$ (PLC 1 ) binds preferentially to $\mathrm{PI}(4,5) \mathrm{P}_{2}$, while 3phosphoinositide-dependent kinase 1 (PDK1) interacts with $\mathrm{PI}(3,4) \mathrm{P}_{2}$ and $\mathrm{PI}(3,4,5) \mathrm{P}_{2}$ (Varnai et al., 2002; Currie et al., 1999). Rush localizes to the plasma membrane and 
endosomes. Lipid binding domains of Rush could mediate its membrane association. Therefore I aimed to determine whether the lipid binding domains of Rush are functional and which lipids they bind to. For this purpose I performed lipid overlay assays with GSTtagged full length Rush and its separate domains (Fig. 3-16 A). As both domains have been described to interact with PIPs, GST fusion proteins were incubated with phospholipids that are immobilized on a nitrocellulose membrane (PIP Strips). A scheme of the distribution of phospholipids on the membrane is shown in Fig. 3-16 B. The results of the lipid overlay assay are shown in Fig. 3-16 C. The PH domain of Rush interacted most strongly with $\mathrm{PI}(3,4) \mathrm{P}_{2}$ and $\mathrm{PI}(4) \mathrm{P}$ and had a weaker interaction with PI(3)P. The FYVE domain, as expected, interacted exclusively with PI(3)P. Full length Rush interacted most strongly with $\mathrm{PI}(3) \mathrm{P}$, but also bound to a lesser extent with $\mathrm{PI}(4) \mathrm{P}, \mathrm{PI}(5) \mathrm{P}, \mathrm{PI}(3,4) \mathrm{P}_{2}$, $\mathrm{PI}(4,5) \mathrm{P}_{2}$ and $\mathrm{PI}(3,4,5) \mathrm{P}_{3}$. Thus, the lipid binding domains of Rush are able to interact with PIPs and Rush has the highest affinity towards PI(3)P, a lipid specific for early endosomes (van Meer et al., 2008).

To analyze how the two lipid binding domains affect the subcellular localization of Rush, I aimed to eliminate lipid binding properties of each of the domains. Single amino acid exchange mutations that abolish lipid binding of PH and FYVE domains have been described before (Kutateladze, 2006; Yagisawa et al., 1998). In both domains basic amino acid residues are responsible for the interaction with phospholipids. In the FYVE domain the core motif RR/KHHCR is responsible for the interaction of the domain with PI(3)P. Mutations in any of the arginine or histidine residues in this motif leads to disruption of the lipid binding (Gaullier et al., 2000). Based on these findings, I exchanged the $\operatorname{Arg}^{176}$ residue of Rush with Gly using site-directed mutagenesis (Fig. 3-16 A). A Lys ${ }^{32}$ exchange with Glu in the phospholipase C PH domain abolished the ability of the protein to interact with $\mathrm{P}(4,5) \mathrm{P}_{2}$ (Yagisawa et al., 1998). The homologous residue Lys ${ }^{48}$ in the $\mathrm{PH}$ domain of Rush was identified based on an alignment with the phospholipase PH domain and mutated to Glu (Fig. 3-16 A). The lipid binding abilities of the mutated domains and the full length Rush are shown in Fig. 3-16 D. The PH domain with the K48E mutation lost its ability to interact with PIPs, as well as the FYVE domain with the R176G mutation (amino acid numbering according to their position in full length Rush). The full length Rush ${ }^{\mathrm{K} 48 \mathrm{E}}$ interacted only with PI(3)P due to the activity of the FYVE domain. Rush ${ }^{\mathrm{K} 48 \mathrm{ER} 176 \mathrm{G}}$ was not able to interact with PIPs and exhibited only background interaction levels. Interestingly, also Rush ${ }^{\mathrm{R} 176 \mathrm{G}}$ lost its affinity to PIPs, although one would expect a similar affinity to PIPs as for the PH domain alone. This effect might be caused by conformational changes in the 
protein caused by the mutation. It is also possible that in a full length protein an interaction between the PH and FYVE domains is necessary for lipid association of Rush.

A

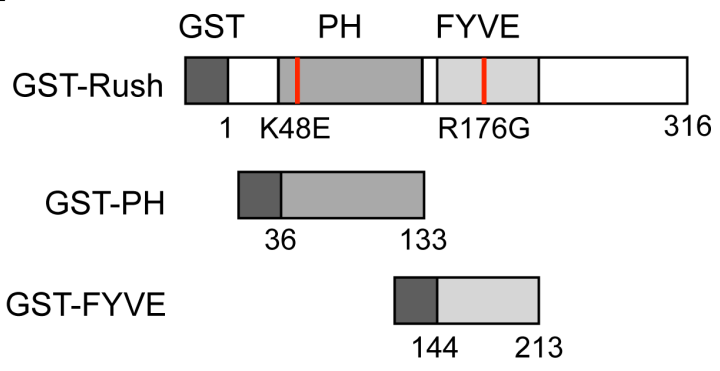

B

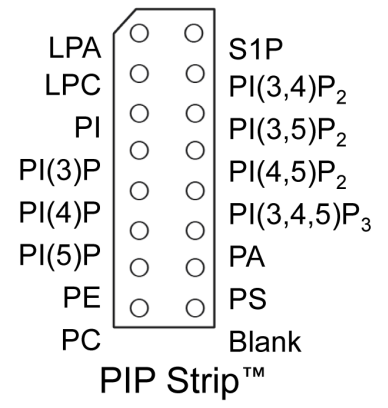

C

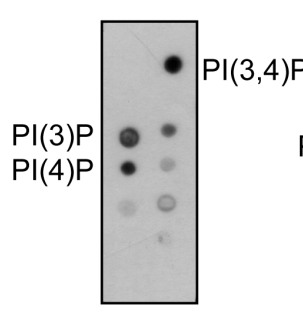

GST-PH

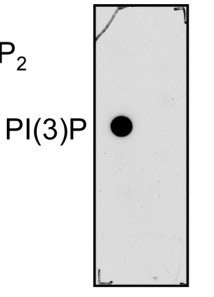

GST-FYVE

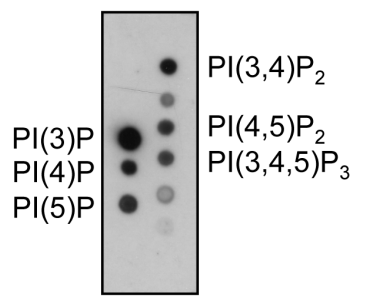

GST-Rush

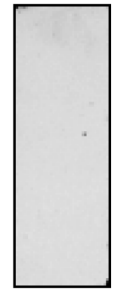

GST

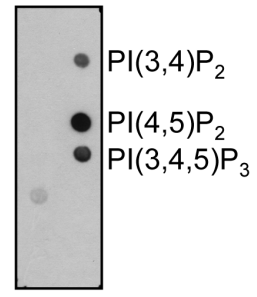

$\mathrm{PIP}_{2}{ }^{-G}{ }^{\mathrm{TM}}$

D

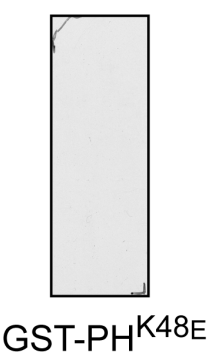

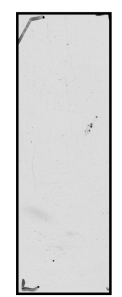

GST-FYVER176G

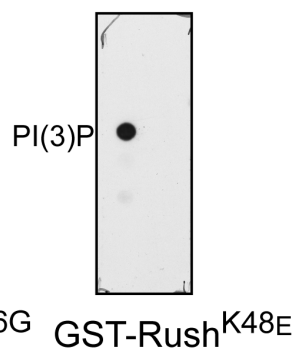

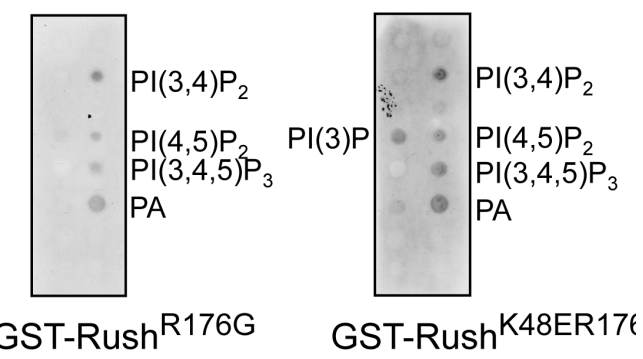

Figure 3-16. Lipid binding specificity of Rush. A - A scheme of GST fusion constructs that were used in lipid overlay assays. Red bars indicate the amino acid residues that were mutated to abolish lipid binding abilities of the respective domain. B - Scheme of a PIP Strip showing the lipid composition of dots. C Binding of Rush and its lipid binding domains to different PIPs. PIP Strips were incubated with GST fusion proteins and lipid-bound proteins were detected with anti-GST antibody. GST only and PIP $_{2}$-Grip were used as controls. PIP ${ }_{2}$-Grip is a GST-tagged $\mathrm{PH}$ domain with the highest affinity towards $\mathrm{PI}(4,5) \mathrm{P}_{2}$. D - Single amino acid mutations in PH and FYVE domains of Rush abolish their ability to bind with PIPs.

To observe how the mutations in lipid binding domains affect the localization of Rush in cells, transgenic flies expressing mutated full length Rush proteins tagged with GFP were created. When expressed in the follicle epithelium, Rush ${ }^{\mathrm{K} 48 \mathrm{E}}$-GFP could still localize to the plasma membrane and endosomes, indicating that the FYVE domain of Rush is sufficient 
for membrane localization of Rush (Fig. 3-17 A). Unexpectedly, Rush ${ }^{\text {R176G }}$-GFP was detected at the plasma membrane (Fig. 3-17 B), although no significant affinity of Rush $^{\mathrm{R} 176 \mathrm{G}}$ towards PIPs could be detected in the lipid overlay assay (Fig. 3-16 D). Rush $^{\text {R176G }}$-GFP did not colocalize with cytoplasmic Rab7 puncta, indicating that the FYVE domain of Rush is needed for the association with endosomes (Fig. 3-17 B). Rush ${ }^{\text {K48ER176G }}$ GFP, as expected from the lipid overlay assay, did not bind to membranes and was distributed in the cytoplasm (Fig. 3-17 D). Overexpression of Rush ${ }^{\mathrm{K} 48 \mathrm{E}}-\mathrm{GFP}$ led to formation of large Rab7-positive endosomes (Fig. 3-17 A), similarly as expression of wild type Rush-GFP (Fig. 3-8 E). Overexpression of either Rush ${ }^{\text {R176G }}$-GFP or Rush ${ }^{\text {K48ER176G }}$ GFP did not enlarge the size of late endosomes (Fig. 3-17 E), suggesting that the FYVE domain of Rush is responsible for its effect on the late endosome size.

Figure 3-17. Subcellular localization in Rush lipid binding defective mutants. A - Rush ${ }^{\mathrm{K} 48 \mathrm{E}}-\mathrm{GFP}$ localizes to the plasma membrane and Rab7-positive endosomes similarly as the wild type Rush. Rush ${ }^{\mathrm{K} 48 \mathrm{E}_{-}}$ GFP mutant also causes formation of enlarged Rab7-positive endosomes. B - Rush ${ }^{\text {R176G }}$ GFP localizes to the plasma membrane and does not localize to Rab7 vesicles. C - The size of Rab7 endosomes is not increased in Rush $^{\text {R176G }}$ GFP expressing follicle cells in comparison to the wild type epithelium. D - Rush ${ }^{\text {K48ER176G_GFP }}$ has lost its ability to associate with membranes and is cytoplasmic. $\mathbf{E}-\mathrm{Rush}^{\mathrm{K} 48 \mathrm{ER} 176 \mathrm{G}}-\mathrm{GFP}$ overexpression does not cause formation of enlarged late endosomes. Wild type follicle epithelium is shown for comparison. Scale bars $=10 \mu \mathrm{m}$. 


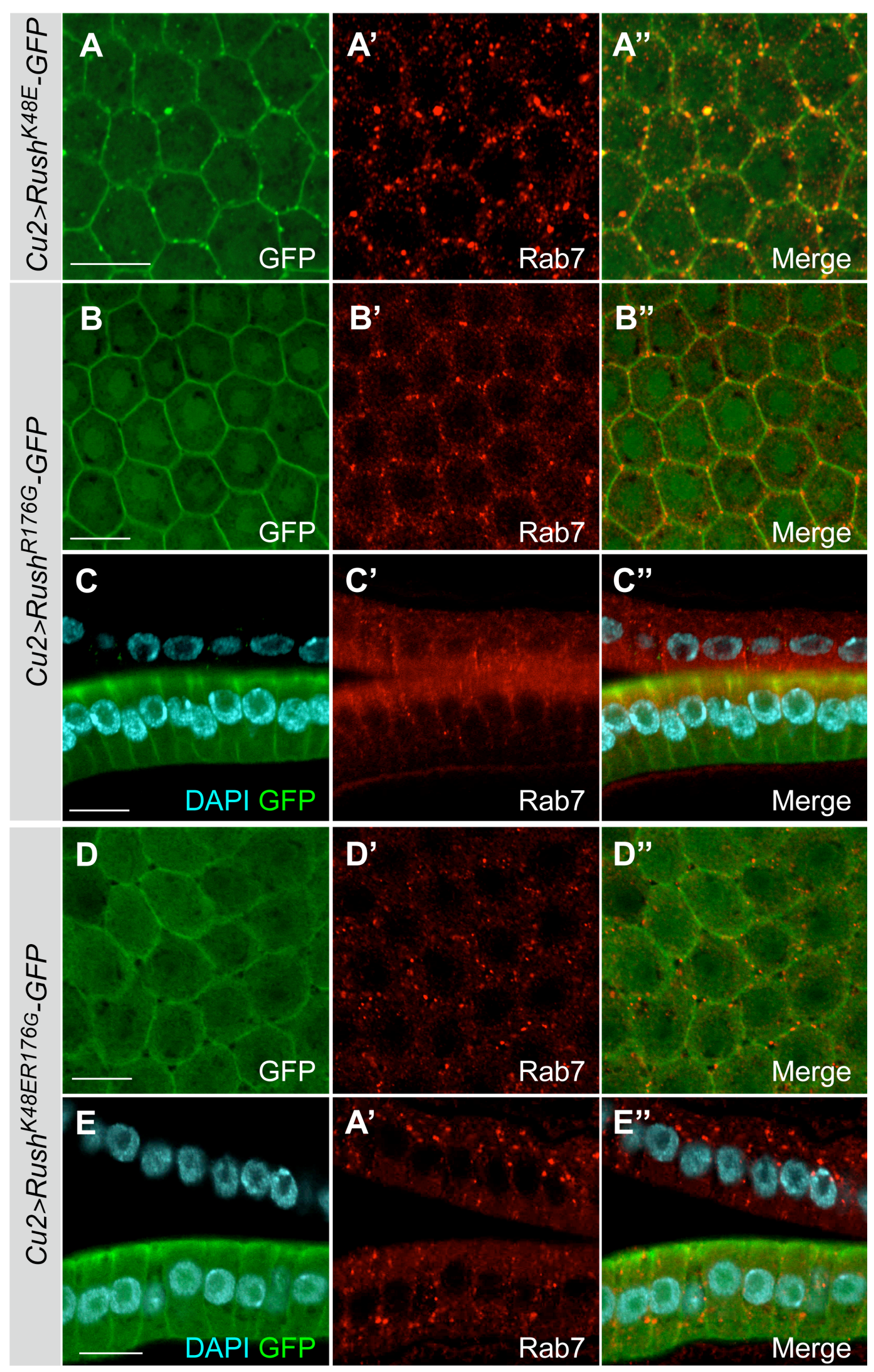




\subsection{Generation of rush mutant allele}

To further investigate the function of Rush, a rush null allele was generated. For this purpose the full coding sequence of rush was removed via FLP/FRT-mediated excision. This method makes use of the ability of FLP recombinase to cause a recombination between two FRT sites positioned on two complementary chromosomes (in trans). Two transposon insertion lines that contain FRT sites were available from the Harvard stock collection. These transposons are inserted upstream and downstream of the rush locus. The $\mathrm{P}(\mathrm{XP}) \mathrm{d} 03799$ element is located in the 5' UTR of rush (Fig. 3-1, Fig. 3-18 A), while pBac(WH)f03712 element is inserted in the 5' UTR of sta, a gene located downstream of rush (Fig. 3-18 A). The FLP recombinase-induced deletion of the genomic region between the two FRT sites was used to remove the rush coding region. The sta gene downstream of rush was also removed during the recombination. sta is an essential gene, therefore a rescue construct containing a full coding sequence of sta including the upstream regulatory sequences was crossed in after the recombination. Mutant flies were selected by the white eye phenotype, since the recombination removed mini-white genes carried by the transposons. Obtained white-eyed flies were homozygous viable, and healthy stocks could be established.

As the obtained putative rush deletion lines were homozygous viable, the loss of rush gene was tested by several methods. The deletion of rush genomic region was verified by PCR on genomic fly DNA (Fig. 3-18 B, C). PCR with the primer pair that encompasses the whole deleted region leads to formation of a $5105 \mathrm{bp}$ long fragment in wild type flies, while only a shorter $2442 \mathrm{bp}$ fragment is obtained from the genomic DNA of rush deletion lines (Fig. 3-18 B). This shorter fragment represents the residual transposon that is left at the deletion site after the recombination has taken place. Primers that are complementary to the N-terminus and C-terminus of rush produce a 951 bp fragment in wild type flies (Fig. 3-18 C). No PCR product is formed in the rush deletion flies, showing that the whole coding region of rush is deleted. To prove that the obtained mutant lines represent a rush null allele, we performed Western blot with protein extracts from the flies of original transposon insertion lines and the rush mutant flies (Fig. 3-18 D). Blotting with the antibody against the C-terminus of Rush resulted in a band of approximately $40 \mathrm{kD}$ that corresponds to the full length Rush in the extracts from original transposon insertion stocks. In comparison, no signal for Rush was detected in the rush ${ }^{4}$ embryo extract, 
indicating that $r u s h^{4}$ is indeed a null allele.

A

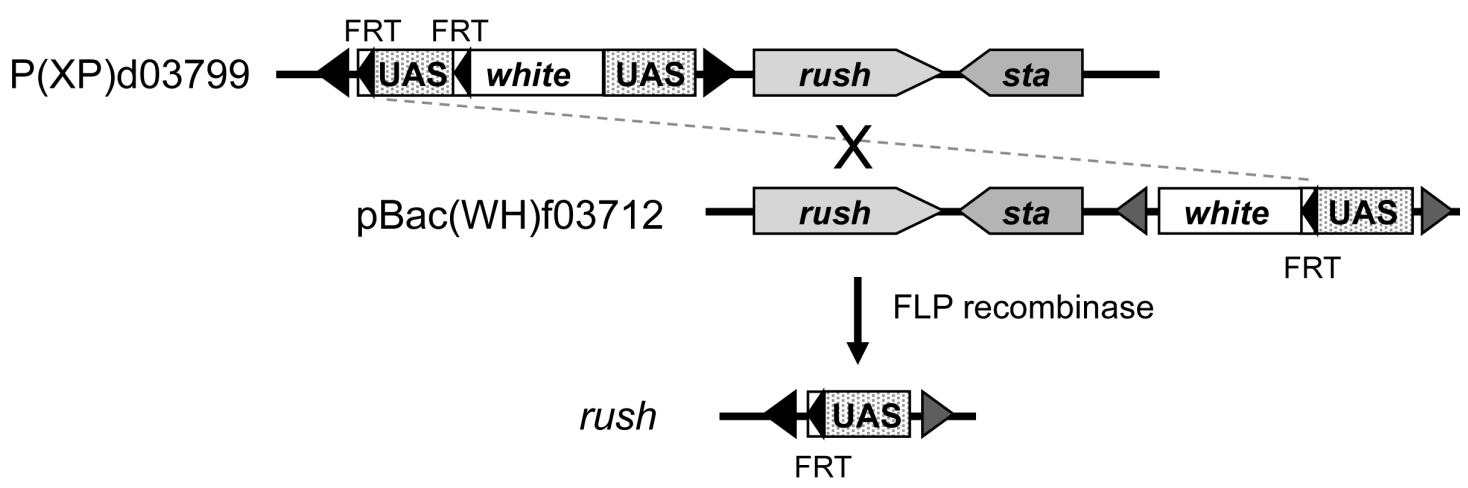

B

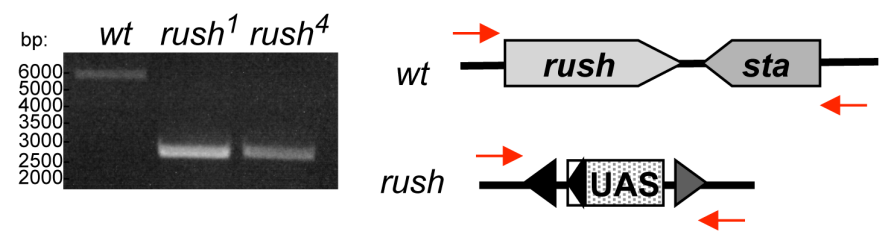

C
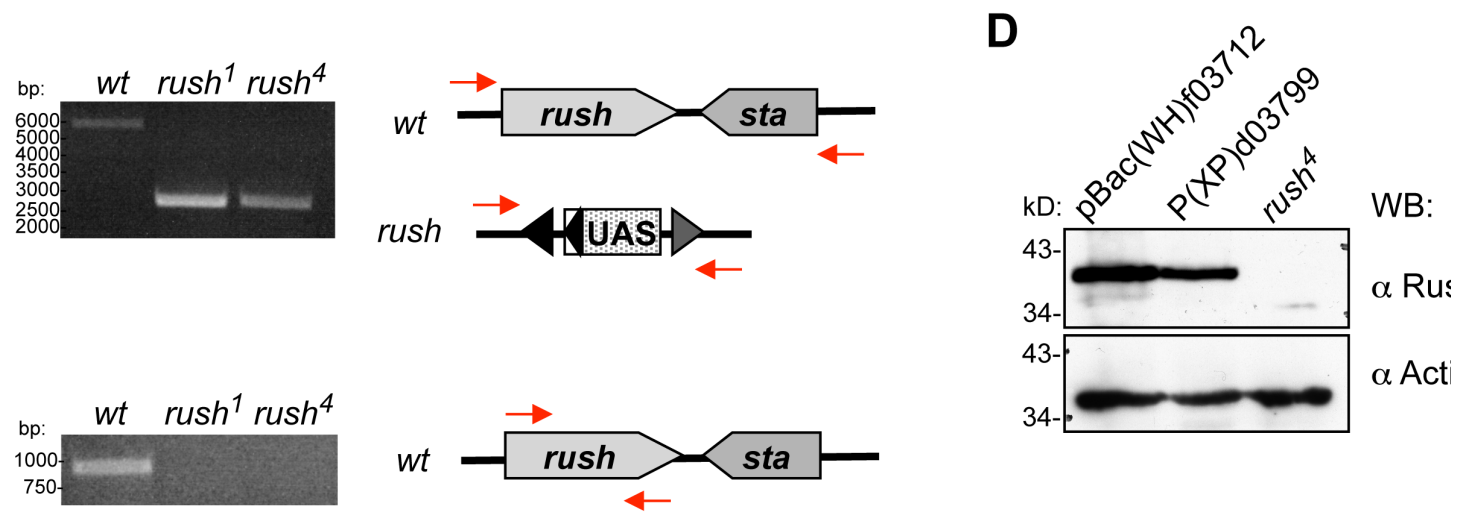

Figure 3-18. Generation of rush null allele. A - The scheme of generation of rush deletion via FLP/FRT recombination. Two transposons that contain FRT sites are inserted upstream and downstream of rush and its neighboring gene sta. Induction of FLP recombinase expression leads to recombination between FRT sites. The recombination in cis happens first, thus removing the UAS sequence of the P(XP)d03799 element and leaving one FRT site. The recombination in trans (shown with a dotted line) leads to removal of the genomic sequence between the two FRT sites. After the recombination a residual transposon is left at the deletion site. A rescue construct for sta was crossed in after the recombination. B, C - Verification of the deletion of the rush gene by PCR on adult fly genomic DNA. B - PCR with primers upstream and downstream of the whole deletion site. In case of the wild type stock, a DNA fragment of 5105 bp that includes rush and sta genes is obtained. In rush deletion lines a shorter DNA fragment of $2442 \mathrm{bp}$ forms that covers the residual transposon after the deletion. C - PCR with rush specific primers. In wild type flies a PCR product of 951 bp length, which covers the full coding sequence of rush, is obtained. No product could be obtained in the rush deletion lines. Results from two deletion lines are depicted. D - Protein extracts from the flies of original transposon stocks and a rush deletion line were blotted with an antibody against Rush C-terminus. No Rush protein was detected in the extract from rush ${ }^{4}$ flies. Antibody against actin was used as a loading control.

\subsection{Characterization of rush null allele}


Flies with rush deletion were homozygous viable and did not show obvious phenotypic defects. To test whether loss of Rush leads to defects in cell polarity I stained ovaries of rush $^{4}$ flies with antibodies against Baz and Rush. Localization of Baz at the cell-cell contacts in rush $^{4}$ mutant follicle epithelium was the same as in the wild type cells (Fig. 319). No signal for Rush could be detected in $r u s h^{4}$ follicle epithelium (Fig. 3-19 B). Optical sections in Fig. 3-19 were taken through the apical side of epithelial cells to detect Baz, while Rush localizes at the plasma membrane slightly below Baz and colocalizes with E-cadherin (Fig. 3-3). Therefore Rush staining in Fig. 3-19 A is detected mainly in cytoplasmic puncta.
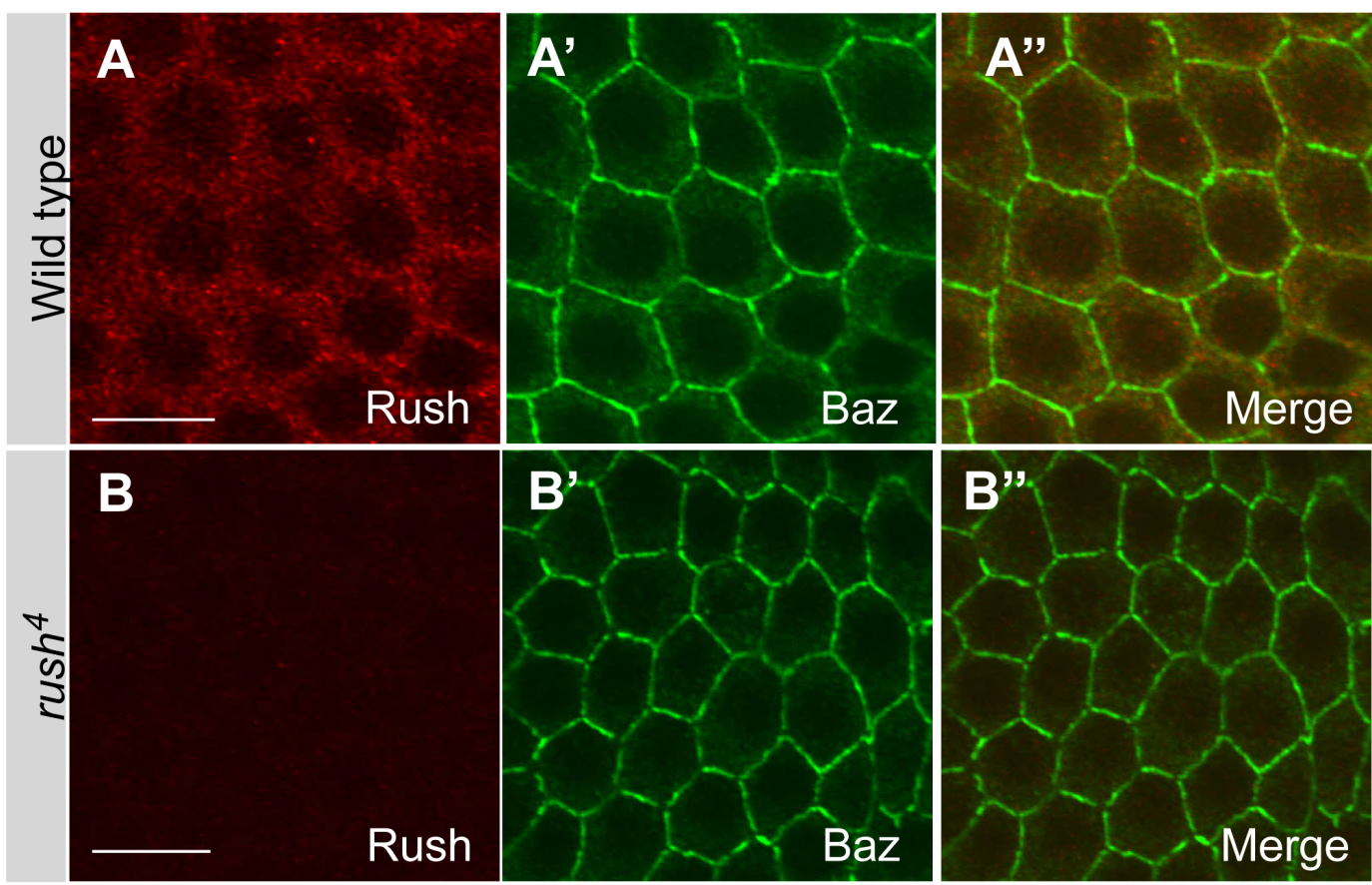

Figure 3-19. Loss of Rush does not affect localization of Baz. Wild type and rush $^{4}$ fly ovaries were stained with antibodies against Rush and Baz. Tangential sections of stage 10 follicle epithelia are shown. No Rush staining was detected in the mutant epithelia (B) in comparison to wild type ovaries (A). Baz is located at the cell-to-cell contacts in the wild type follicle epithelium (A). B - Localization of Baz in $\mathrm{rush}^{4}$ mutant follicle epithelium is the same as in the wild type. Scale bars $=10 \mu \mathrm{m}$.

In a low number of cases abnormally large rush $^{4}$ egg chambers were observed (Fig. 3-20 A, B). In contrast to wild type egg chambers that are comprised of 16 cells and have one oocyte (Fig. 3-20 C), these egg chambers are formed by 32 cells and often have two oocytes (Fig. 3-20 D). Increased number of nuclei in an egg chamber can be caused by two reasons. First, an increased number of germline stem cell divisions can lead to an abnormal cell number. Second, a fusion of two egg chambers might have taken place. The second 
possibility is supported by the double number of cells and the presence of two oocytes. Egg chambers are separated from each other by stalk cells. Formation of stalk cells is induced by differentiated follicle cells, so called polar cells. In wild type egg chambers, two pairs of polar cells are specified at the anterior and posterior end of the egg chamber (Fig. 3-20 H', white arrows). If differentiation of polar cells is impaired, stalks do not form. Lack of stalk cells can lead to fusion of two neighboring egg chambers. To test this possibility, I stained rush $^{4}$ ovaries with antibody against FasIII, a protein that is expressed in all follicle cells of newly formed egg chambers and specifically marks polar cells in later stages. In rush ${ }^{4}$ ovaries, some of the enlarged egg chambers have three clusters of polar cells (Fig. 3-20 E - H, white arrowheads). Therefore it is possible that the fusion of rush egg chambers is caused by defects in polar cell differentiation, which then leads to fusion of egg chambers. Polar and stalk cells differentiate from a common pool of progenitor cells, therefore defects in formation of polar cells often affect the number of stalk cells (Grammont and Irvine, 2001). To test whether stalk formation is affected in rush mutants, I counted the number of stalk cells in rush ${ }^{4}$ and wild type ovarioles. The average number if stalk cell was increased in rush ovarioles (Fig. 3-20 I). Thus the differentiation of both polar and stalk cells is affected in rush mutant ovaries.

As wild type Rush localized to endosomes and Rush overexpression increased late endosome size, I tested rush $^{4}$ mutant flies for changes in compartments of the endocytic pathway. For this purpose I stained $r u s h^{4}$ ovaries with antibodies against Rab7 and Rab11 for analysis of late and recycling endosomes respectively. Staining of the pBac(WH)f03712 insertion stock (marked as f03712 in Fig. 3-21) was used as a control. Rab7 staining in the follicle epithelium of rush $^{4}$ ovaries was often weaker than in the epithelium of the control ovaries (Fig. 3-21 A, B). To find out whether the observed difference in Rab7 signal was due to changes in endosome formation, I compared the size and number of Rab particles in the samples using ImageJ software. Interestingly, Rab7 vesicles were smaller in $r_{u s h}^{4}$ epithelia $(2,21 \mu \mathrm{m})$ than in control sample $(2,48 \mu \mathrm{m})$. This size difference was highly statistically significant ( $<<0,0001$; Fig. 3-21 C). In comparison, the size of Rab11 marked recycling endosomes in both samples did not differ to a statistically significant level (Fig. 3-21 C). The number of the Rab7 and Rab11 endosomes did not significantly differ between the two samples (Fig. 3-21 D, E). Thus loss of rush decreases the size of late, but not recycling, endosomes. 

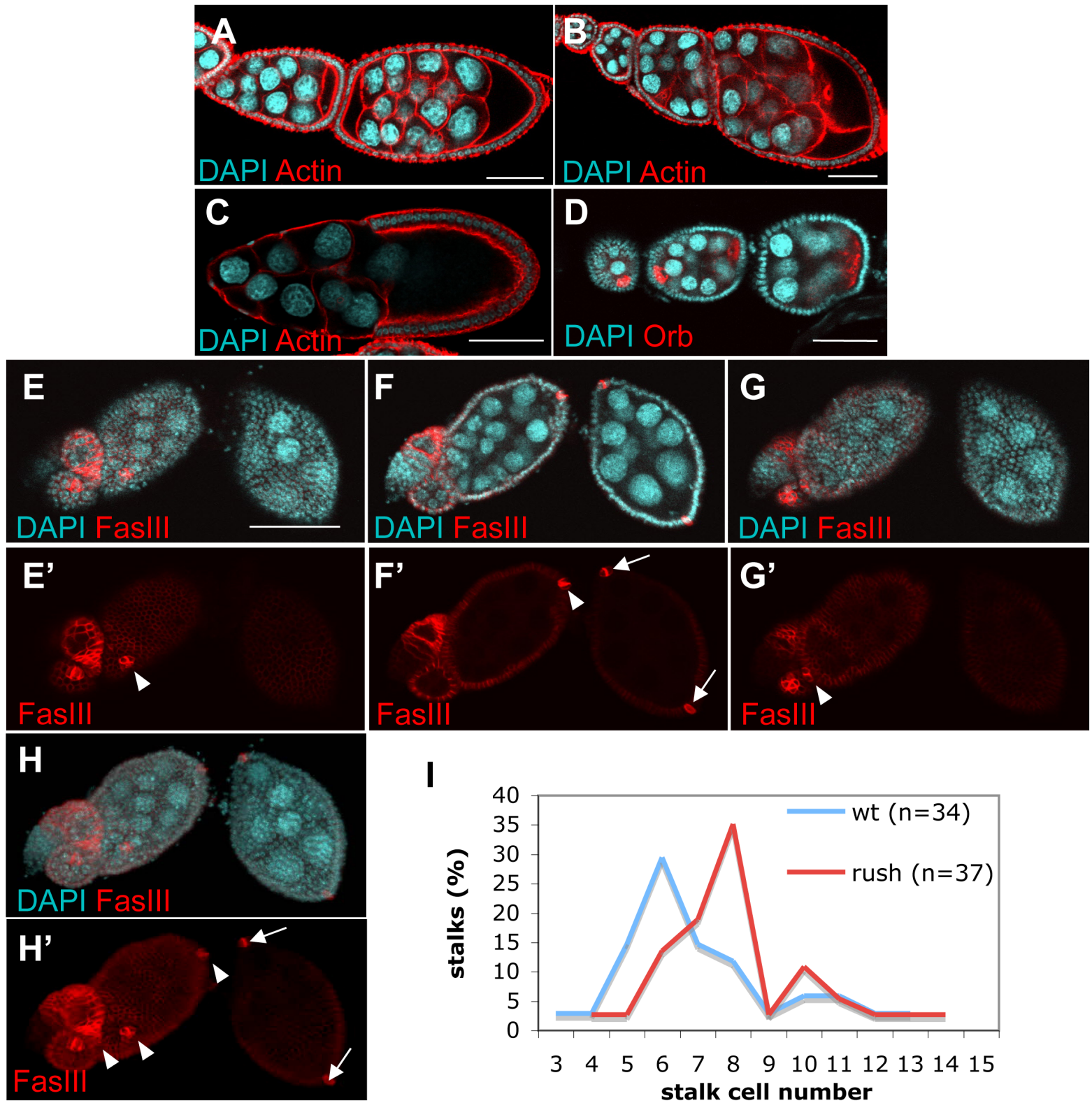

Figure 3-20. Egg chambers of $r u s h^{4}$ flies display defects in oogenesis. The ovaries of $r u s h^{4}$ flies were stained with phalloidin to mark actin cytoskeleton and DAPI. In some cases fused egg chambers comprised of 32 cells were observed (A, B). A normal wild type egg chamber contains 16 cells $(\mathbf{C})$. D - Fused egg chambers contain two oocytes, marked by Orb staining (in the middle). In comparison, only one Orb-positive oocyte is found in normal egg chambers. E, F, G, H $-r u s h^{4}$ ovaries were stained with the antibody against polar cell marker FasIII. Panels E-G represent z sections through the enlarged egg chamber. H - projection of z-stacks taken through the egg chambers. H' - Wild type egg chambers have two pairs of polar cells that are positioned at the anterior and posterior end of the egg chamber (marked with white arrows). In the fused egg chamber three clusters of polar cells are marked by FasIII (white arrowheads). Anterior is to the left. Scale bars $=50 \mu \mathrm{m}$. I - The average stalk length is increased in $\mathrm{rush}^{4}$ ovarioles in comparison to the wild type. 

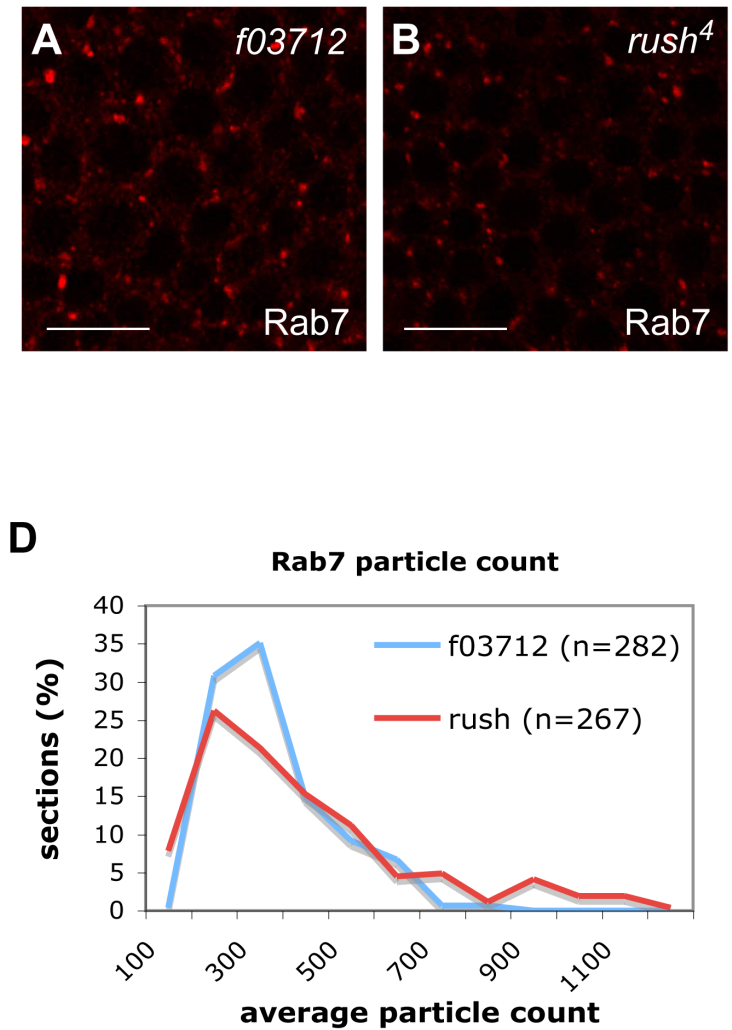

C

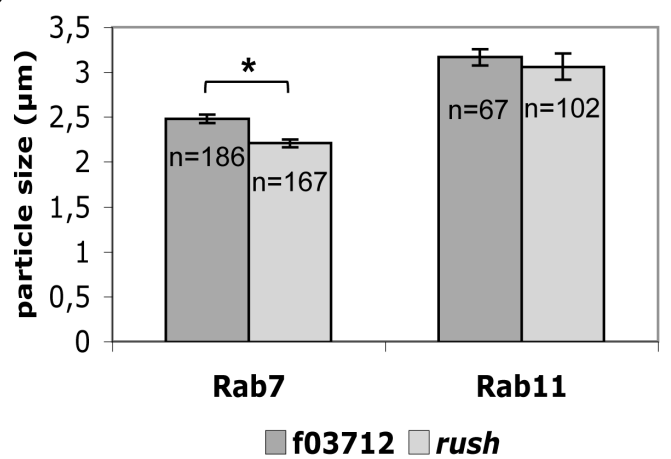

E

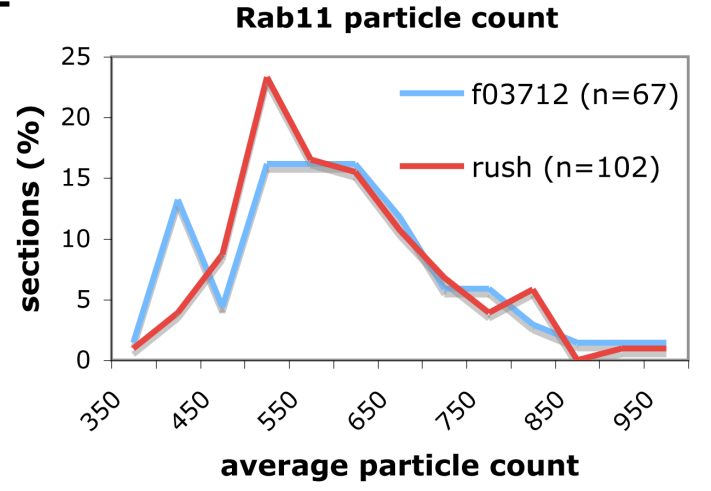

Figure 3-21. The effect of rush deletion on endosomal compartments. A, B - The ovaries of rush $^{4}$ and original transposon insertion stock (f03712) flies were stained against Rab7. Middle sections of the follicle epithelium of stage 8 egg chambers are shown. Scale bars $=10 \mu \mathrm{m}$. $\mathbf{C}-$ Rab7 and Rab11 particle size was measured from z-stacks taken through the follicle epithelium of individual stage 8 egg chambers (mean $\pm \mathrm{SE}$ [error bars]). Average size of Rab7 particles was significantly smaller in rush ${ }^{4}$ epithelium than in the wild type ( $<0,0001)$. The difference between Rab11 particle size in $r u s h^{4}$ and wild type cells was not statistically significant. The number of Rab7 (D) and Rab11 (E) particles was measured in the same z-sections of rush ${ }^{4}$ and $\mathrm{pBac}(\mathrm{WH}) \mathrm{f0} 3712$ follicle epithelia as in $\mathbf{C}$.

To check whether the loss of rush affects formation of early endosomes, I stained wild type and rush mutant ovaries with anti-Rab5 antibody. Unfortunately the staining did not give a strong signal that would allow a comparison of early endosome size between the samples. To overcome this problem, I expressed YFP-Rab5CA transgene in the follicle epithelium with the Cu2-Gal4 driver. No significant difference in formation of Rab5CAinduced large early endosomes in the rush ${ }^{4}$ or wild type cells was observed (Fig. 3-22). 


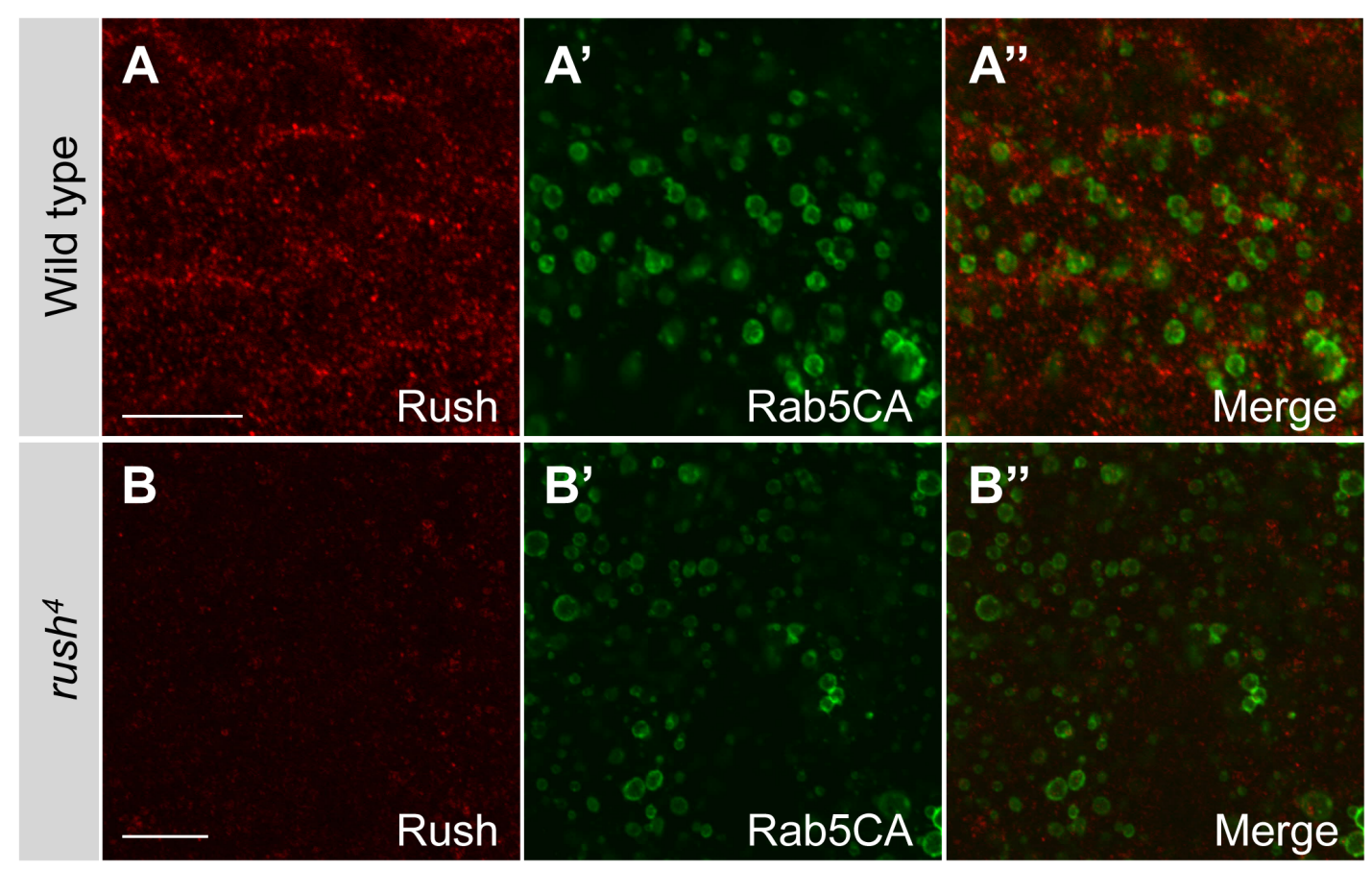

Figure 3-22. Formation of early endosomes is not affected in rush mutant cells. UAS-YFP-Rab5CA was expressed under the control of Cu2-Gal4 driver in the ovaries of wild type (A) and rush mutant (B) flies. Tangential sections of the follicle epithelium of stage 10 egg chambers are shown. Scale bars $=10 \mu \mathrm{m}$.

\section{6. rush genetically interacts with $c d c 42$}

Although loss or overexpression of Rush did not cause defects in cell polarity, I tested whether Rush-induced enlarged endosomes participate in trafficking of polarity proteins. $\mathrm{Crb}$ is localized apically in epithelial cells and determines apical character of the plasma membrane (Wodarz et al., 1995). Regulation of Crb endocytosis by several factors, including Cdc42, has been described recently (Georgiou et al., 2008; Harris and Tepass, 2008; Leibfried et al., 2008). I investigated Crb endocytosis in Rush-GFP-overexpressing epithelial cells. As I was not able to obtain good Crb staining in the follicle epithelium, I overexpressed UAS-Rush-GFP in the embryonic ectoderm under control of the $t u b$-Gal4 driver $(t u b>$ Rush-GFP). In the embryonic ectoderm, similarly as in the follicle epithelium, overexpression of Rush-GFP leads to formation of large Rush-GFP vesicles (Fig. 3-23 A'). Crb colocalizes with Rush-GFP in these vesicles (Fig. 3-23 A). As Rush-GFP overexpression caused an increase in the endosome size, I wondered if it also increases the endocytic uptake of Crb. In comparison to $t u b>$ Rush-GFP embryos, cytoplasmic puncta of $\mathrm{Crb}$ were smaller in wild type embryos (Fig. 3-23 B). I quantified the size of Crb cytoplasmic puncta in wild type and tub>Rush-GFP embryonic ectoderm (Fig. 3-23 C). The quantification revealed that the average size of $\mathrm{Crb}$-containing vesicles is increased 
approximately two-fold in $t u b>$ Rush-GFP embryos $(0,60 \mu \mathrm{m})$ in comparison to the wild type $(0,37 \mu \mathrm{m})$. Although the endocytosis of Crb seems to be increased in $t u b>$ Rush-GFP embryos, I did not observe loss of Crb from the apical plasma membrane (Fig. 3-23 A, B). It might be explained by the activity of recycling endosomes that ensure the delivery of Crb back to the plasma membrane.

Expression of dominant negative $\mathrm{Cdc} 42(\mathrm{Cdc} 42 \mathrm{DN})$ in the embryos has been described to result in accumulation of Crb in large Hrs-positive endosomes (Harris and Tepass, 2008). This phenotype is similar to the Rush-GFP overexpression phenotype, therefore it was interesting to determine whether Rush interacts with Cdc42 in Crb endocytosis. First, to verify the effect of Cdc42DN on Crb localization, I expressed UAS-Cdc42DN in the embryos under the control of arm-Gal4 ( $\mathrm{arm}>\mathrm{Cdc} 42 \mathrm{DN})$. In the ectoderm of wild type embryos Crb and E-cadherin are localized to the cell-cell contacts (Fig. 3-24 A). In the embryonic ectoderm of arm $>$ Cdc42DN embryos, Crb was lost from the plasma membrane and localized to cytoplasmic punctate structures (Fig. 3-24 B'). The localization of Ecadherin was less affected, although loss of E-cadherin at the plasma membrane in the ventral ectoderm was observed (Fig. 3-24 B''). These observations are in line with the effects of $\mathrm{Cdc} 42 \mathrm{DN}$ on the $\mathrm{Crb}$ and E-cadherin localization, described by Harris and Tepass (2008). 

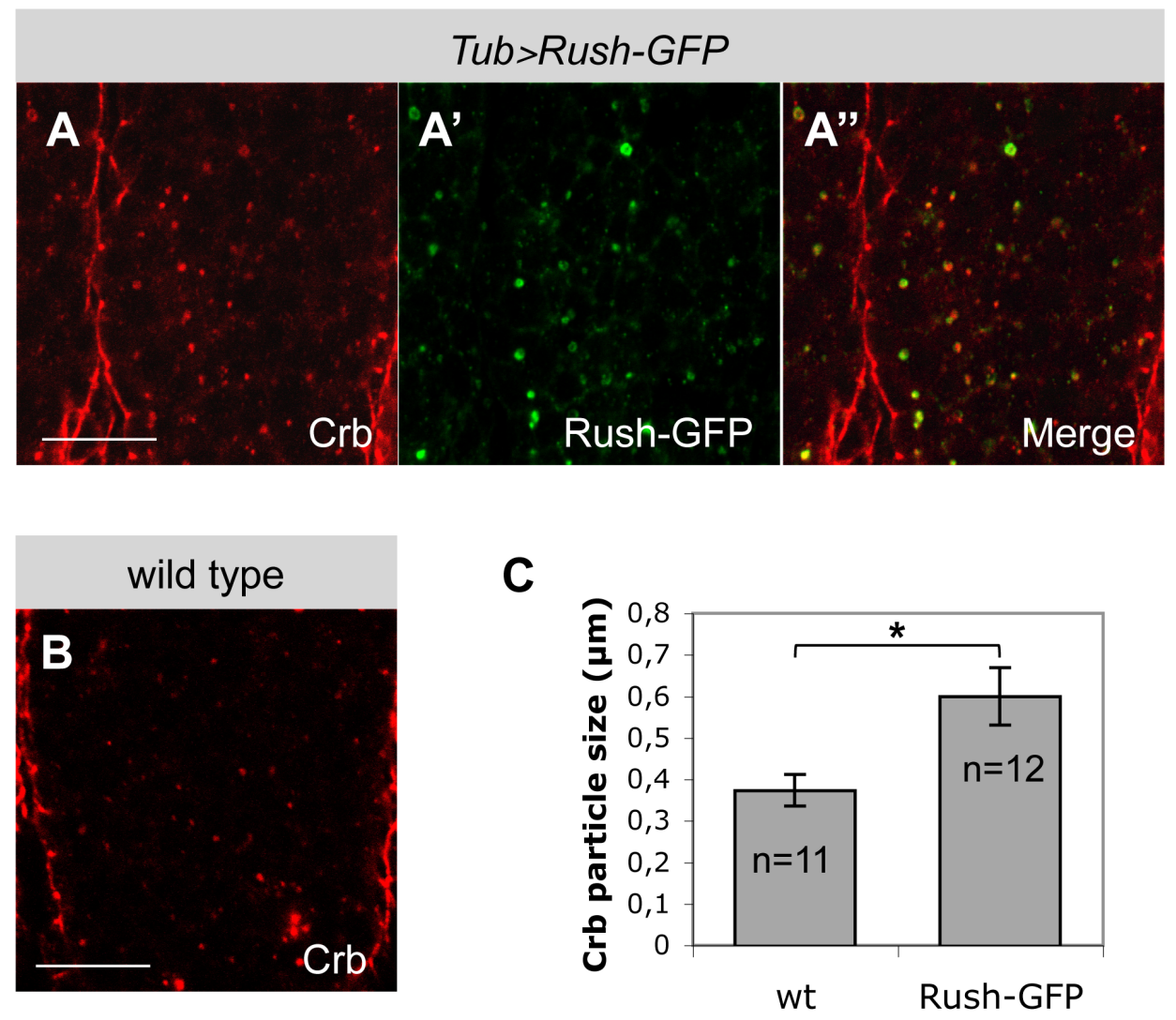

Figure 3-23. Overexpression of Rush-GFP in embryonic ectoderm leads to an increase in Crb endocytosis. Wild type and $t u b>$ Rush-GFP embryos were stained with an anti-Crb antibody. A, B Tangential sections of the ectoderm of stage 12 embryos. A - Large Rush-GFP vesicles colocalize with Crb in $t u b>$ Rush-GFP ectodermal cells. B - Cytoplasmic Crb puncta are smaller in the wild type ectoderm. Scale bars $=10 \mu \mathrm{m}$. $\mathbf{C}-$ The size of Crb vesicles is significantly increased upon Rush-GFP overexpression (mean \pm SEM [error bars]), $\mathrm{p}<0,05$.

Expression of $a r m>C d c 42 D N$ was lethal. In the early stages of development $a r m>\mathrm{Cdc} 42 \mathrm{DN}$ embryos do not have obvious morphological defects (data not shown). In later stages of embryonic development morphological defects of embryos become apparent (Fig. 3-24 D). Epithelial sheets of the embryos bulge out, most probably due to loss of cell polarity caused by mislocalization of polarity complexes. Interestingly, head structures were most heavily affected (Fig. 3-24 D).

Figure 3-24. Cdc42DN causes mislocalization of Crb and E-cadherin. A - In wild type embryonic ectoderm Crb and E-cadherin localize to cell-cell contacts. B - In arm $>$ Cdc42DN embryos Crb is lost from the plasma membrane and localizes in dots in the cytoplasmic puncta (B'). E-cadherin is lost from the plasma membrane in the ventral ectoderm (B'). Ectoderrm of stage 11 embryos is shown. C - wild type stage 15 embryo. D - arm $>$ Cdc42DN stage 15 embryo. Head structures are deformed and epithelial bulges can be observed. Anterior is to the left, dorsal is to the top. Scale bars A, B $=20 \mu \mathrm{m}, \mathrm{C}, \mathrm{D}=100 \mu \mathrm{m}$. 


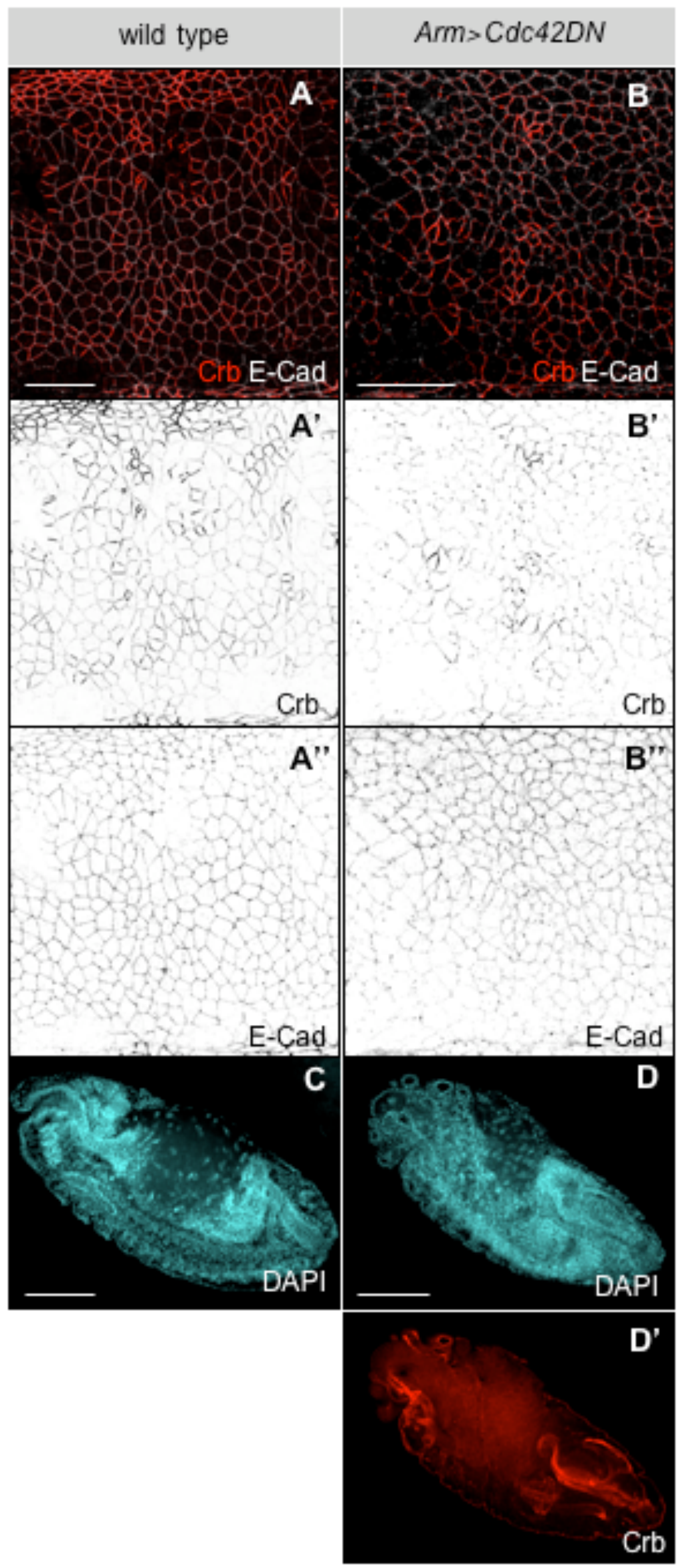


To test whether Cdc42DN affects formation of late endosomes in other tissues, I expressed Cdc42DN in the follicle epithelium under control of $\mathrm{Cu2-Gal4.} \mathrm{In} \mathrm{early} \mathrm{egg} \mathrm{chambers}$ expression of $\mathrm{Cu2-Gal4}$ takes place in patches, offering a possibility to compare neighboring cells that differ in the expression of the transgene. Follicle epithelial cells that express Cdc42DN had elevated levels of Rab7 in comparison to their neighbors that had not yet started to express the transgene (Fig. 3-25 A). In stage 8, when the expression of the transgene takes place in the whole follicle epithelium, follicle cells that express Cdc42DN have increased Rab7 staining in comparison to the cells of wild type chambers (Fig. 3-25 B).

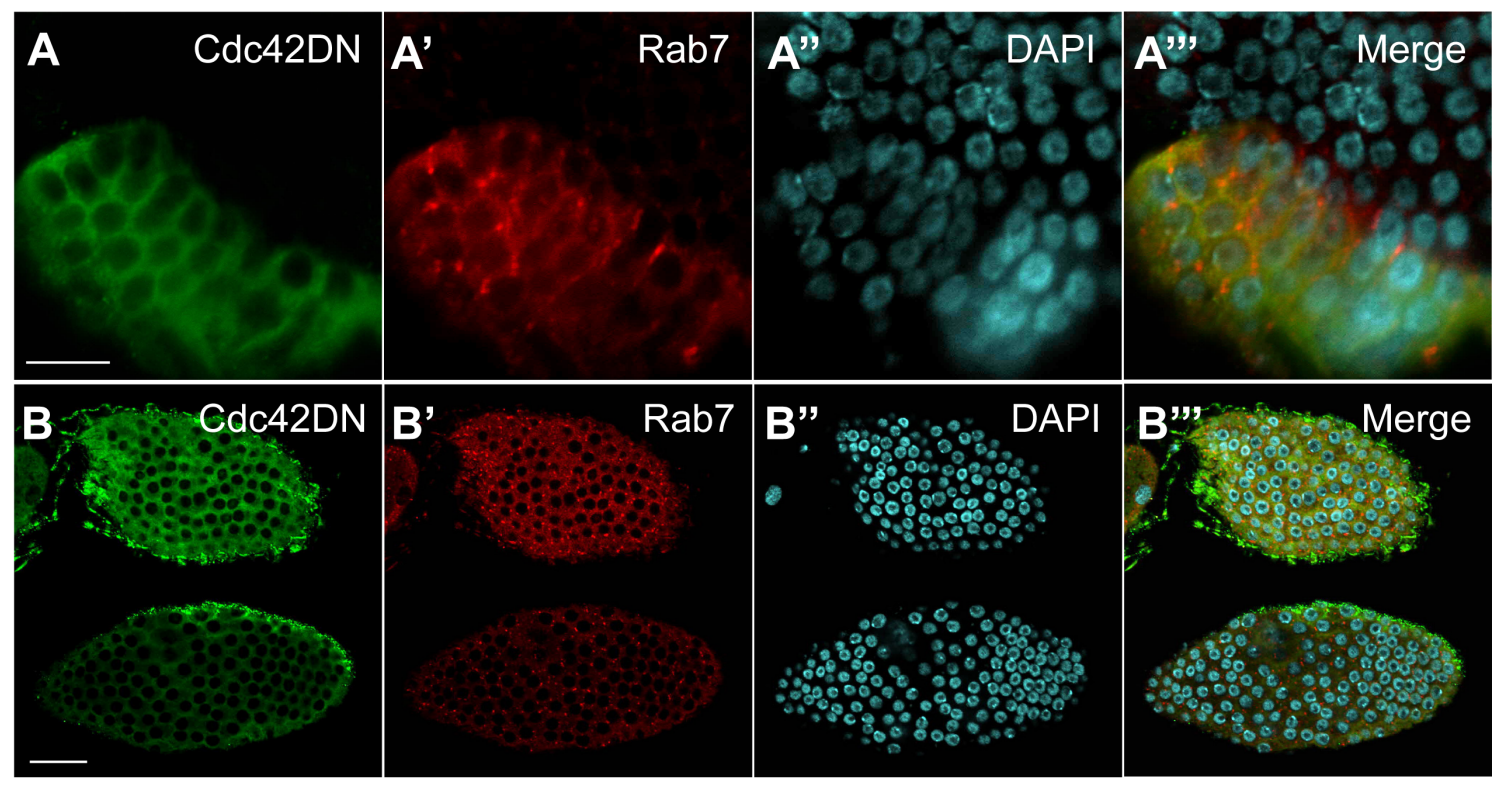

Figure 3-25. Cdc42DN causes formation of enlarged Rab7 endosomes. Expression of Cdc42DN in the follicle epithelium under the control of $\mathrm{Cu2-Ga14}$. A - The follicle epithelium of stage 7 egg chamber. B Stage 8 egg chambers. Scale bar $A=10 \mu \mathrm{m}$., $B=20 \mu \mathrm{m}$.

As overexpression of Rush and disruption of Cdc42 function lead to a similar phenotype regarding late endosome formation and Crb endocytosis, I wondered whether loss of Rush could reverse the effect of Cdc42DN expression. For this purpose I analyzed rush ${ }^{4}$; arm $>\mathrm{Cdc} 42 \mathrm{DN}$ embryos. Loss of rush decreased the frequency of late embryonic defects (Fig. 3-26 A) and the lethality of Cdc42DN-expressing embryos (Fig. 3-26 B). Adult $r \mathrm{sh}^{4}$; arm $>\mathrm{Cdc} 42 \mathrm{DN}$ flies exhibited several defects, including clefts in abdominal segments (Fig. 3-26 D), incomplete rotation of male genitalia (Fig. 3-26 G) and ectopic wing crossveins (Fig. 3-26 J). Formation of extra wing crossveins in result of disruption of 
Cdc42 function has been described previously (Baron et al., 2000; Genova et al., 2000). Interestingly, UAS-Rush-GFP overexpression with an ubiquitous $d a-G a 14$ driver leads to similar abdominal defects in adult flies (Fig. 3-26 E, H).

A

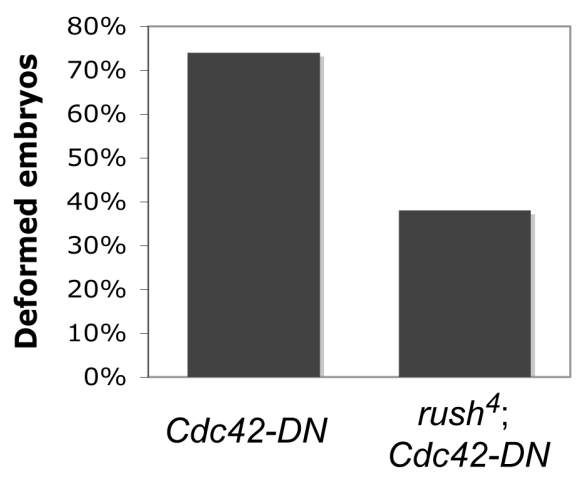

B

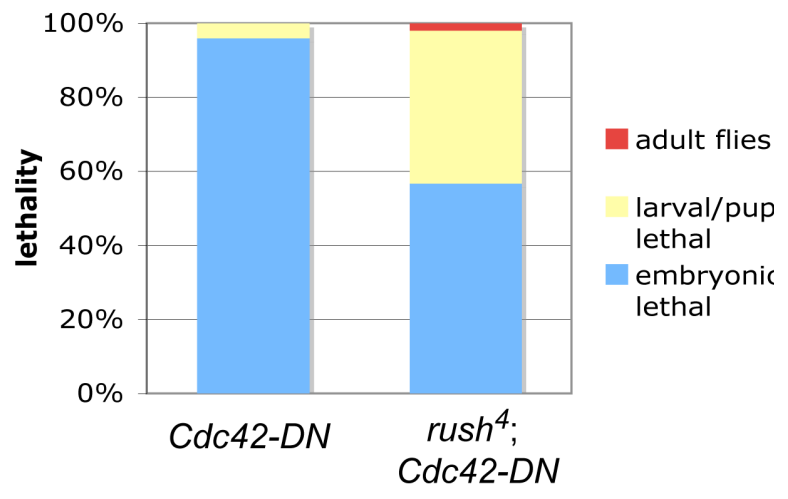

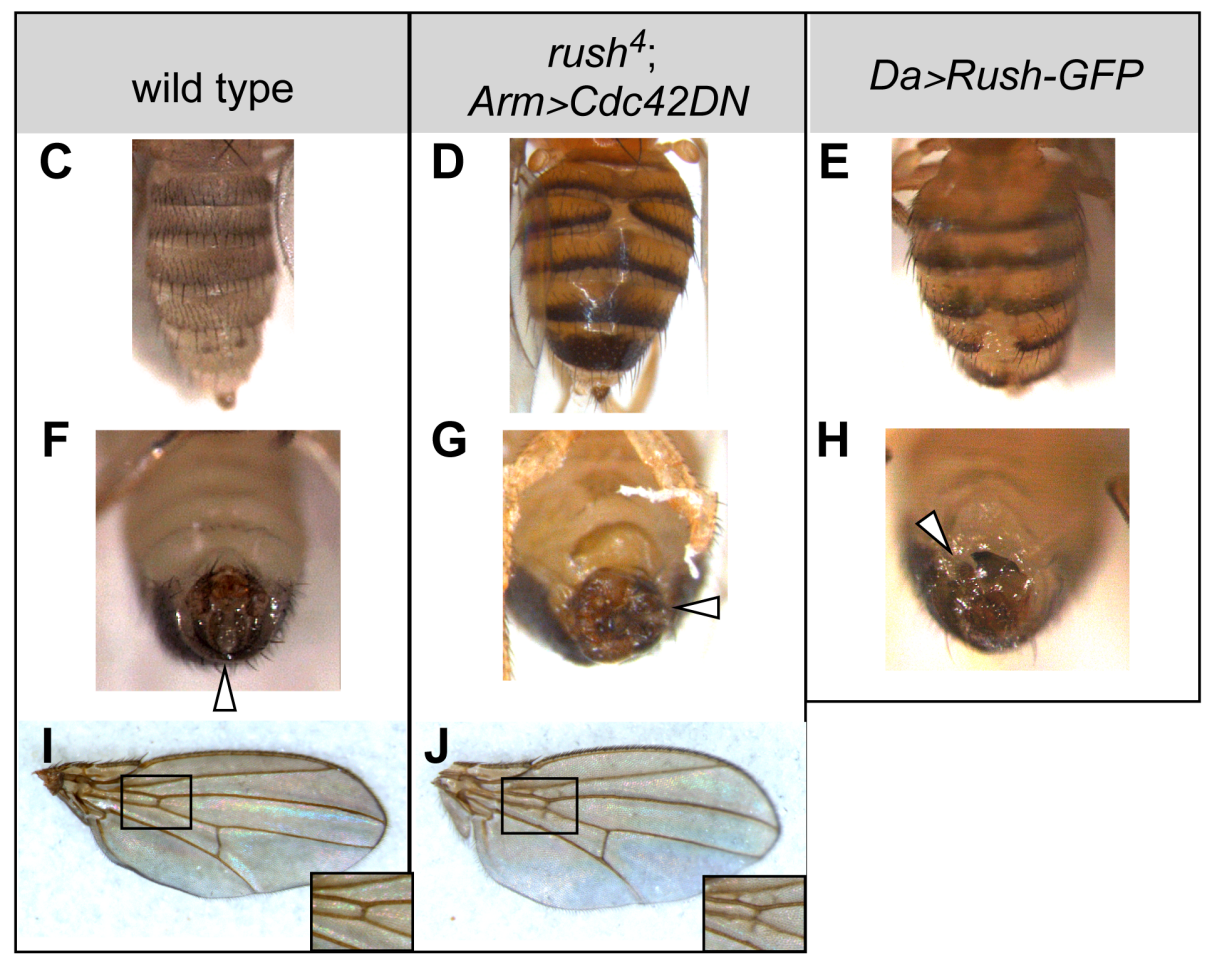

Figure 3-26. Loss of rush rescues arm $>$ Cdc42DN phenotype. A - Loss of rush reduces number of deformed $a r m>$ Cdc42DN embryos. B - Loss of rush decreases arm $>$ Cdc $42 \mathrm{DN}$ induced lethality. Survival of 200 embryos of each genotype is depicted. Phenotypes of $r u s h^{4}$; $a r m>C d c 42 D N$ adult flies resemble RushGFP overexpression phenotype. Similar phenotypes include cuticle clefts in abdominal segments (D, E) and defects in rotation of terminal segments of male genitalia $(\mathbf{G}, \mathbf{H})$. Wild type male genitals rotate during pupal stage to become aligned along the dorsal-ventral axis, indicated by the white arrowhead (F). rush ${ }^{4}$; arm $>\mathrm{Cdc} 42 \mathrm{DN}$ and $d a>$ Rush-GFP males in some cases do not undergo complete genital rotation. Wings of arm $>$ Cdc42DN flies $(\mathbf{J})$ often have additional crossveins, as shown in the inset $(\mathbf{J})$ in comparison to wild type wings (I). 
Taken together, Rush and Cdc42 have opposing effects on Crb endocytosis. Increase of Rush expression led to accumulation of $\mathrm{Crb}$ in endocytic vesicles. A similar effect is exhibited upon overexpression of Cdc42DN. Loss of rush was able rescue the Cdc42DN overexpression phenotype, suggesting that Rush acts downstream of Cdc42 in regulation of Crb endocytosis. Overexpression of Rush-GFP in the arm $>\mathrm{Cdc} 42 \mathrm{DN}$ background did not lead to increased defects in embryonic development (data not shown), suggesting that both proteins act in the same pathway.

\subsection{Rush interacts with Rab GDI and Drosophila homolog of GDF}

Multiple effects of Rush on the endocytic pathway were observed, therefore posing the question about the molecular mechanism behind the effect of Rush on late endosome formation, morphology of early endosomes and Cdc42 activity. Genome-wide yeast twohybrid screens with mammalian and yeast proteins have identified possible interaction partners of Rush homologs in these organisms. Among the putative interaction partners is GDF, a protein that is involved in vesicular trafficking (Ito et al., 2001; Rual et al., 2005). GDF promotes the release of inactive Rabs from GDI and their integration in the membrane, where Rabs can be activated again (Sivars et al., 2003). The interaction between GDF and GDI factors has been described in mammalian cells (Hutt et al., 2000). In Drosophila, only one homolog of GDF factors exist, namely CG1418. To test whether Rush interacts with CG1418, I performed pulldown experiments with purified recombinant proteins. Drosophila Rab GDI was used as a positive control. GST-Rush bound to both MBP-CG1418 and MBP-GDI, but not MBP alone (Fig. 3-27 A). As a direct interaction between Rush and GDI has not been described, I repeated the experiment by pulling down GST-GDI with MBP-Rush and MBP-CG1418. GST-GDI could be precipitated with both proteins, while interaction with MBP-Rush was stronger than with MBP-CG1418 (Fig. 3$27 \mathrm{~B})$. Therefore pulldown experiments with purified proteins indicate that an interaction between Rush and CG1418 can take place. The pulldown shows that Drosophila GDI and GDF can interact with each other, as described in mammalian cells (Hutt et al., 2001). Interestingly, Rush also directly interacted with GDI, suggesting that Rush might participate in regulation of the Rab activation cycle. 
A

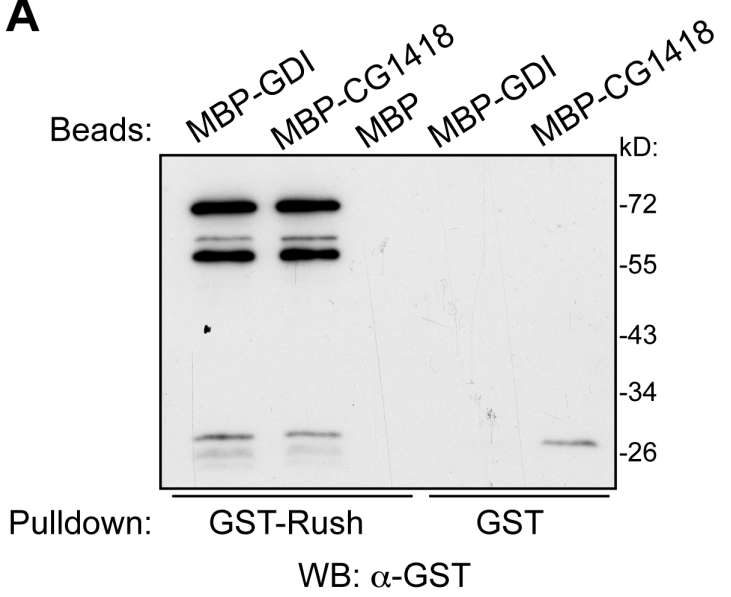

C

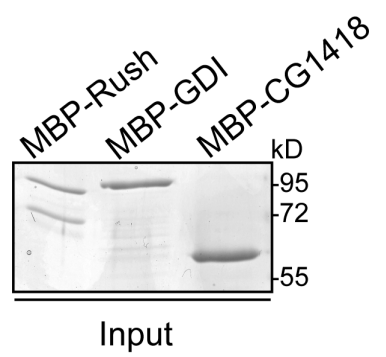

B

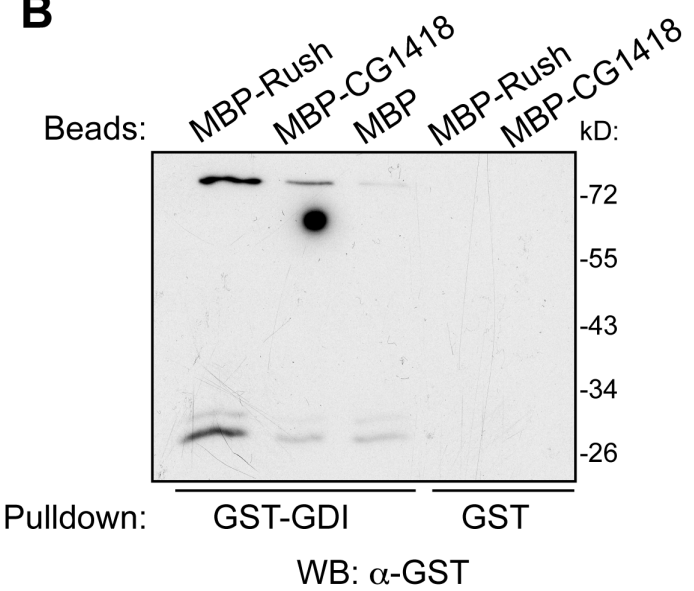

D

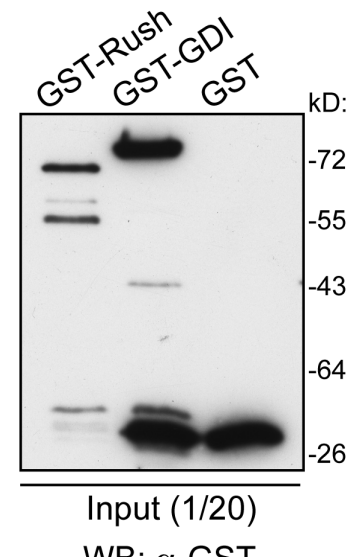

WB: $\alpha-G S T$

Figure 3-27. Rush directly interacts with CG1418 and GDI. MBP-fusion proteins were bound to amylose beads and incubated with GST-tagged proteins or GST alone. Proteins that were precipitated together with beads were analyzed with a Western blot. A - GST-Rush precipitates with MBP-GDI and MBP-CG1418, but not MBP alone, as shown by blotting with anti-GST antibody. GST alone was used as a negative control. B GST-GDI precipitates with MBP-Rush and MBP-CG1418, but not MBP alone. GST alone was used as a negative control. Blotting was done with anti-GST antibody. C - Input for MBP-fusion proteins, used for pulldowns, shown by Coomassie staining. D - Input for GST-fusion proteins.

Since pulldown experiments indicated that Rush can interact with CG1418 and GDI, I expressed all three proteins in Drosophila S2 cells to observe their localization. Endogenous Rush localizes to the cytoplasm and plasma membrane of S2 cells (Fig. 3-28 A). HA-CG1418 is localized to large intracellular compartments, while GFP-GDI is cytosolic. There is no significant colocalization between HA-CG1418 and endogenous Rush, while GFP-GDI partially colocalizes with Rush (Fig. 3-28 A). Upon overexpression of Rush-HA, the protein accumulates asymmetrically at the plasma membrane (Fig. 3-28 B, C). Interestingly, GFP-GDI becomes relocalized to the accumulations of Rush, 
suggesting that Rush and GDI can interact with each other in S2 cells (Fig. 3-28 B, C). HA-Rush does not colocalize with GFP-CG1418 and does not cause relocalization of GFPCG1418 (Fig. 3-28 D).

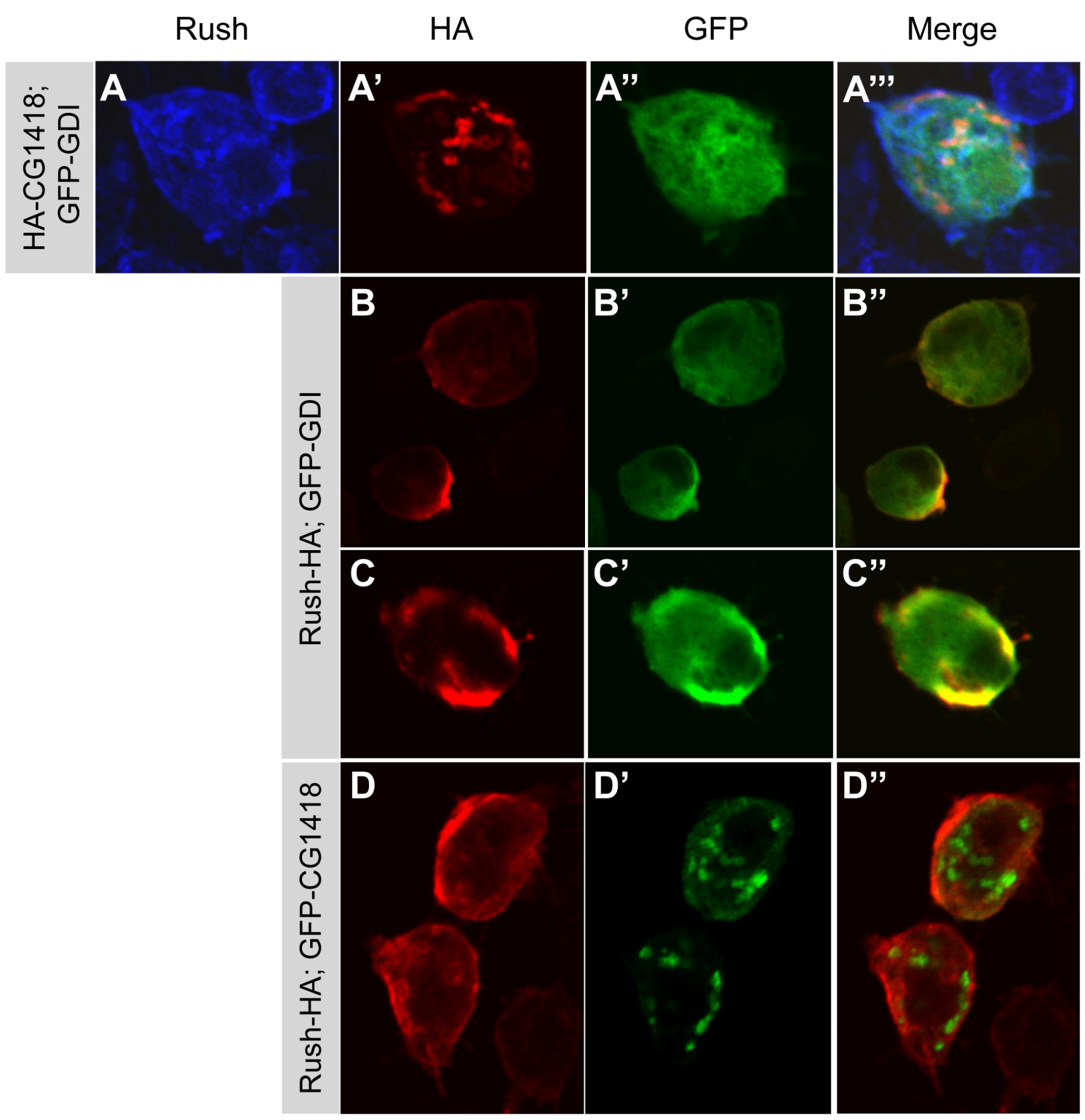

Figure 3-28. Localization of GDI and CG1418 in S2 cells. HA- or GFP-tagged Rush, GDI and CG1418 were expressed in S2 cells and their localization was observed. A - HA-CG1418 localizes in large intracellular organelles, while GFP-GDI is cytoplasmic. Endogenous Rush localizes in the cytoplasm and at the plasma membrane. Endogenous Rush partially colocalizes with GFP-GDI. B, C - When overexpressed, Rush-HA accumulates at the plasma membrane. GFP-GDI is recruited to the sites of Rush-HA accumulation. D - GFP-CG1418 does not colocalize with Rush-HA. 


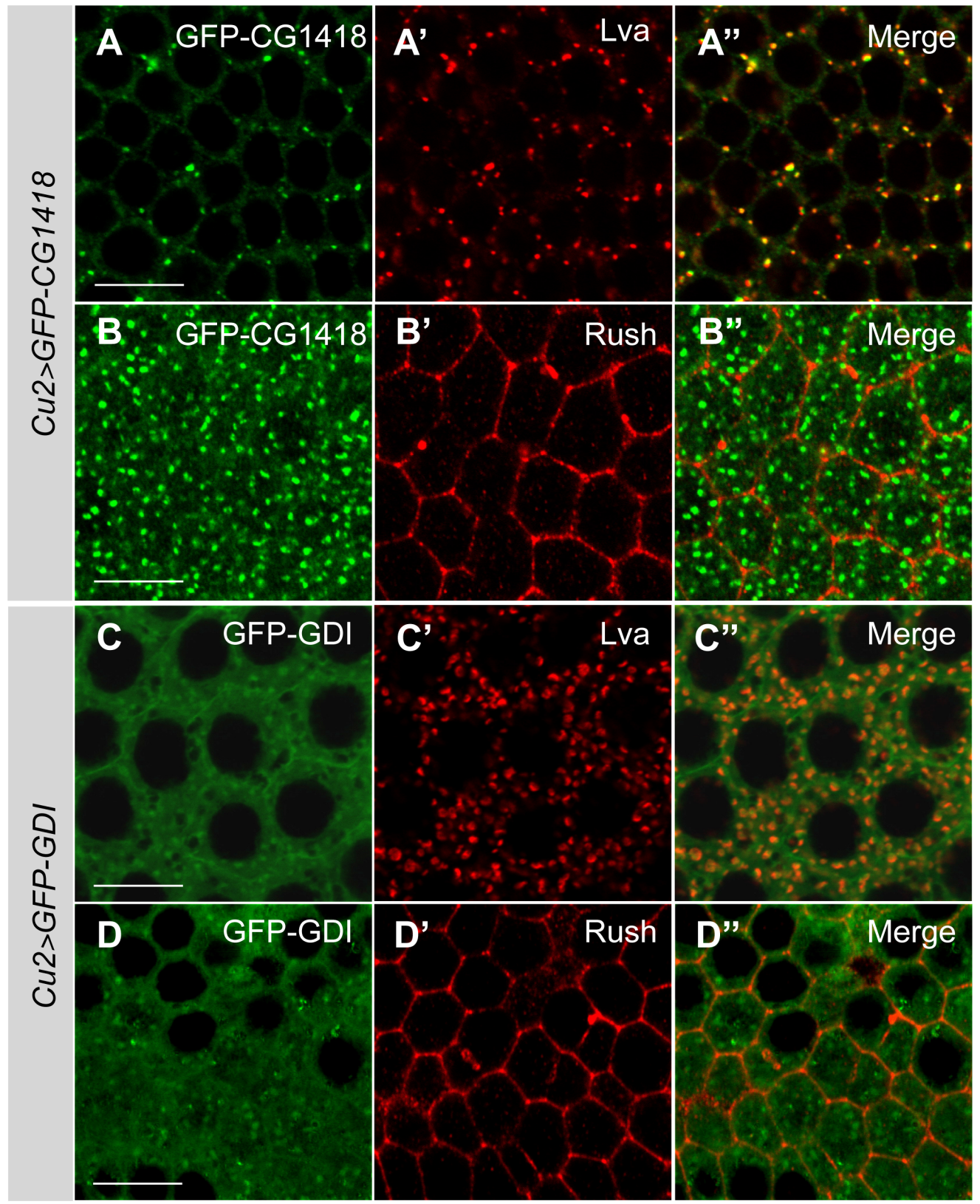

Figure 3-29. Localization of GFP-GDI and GFP-CG1418 in the follicle epithelium. A - GFP-CG1418 colocalizes with Golgi marker Lva. B - GFP-CG1418 does not colocalize with Rush. C - GFP-GDI localizes to the cytoplasm. Slightly increased GDI staining was observed at the plasma membrane and in Lva-positive compartments. D - Localization of Rush in Cu2>GFP-GDI follicle epithelium. All panels represent tangential sections of stage 10 egg chamber follicle epithelium. Scale bars $=10 \mu \mathrm{m}$.

For further analysis of Rush interaction with GDI and CG1418 I generated transgenic flies that carry UAS-GFP-GDI and UAS-GFP-CG1418. I expressed the transgenes under control of $\mathrm{Cu2-Ga14}$ in follicle epithelia to observe their localization. GFP-CG1418 localized to large cytoplasmic puncta, which colocalized with Golgi marker Lava Lamp (Lva) (Fig. 3-29 A). Mammalian GDF PRA1 also localizes to Golgi complex in addition to its localization at endosomes (Abdul-Ghani et al., 2001; Hutt et al., 2000). Rush did not 
colocalize with GFP-CG1418 in follicle epithelium (Fig. 3-29 B), therefore, although biochemically possible, the interaction between Rush and CG1418 most probably does not take place in cells. GFP-GDI, similarly as in S2 cells, was localized to the cytosol (Fig. 329 C, D). More intensive GFP-GDI signal was observed at the plasma membrane and in cytoplasmic accumulations, which co-stained with anti-Lva antibody (Fig. 3-29 C).

A fraction of mammalian GDI is associated with membranes (Ullrich et al., 1993). To test whether Drosophila GDI associates with endosomes, I performed sucrose gradient fractionation of embryo lysates. GDI was detected in the early endosome fraction together with Rab5 and Rab7 (Fig. 3-30). Rush also cofractionates with Rab5 and Rab7 (Fig. 3-6). Thus GDI localizes to similar membrane compartments as Rush and an interaction between the two proteins could take place on endosomal membranes.

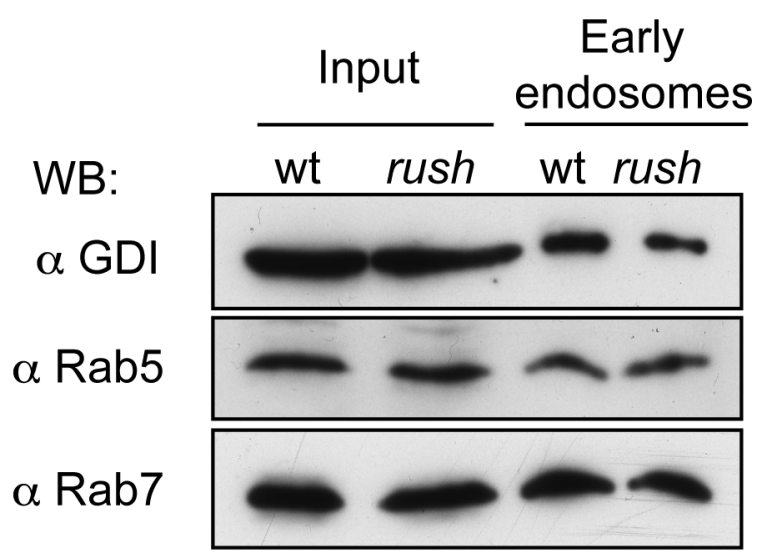

Figure 3-30. GDI associates with endosomes. Wild type and rush embryo extracts were fractionated on a sucrose gradient. GDI is found in the early endosome fraction together with Rab5 and Rab7 in wild type and $r u s h^{4}$ embryo lysates.

Thus, Rush is able to directly interact with GDI and CG1418, the Drosophila homolog of GDF. Rush colocalized with GDI in S2 cells and could relocalize GDI upon overexpression. GDI localizes to a similar endosome fraction as Rush and could interact with Rush on endosomal membranes. 


\section{Discussion}

Over the years endocytosis has been found to participate in a wide range of cellular functions, including regulation of cell polarity. Interestingly, the polarity proteins themselves can influence endocytosis (Balklava et al., 2007; Harris and Tepass, 2008). The regulation of endocytosis in regard to uptake of polarity proteins is still largely unknown. In this work I describe a novel endosome associated protein Rush hour (Rush). Rush influences formation of late endosomes and affects endocytosis of the apical protein Crb. rush genetically interacts with $C d c 42$, implicating a role of Rush in Cdc42-regulated endocytosis. Rush directly interacts with Rab GDI in biochemical assays and might thus affect the Rab activation cycle.

\subsection{Localization of Rush}

\subsubsection{Subcellular localization of Rush}

Rush exhibited a dual localization in epithelial cells and is found both at the lateral plasma membrane and on endosomes. Localization of Rush to endosomes was confirmed by both immunofluorescence and cell fractionation experiments. Immunofluorescence experiments revealed colocalization of Rush with Hrs and Rab7. Rab7 is a marker of late endosomes (Chavrier et al., 1990), while Hrs localizes to the early endosomes via its FYVE domain (Raiborg et al., 2001) and facilitates the transition between early and late endosomes (Lloyd et al., 2002; Sun et al., 2003). Interestingly, a recent report indicates that a fraction of Hrs remains associated with late endosomes (Mari et al., 2008). Rush colocalized only partially with Rab5, possibly reflecting the Hrs-positive fraction. In cell fractionation experiments Rush co-fractionated with both Rab5 and Rab7, but not the fraction that contained Rab7 alone. These results suggest that Rush associates with late endosomes and/or early-late endosome intermediates. The human ortholog of Rush, Phafin2 (70\% sequence identity to Rush) colocalizes with EEA1, a FYVE domain-containing early endosome protein, in the HepG2 human liver cancer cell line (Lin et al. 2010). However, only a fraction of Phafin2 puncta colocalize with EEA1, suggesting that Phafin2 might be associated also with later endocytic compartments. In contrast, other publications describe cytoplasmic localization of Phafin2 and Phafin1, another homolog of Rush (57\% sequence identity to Rush) GFP fusion proteins in L929 mouse fibroblast cell line (Li et al., 2008; Chen et al., 2005). However, colocalization of Phafins with endosomal markers was not 
analyzed in these publications. The difference between the observations may also arise from the use of different experimental cell systems or the effects of overexpression.

Rush localized to the plasma membrane in a polarized manner and was found exclusively at the lateral plasma membrane. Rush colocalized with E-cadherin at the adherens junctions, however, the role of the polarized plasma membrane localization of Rush is not clear. Rush is not required for localization of other polarity proteins, since overexpression and loss of Rush did not lead to defects in cell polarity. The polarized localization of Rush might be necessary for its function in endocytosis, although Rush mainly influenced formation of late and not early endosomes as discussed in further chapters. Rush participated in regulation of $\mathrm{Crb}$ endocytosis together with $\mathrm{Cdc} 42$. Rush could affect endocytosis of plasma membrane proteins that are localized in a polarized fashion. In mammalian cells the Rich1/Amot protein complex localizes to tight junctions and selectively activates Cdc42 to promote endocytosis of polarity proteins (Wells et al., 2006). Homologs of Amot are not present in Drosophila, while a homolog of Rich1, a presumed GAP of Cdc42, is encoded by RhoGAP92B. Genetic interaction studies could clarify whether the fly homolog of Rich1 participates in Cdc42-regulated endocytosis and if Rush and Rich1 might act together at the plasma membrane.

\subsubsection{Role of lipid binding domains in Rush localization}

Rush contains two lipid binding domains - a PH and a FYVE domain. Results of lipid overlay assays revealed that Rush can bind to a number of phosphatidylinositides. Rush bound most strongly to PI(3)P. Interaction of Rush with PI(3)P was mediated mainly by its FYVE domain. The PH domain of Rush was able to bind to PI(3)P, PI(4)P and PI( 3,4$) \mathrm{P}_{2}$. Surprisingly, full length Rush interacted not only with PIPs that were specific for its separate domains, but also to $\mathrm{PI}(4,5) \mathrm{P}_{2}$ and $\mathrm{PI}(3,4,5) \mathrm{P}_{3}$. It could be possible that both lipid domains interact with each other on a functional level and broaden lipid binding capabilities of Rush. In addition, the lipid domains of Rush could act as so-called coincidence detectors and act together to increase the affinity of Rush towards the membrane (Carlton and Cullen, 2005; Lemmon, 2008).

Experiments with lipid binding defective Rush constructs indicated that the FYVE domain plays the main role in the endosome localization of Rush. Rush ${ }^{\mathrm{K} 48 \mathrm{E}}$, which harbors a lipid binding defective PH domain, was able to bind only to PI(3)P in lipid overlay assays. $\mathrm{Rush}^{\mathrm{K} 48 \mathrm{E}}$ could still localize to endosomes and, surprisingly, also to the plasma membrane. 
PI(3)P, the target lipid of the FYVE domain, is almost exclusively found in early endosomes and multivesicular bodies (Gillooly et al., 2001; van Meer et al., 2008). The levels of PI(3)P are low at the plasma membrane, where most abundant PIPs are PI(4,5) $\mathrm{P}_{2}$ and $\mathrm{PI}(3,4,5) \mathrm{P}_{3}$ (Di Paolo and De Camilli, 2006; van Meer et al., 2008). The localization of $\mathrm{Rush}^{\mathrm{K} 48 \mathrm{E}}$ to the plasma membrane could be mediated by an interaction with another membrane-associated protein or by dimerization with wild type Rush. Dimerization of FYVE domains has been described to take place for several endosomal proteins like EEA1 and Hrs (Hayakawa et al., 2004) and increases affinity of the domain to PI(3)P, but in this case it could lead to plasma membrane recruitment of Rush ${ }^{\mathrm{K} 48 \mathrm{E}}$. The localization of the Rush homolog Phafin2 to endosomes is also mediated by its FYVE domain, and deletion of the N-terminus together with the $\mathrm{PH}$ domain did not lead to mislocalization of the protein (Lin et al., 2010).

The Rush ${ }^{\text {R176G }}$ mutant with a nonfunctional FYVE domain localized solely to the plasma membrane. Therefore the $\mathrm{PH}$ domain or the activity of both lipid binding domains together, as indicated by $\mathrm{Rush}^{\mathrm{K} 48 \mathrm{E}}$ localization, is needed for the plasma membrane association of Rush. Localization of the PH domain to the plasma membrane may be mediated by its interaction with $\mathrm{PI}(3,4) \mathrm{P}_{2}$, which is produced in the plasma membrane by dephosphorylation of PI(3,4,5) $\mathrm{P}_{3}$ (Di Paolo and De Camilli, 2006; Ivetac et al., 2005). Rush $^{\mathrm{R} 176 \mathrm{G}}$ exhibited only a background interaction with PIPs in lipid overlay assays. The PIP binding ability of the PH domain might be diminished due to the mutation in the FYVE domain, possibly because of surface charge changes or conformational changes caused by the R176G mutation. The presence of at least one functional lipid binding domain is necessary for the membrane localization of Rush, since Rush ${ }^{\mathrm{K} 48 \text { ER176G }}$ was cytoplasmic. Thus the two lipid binding domains are responsible for the dual localization of Rush in epithelial cells, with the PH domain localizing Rush to the plasma membrane and the FYVE domain regulating the localization to endosomes.

\subsection{Function of Rush in endocytosis}

\subsubsection{Rush regulates late endosome formation}

Results presented in this work show that Rush has a positive effect on late endosome size. Overexpression of Rush led to formation of enlarged late endosomes, while the late endosome size was decreased in rush mutants. Formation of early endosomes, monitored 
by expression of Rab5CA, was not affected in rush mutants, suggesting that Rush acts downstream of Rab5. Also in human cells dominant negative Rab5 disrupted formation of Phafin2-induced large endosomes, positioning Rab5 activity upstream of Phafin2 (Lin et al., 2010). The effect of Rush on late endosomes can be caused by increased transition from early to late endosome, or by downregulated late endosome to lysosome traffic. Rush overexpressing cells exhibited a weaker staining for the $\mathrm{pH}$ sensitive LysoTracker dye, which marks acidic intracellular compartments, such as lysosomes. Mutants for Drosophila V-ATPase, a proton pump necessary for acidification of the lysosomal lumen, also develop enlarged late endosomes and show decreased LysoTracker staining (Yan et al., 2009). Therefore the increase in late endosome size in cells that overexpress Rush might be caused by defects in transport from late endosomes to lysosomes. A staining against an alternative lysosome marker, e.g. lysobiphosphatidic acid that accumulates in mature late endosomes and lysosomes (Kim et al., 2010), will be used to verify this result. In the future I also plan to investigate lysosome formation in rush mutant epithelia by LysoTracker staining. If Rush negatively regulates trafficking to lysosomes, the transport to lysosomes would be increased in rush mutants, thus also explaining the decrease in late endosome size.

Increased late endosome size could also be caused by defects in endocytic recycling, thus directing all endocytosed material for degradation. Recycling of endocytosed proteins like Crumbs or E-cadherin plays an important role in the regulation of cell polarity (Roeth et al., 2009). When Rush is overexpressed, the apical polarity protein Crumbs accumulates in Rush positive enlarged endosomes. However, if Rush overexpression would cause disruption of the recycling endosome pathway, one would expect a gradual loss of membrane proteins like Crumbs or E-cadherin, in the end resulting in loss of cell polarity (Desclozeaux et al., 2008; Roeth et al., 2009). On the contrary, the polarity of follicle epithelial cells was not disrupted either by overexpression or loss of Rush. In addition, the size of Rab11-marked recycling endosomes was not affected in rush mutant cells. Thus the Rush-mediated effects on late endosome morphology are most probably not caused by defects in recycling of endocytosed proteins.

Phafin2, the human homolog of Rush, has been shown to increase the binding of Rab5 with its effectors, monitored by a FRET (fluorescence resonance energy transfer) assay with the Rab5 binding domain of Rabaptin5 (Lin et al., 2010). The data presented here rather position Rush downstream of Rab5 on the endocytic pathway, since overexpression of Rush resulted in increased late, but not early, endosome size. In addition, Rush and 
Rab5 did not substantially colocalize in the follicle epithelium, although Rush colocalized with Hrs, a protein that associates with early endosomes but also to a lesser degree to late endosomes (Komada et al., 1997; Mari et al., 2008).

\subsubsection{Rush changes the morphology of Rab5CA vesicles}

Although a significant colocalization between wild type Rab5 and Rush was not observed, expression of constitutively GTP-bound Rab5CA led to association of Rush with early endosomes. Also Rab7, the marker of late endosomes, was found in Rab5CA vesicles. In line with this observation, several publications have described association of late endosome and even lysosome proteins with enlarged Rab5CA vesicles (Rink et al., 2005; Rosenfeld et al., 2001; Wegner et al., 2010). In cell culture experiments it has been shown that activated Rab5 recruits Rab7 to endosomes via the class C VPS/HOPS complex (Rink et al. 2005). In the case of Rab5CA, Rab5 is constantly bound to GTP and cannot be inactivated and removed from the endosome after Rab7 recruitment, thus resulting in formation of Rab5/Rab7 double labeled endosomes (Rink et al., 2005). Similarly, I observed double Rab5 and Rab7 staining of enlarged Rab5CA endosomes in Drosophila follicle cells. This result supports the Rab conversion mode of late endosome formation, according to which the transition between early and late endosomes takes place by exchange of Rabs (Spang, 2009). The recycling endosome marker Rab11 did not associate with the Rab5CA and/or Rush-induced large endosomes, in line with the observation that expression of Rab5CA does not affect endocytic recycling (Ceresa et al., 2001; Rosenfeld et al., 2001).

Surprisingly, a simultaneous overexpression of Rush and Rab5CA induced fractionation of Rab5CA vesicles. Interestingly, downregulation of Vps39, a component of the class C VPS/ HOPS complex, has a similar effect on the morphology of Rab5 vesicles (Rink et al., 2005). Vps39 acts as a GEF of the yeast ortholog of Rab7 (Wurmser et al., 2000). The phenotype caused by loss of Vps39 is proposed to arise due to delayed recruitment and activation of Rab7 to the endosomes (Rink et al., 2005). So far it is not clear whether the Rush-induced fractionation of early endosomes is caused by regulation of Rab7 activation. The Drosophila homolog of Vps39 has not been characterized so far. However, mutations in other class C VPS/HOPS complex genes - vps16A, deep orange (vps18) and carnation (vps33) cause defects in lysosome formation (Akbar et al., 2009; Pulipparacharuvil et al., 2005; Sriram et al., 2003). As overexpression of Rush caused weaker lysosome staining in 
epithelial cells, one can speculate that Rush might counteract the class C VPS/HOPS complex in Rab7 activation and therefore delay the transition between late endosomes and lysosomes. The interaction between Rush and GDI might affect the activation of Rab7 on late endosomes by removing the inactive Rab7-GDP from the membrane and preventing reactivation of Rab7 by its GEF.

The phenotype of fractionated Rush/Rab5CA-containing early endosomes resembles a cluster of smaller vesicles. Rab5CA causes formation of large early endosomes by promoting homotypic fusion of early endosomes (Gorvel et al., 1991). The clustering of early endosomes might be caused by an inhibition of the early endosome fusion by Rush. The early endosomal protein Hrs has been found to promote the transition to late endosomes by inhibiting the homotypic fusion of early endosomes (Sun et al., 2003; Visser Smit et al., 2009). Inhibition of the early endosome fusion leads to clustering of early endosomes that resembles the effect of Rush on Rab5CA-induced early endosomes (Visser Smit et al., 2009). Rush colocalized with the Hrs-positive endosome fraction and could function together with Hrs at this step of endocytosis. However, at the moment it is not clear, how Rush could affect early endosome homotypic fusion.

Thus the clustering of Rab5CA vesicles, caused by Rush overexpression, can be a result of either a delayed activation of Rab7, or an inhibition of early endosome homotypic fusion. Future experiments in rush mutant and Rush-overexpressing flies harboring mutations in Hrs and the class C VPS/HOPS complex genes will be needed to clarify the cause of Rushinduced changes of Rab5CA-induced large early endosome morphology.

\subsection{Possible role of Rush in signaling pathways}

Ovaries of flies that are mutant for rush showed low penetrance egg chamber fusion defects and an increased length of stalks that separate egg chambers. The fusion between egg chambers seems to be caused by defects in polar cell differentiation. Polar and stalk cell formation is induced by JAK/STAT and Notch signaling pathways in early egg chamber development stages (McGregor et al., 2002; Grammont and Irvine, 2001). The specification of polar cells is induced by Delta signaling from the germline that activates Notch in the follicle epithelium (Grammont and Irvine, 2001; Lopez-Schier and St. Johnston, 2001). Polar cells in turn express Unpaired, a ligand which activates JAK/STAT signaling in stalk cell precursors and specifies their fate (McGregor et al, 2002). Overactivation of the JAK/STAT pathway due to overexpression of Unpaired results in a 
decreased polar cell number, increased stalk length and egg chamber fusions (McGregor et al., 2002). Defects in Notch signaling cause egg chamber fusion, lack of polar cells and increased stalk length (Grammont and Irvine, 2001). A similar phenotype was observed in rush mutant egg chambers. Both JAK/STAT and Notch signaling pathways require endocytosis for their activation (Devergne et al., 2007; Le Borgne, 2006). Thus Rush might affect polar cell and stalk cell differentiation by modifying JAK/STAT and/or Notch pathways. Receptors of both pathways become endocytosed upon binding with a ligand and activated in late endosomes (Devergne et al., 2007; Vaccari et al., 2008). Deletion of rush decreased the size of late endosomes, possibly by affecting the transport to or from the late endosomal compartment. It has been shown that disruption of endocytic trafficking of Dome, the receptor of JAK/STAT pathway, to or from late endosomes downregulated the JAK/STAT signaling pathway (Devergne et al., 2007). Similarly, Notch signaling requires the transport to early endosomes and multivesicular bodies for the activation of the pathway (Vaccari et al., 2008). Thus the egg chamber fusion defects observed in rush mutants might be caused by perturbations in JAK/STAT and/or Notch signaling pathways, most probably due to changes in trafficking through late endosomes.

Overexpression of Rush in the follicle epithelium in some cases led to apoptosis in the germline. This unexpected non-cell-autonomous effect might be caused by changes in signaling between the germline and the follicle epithelium. Some evidence that signals from the follicle epithelium can regulate germline survival can be found in the literature. Removal of the TGF $\beta$ receptor Saxophone (Sax) in the germline leads to germline cell apoptosis, suggesting that a TGF $\beta$ signal from the follicle epithelium might be necessary for oogenesis (Twombly et al., 1996). Overexpression of the c-Jun N-terminal kinase (JNK) pathway activator D-GADD45 in follicle cells also induces apoptosis of the germline (Peretz et al., 2007). At the moment it is not clear, how overexpression of Rush in follicle epithelium induces germline apoptosis. For example, increased endocytosis in Rush overexpressing follicle cells could titrate out a ligand that is required for germline survival, or, alternatively, inhibit activation of a yet unknown signaling pathway in follicle cells that is needed for the communication with germline cells.

\subsection{Genetic interaction between rush and $C d c 42$}

Cdc42 has been described to play an important role in endocytosis from yeast to mammals. In recent years the evidence for a role of Cdc42 together with the Par/aPKC complex in 
trafficking of polarity proteins has accumulated (Balklava et al., 2007; Duncan and Peifer, 2008). In Drosophila epithelial cells, Cdc42 acts on several steps of endocytosis, including protein uptake into early endosomes and trafficking to late endosomes (Harris and Tepass, 2008; Georgiou et al., 2008; Leibfried et al., 2008). The effects of Cdc42DN expression in the embryonic ectoderm, that are described in this thesis, generally are in line with the data by Harris and Tepass (2008). Similarly as published by Harris and Tepass (2008), expression of $\mathrm{Cdc} 42 \mathrm{DN}$ caused loss of $\mathrm{Crb}$ from the plasma membrane and accumulation of $\mathrm{Crb}$ in intracellular vesicles. In addition, an increased loss of E-cadherin from the plasma membrane at the ventral ectoderm was observed. Interestingly, E-cadherin did not accumulate in vesicles together with $\mathrm{Crb}$, suggesting different trafficking routes for the two proteins. In $C$. elegans $\mathrm{Cdc} 42$ together with other members of the Par/aPKC complex differentially regulates trafficking of molecules by promoting uptake via the clathrindependent pathway and increasing the recycling of molecules endocytosed via clathrin independent pathways (Balklava et al., 2007). These effects could account for the different behavior of $\mathrm{Crb}$ and E-cadherin in Cdc42DN cells. However, the clathrin-dependent and independent endocytic pathways in Drosophila have not been investigated in detail.

Rush and Cdc42DN overexpression results in similar phenotypes in epithelial cells - an increase of late endosome size and increased $\mathrm{Crb}$ accumulation in late endosomes. Thus Rush and Cdc42 have opposing effects in regulation of endocytosis. It is not clear, whether Rush is directly regulated by $\mathrm{Cdc} 42$, or is a part of another pathway. Loss of rush could rescue the Cdc42DN overexpression phenotype, suggesting that Rush acts downstream of $\mathrm{Cdc42}$. Studies in a human breast cancer cell line indicate a role of $\mathrm{Cdc} 42$ in targeting of E-cadherin to lysosomes (Shen et al., 2008). One possibility is that Cdc42 promotes transition between late endosomes and lysosomes, and inactivates or counteracts Rush in this process. In such case Cdc42DN expression would inhibit, e.g. via Rush, endocytic transport to lysosomes and would cause accumulation of endocytosed molecules like Crb in late endosomes. Upon deletion of rush the degradation of endocytosed $\mathrm{Crb}$ would proceed normally. However, it is not clear how the deletion of rush leads to rescue of cell polarity loss, caused by Cdc42DN expression in embryos. Another possible explanation is that in Cdc42DN-expressing epithelial cells endocytic recycling is inhibited by enhanced transition from early to late endosomes, thus disrupting the sorting into recycling endosomes. For example, overexpression of Hrs increases retention of transferrin receptors in endosomes (Raiborg et al., 2002). If Rush promotes the transition from early to late endosomes, as suggested by the Rush overexpression phenotype, loss of Rush could slow 
down the formation of late endosomes and allow endocytic recycling to take place.

In this work I analyzed the genetic interaction between rush and $C d c 42$. However, other members of the Par/aPKC complex, like Baz, Par6 and aPKC, have been shown to be involved in Cdc42-regulated endocytosis (Harris and Tepass, 2008; Georgiou et al., 2008; Leibfried et al., 2008). Further experiments will be needed to show whether rush genetically interacts with other Par/aPKC complex members in regulation of endocytosis. Expression of constitutively active aPKC rescued the Cdc42DN overexpression phenotype - the loss of $\mathrm{Crb}$ from the plasma membrane and the accumulation of $\mathrm{Crb}$ in endosomes (Harris and Tepass, 2008). Expression of dominant negative Rab5 rescued the loss of Crb from the plasma membrane, but not the defect in Crb endosomal trafficking, suggesting that the accumulation of $\mathrm{Crb}$ in endosomes is independent of Rab5 function. Rush might be the effector of the Par/aPKC complex at later stages of endocytosis. To test this possibility, I plan to analyze the effect of aPKC and $\mathrm{Cdc} 42$ constitutive activation on late endosome size in Rush overexpressing and rush mutant flies.

\subsection{Rush interaction with Rab GDI and GDF}

Yeast two-hybrid screens with yeast and mammalian proteins suggested an interaction between Rush orthologs and Rab GDF (Ito et al., 2001; Rual et al., 2005). GDF interacts with GDI and promotes insertion of Rab into the membrane and the release of Rab from GDI (Dirac-Svejstrup et al., 1997; Hutt et al., 2000; Sivars et al., 2003). Pulldown experiments with purified proteins supported the possibility of the interaction between Rush and CG1418, the Drosophila ortholog of GDF. Interestingly, Rush could also bind GDI and recruits GDI to the cortex of S2 cells. However, the localization of Rush and CG1418 to different subcellular compartments indicates that Rush and CG1418 most probably do not interact in vivo. As both GDI and Rush were associated with a Rab5 and Rab7 positive endosomal fraction, an interaction between GDI and Rush on the endosomal membrane is possible.

The function of GDI in Drosophila has not been well characterized. The work by Ricard et al. (2001) shows that Drosophila GDI is able to extract Rab5 from membranes, similarly to the mammalian homolog (Ullrich et al., 1993). Rush could facilitate recruitment of GDI to late endosomes and thus regulate the activity of Rabs. GDI has been shown to inhibit the fusion of late endosomes with lysosomes (Mullock et al., 1998). Therefore the interaction between Rush and GDI on late endosomes might cause the decrease in the transition from 
late endosomes to lysosomes upon overexpression of Rush. Rab7 activity is needed for delivery of endocytosed material from late endosomes to lysosomes (Bucci et al., 2000). Increased recruitment of GDI to late endosomes would lead to removal of inactive Rab7 from the endosome membrane and prevent the reactivation of Rab7 by GEF-catalyzed nucleotide exchange. Further experiments will be necessary to characterize the interaction between Rush and GDI and its possible implications in Rush overexpression and deletion phenotypes.

\subsection{Model of Rush function}

The results presented in this thesis suggest multiple roles of Rush in endocytosis in epithelial cells. Rush localizes to late endosomes, and positively influences late endosome size. On the contrary, loss of Rush leads to a decreased late endosome size. Rush overexpression leads to a weaker staining for the lysosomal marker Lysotracker, therefore Rush might increase the size of late endosomes by inhibiting the transition between late endosomes and lysosomes. Rush interacts directly with GDI and might delay transition to lysosomes by a GDI-mediated inhibition of Rab7 activity. Alternatively, Rush might promote the transition from early to late endosomes. Rush overexpression together with Rab5CA leads to fractionation of the early endosomes. The effects of Rush on early endosome shape suggest a possible role of Rush in inhibition of early endosome fusion.

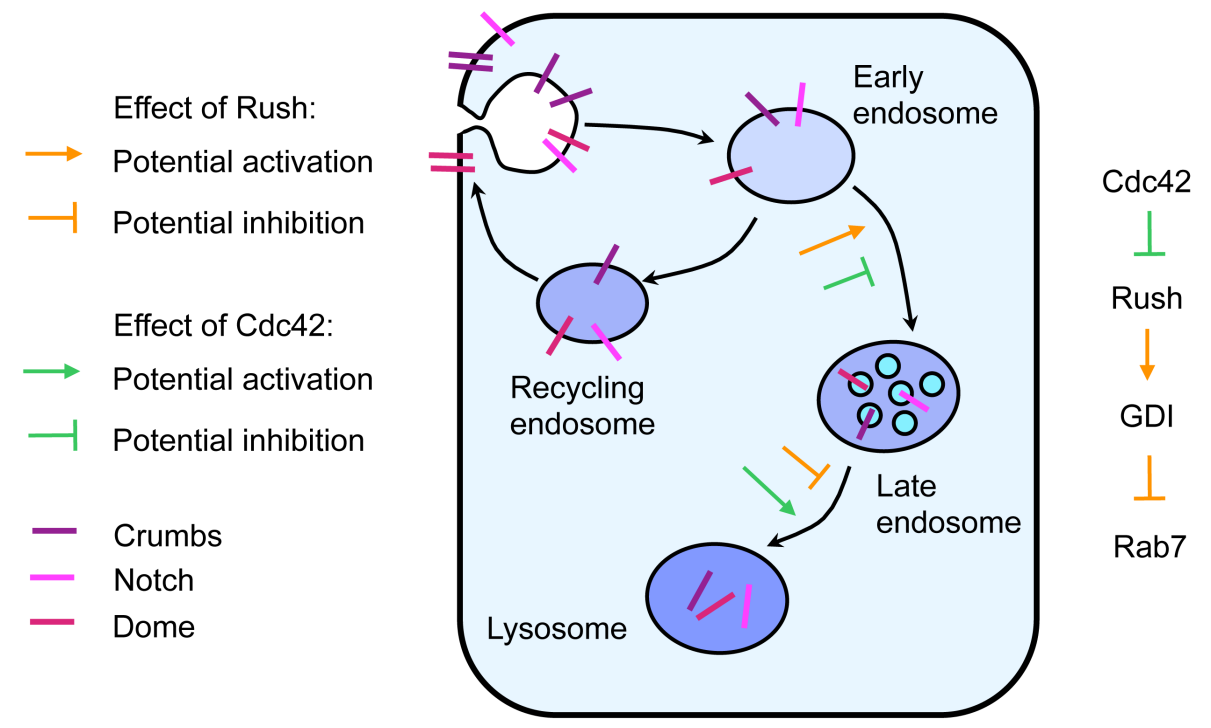

Figure 4.1. Model of Rush function in endocytosis. Activation or inhibition of trafficking steps is indicated with orange (Rush) or green (Cdc42) arrows. Colored bars indicate endocytosed proteins. 
Rush plays a role in the endocytosis of $\mathrm{Crb}$, and causes accumulation of $\mathrm{Crb}$ in late endosomes upon Rush overexpression. Rush might be also involved in endocytic regulation of Notch and JAK/STAT pathway signaling, as deduced from the rush mutant phenotype. The Rush overexpression phenotype is similar to the effect of Cdc42DN overexpression, suggesting that Rush counteracts $\mathrm{Cdc} 42$ in regulation of Crumbs endocytosis. This hypothesis is supported by the rescue of Cdc42DN overexpression flies by deletion of rush. Judging from this result, Rush most probably acts downstream of Cdc42, and might be inhibited by active Cdc42.

In the sum, Rush promotes formation of late endosomes, either by increasing the transition from early to late endosomes, or by inhibition of downstream transport to lysosomes (Fig. 4-1). Rush counteracts Cdc42 in this process, possibly via its binding to GDI. Further experiments will be needed to clarify the molecular mechanism of Rush function in regulation of endocytosis. 


\section{Summary and conclusions}

Endocytosis and endosome trafficking regulates many cellular processes, including regulation of plasma membrane composition, cell polarity and intercellular signaling. Overactivation or inhibition of different steps of endocytosis can lead to defects in diverse cell functions. Although many factors that participate in endocytosis have already been identified, still many aspects of regulation of endocytosis are not known. In recent years Cdc42 together with other members of the Par/aPKC complex have been described to function in endocytosis. The Par/aPKC complex proteins are well known as cell polarity regulators. However, the molecular mechanism of the activity of $\mathrm{Cdc} 42$ and other Par/aPKC complex members in regulation of endocytosis is largely unknown.

In this work I describe the characterization of a novel endocytosis regulating protein Rush hour (Rush). Rush is a highly conserved protein and contains two lipid binding domains a PH and a FYVE domain. Rush is ubiquitously expressed and localizes to the lateral plasma membrane of epithelial cells and to late endosomes. Generation of Rush mutants with lipid binding defective $\mathrm{PH}$ and FYVE domains revealed that a functional $\mathrm{PH}$ domain is sufficient to localize Rush to the plasma membrane, while the FYVE domain mediates endosomal association of Rush. Overexpression of Rush led to formation of enlarged late endosomes. Flies that are mutant for rush are homozygous viable, but have a decreased late endosome size, which is consistent with the role of Rush in regulation of late endosome formation. Rush mutants show a number of low penetrance phenotypes in oogenesis, including egg chamber fusions and an increased number of stalk cells. Similar phenotypes are observed in mutants of Notch and JAK/STAT signaling pathway genes. Both pathways require endosomal trafficking for their activation. Therefore the oogenesis phenotypes in rush flies are most probably caused by defects in signaling pathways due to changes in late endosome formation.

Rush seems to affect endocytosis at several levels. Overexpression of Rush led to the fractionation of Rab5CA-induced large early endosomes, suggesting that Rush acts in the transition between early and late endosomes. Rush might inhibit Rab5-induced homotypic fusion of early endosomes, thus promoting the transition to late endosomes. In addition, the staining of LysoTracker, a lysosome specific dye, was decreased upon overexpression of Rush, suggesting that Rush negatively affects lysosome formation.

Remarkably, Rush enhanced endocytosis of Crumbs, a determinant of apical characteristics of the plasma membrane, and caused accumulation of Crumbs in late 
endosomes. A similar phenotype has been observed in Cdc42DN-expressing tissues, pointing to a common function for both proteins. Loss of rush rescued Cdc42DN overexpression phenotype, suggesting that Rush acts downstream of $\mathrm{Cdc} 42$ in regulation of late endosome formation. I found that Rush interacted directly with GDI and recruited GDI to the membrane in S2 cells. Thus Rush might regulate endosome formation by directing GDI to the endosomal membrane.

Taken together, the results presented here describe Rush as a novel regulator of late endosome formation. Rush acts downstream of Cdc42 in trafficking to late endosome, and regulates together with $\mathrm{Cdc} 42$ endocytosis of the polarity marker Crumbs. Rush binds to GDI directly and might thus regulate endocytosis by affecting the Rab activation cycle. 


\section{Bibliography}

Abdul-Ghani M., Gougeon P.Y., Prosser D.C., Da-Silva L.F., Ngsee J.K. 2001. PRA isoforms are targeted to distinct membrane compartments. J. Biol. Chem. 276: 62256233.

Akbar M.A., Ray S., Krämer H. 2009. The SM protein Car/Vps33A regulates SNAREmediated trafficking to lysosomes and lysosome-related organelles. Mol. Biol. Cell 20: $1705-1714$

Ashburner M. 1989. Drosophila: a laboratory handbook. Cold Spring Harbor Press, Plainview, NY.

Babst M., Katzmann D.J., Estepa-Sabal E.J., Merloo T., Emr S.D. 2002a. ESCRT-III: an endosome-associated heterooligomeric protein complex required for MVB sorting. Dev. Cell 3: 271-282.

Babst M., Katzmann D.J., Snyder W.B., Wendland B., Emr S.D. 2002b. Endosomeassociated complex, ESCRT-II, recruits transport machinery for protein sorting at the multivesicular bodies. Dev. Cell 3: 283-289.

Bache K.G., Brech A., Mehlum A., Stenmark H. 2003. Hrs regulates multivesicular body formation via ESCRT recruitment to endosomes. J. Cell Biol. 162: 435-442.

Bachmann A. and Knust E. 2008. The use of P-element transposons to generate transgenic flies. From: Methods in Molecular biology: Drosophila: Methods and Protocols. Ed. Dahmann C. Humana Press, Totowa, NJ, pp 71-77.

Bachmann A., Schneider M., Theilenberg E., Grawe F., Knust E. 2001. Drosophila Stardust is a partner of Crumbs in the control of epithelial cell polarity. Nature 414: 638-643.

Balklava Z., Pant S., Fares H., Grant B.D. 2007. Genome-wide analysis identifies a general requirement for polarity proteins in endocytic traffic. Nat. Cell Biol. 9: 1066-1073.

Baron M., O’Leary V., Evans D.A.P., Hicks M. 2000. Multiple roles of the Dcdc42 GTPase during wing development in Drosophila melanogaster. Mol. Gen. Genet. 264: 98-104.

Betschinger J., Mechtler K., Knoblich J.A. 2003. The Par complex directs asymmetric cell division by phosphorylating the cytoskeletal protein Lgl. Nature 422: 326-330.

Bilder D., Li M., Perrimon N. 2000. Cooperative regulation of cell polarity and growth by Drosophila tumor supressors. Science 289: 113-116.

Bilder D. and Perrimon N. 2000. Localization of apical epithelial determinants by the 
basolateral PDZ protein Scribble. Nature 403: 676-680.

Bilder, D., Schober, M., Perrimon, N. 2003. Integrated activity of PDZ protein complexes regulates epithelial polarity. Nat. Cell Biol. 5: 53-57.

Bökel C., Schwabedissen A., Entchev E., Renaud O., Gonzalez-Gaitan M. 2006. Sara endosomes and the maintenance of Dpp signaling levels across mitosis. Science 314: 1135-1139.

Bond J.S. and Butler P.E. 1987. Intracellular proteases. Annu. Rev. Biochem. 56:333-364.

Brand A.H. and Perrimon N. 1993. Targeted gene expression as a means of altering cell fates and generating dominant phenotypes. Development 118: 401-415.

Bucci C., Parton R.G., Mather I.H., Stunnenberg H., Simons K., Hoflack B., Zerial M. 1992. The small GTPase rab5 functions as a regulatory factor in the early endocytotic pathway. Cell 70: 715-728.

Bucci C., Thomsen P., Nicoziani P., McCarthy J., van Deurs B. 2000. Rab7: a key to lysosome biogenesis. Mol. Biol. Cell 11: 467-480.

Burd C.G. and Emr S.D. 1998. Phosphatidylinositol (3)-phosphate signaling mediated by specific binding to RING FYVE domains. Mol. Cell 2: 157-162.

Buszczak M. and Cooley L. 2000. Eggs to die for: cell death during Droosphila oogenesis. Cell Death Differ. 7: 1071-1074.

Candiano G., Bruschi M., Musante L., Santucci L., Ghiggeri G.M., Carnemolla B., Orecchia P., Zardi L., Righetti P.G. 2004. Blue silver: a very sensitive colloidal Coomassie G-250 staining for proteome analysis. Electrophoresis 25: 1327-1333.

Carlton J.G. and Cullen P.J. 2005. Coincidence detection in phosphoinositide signaling. Trends Cell Biol. 15: 540-547.

Ceresa B.P., Lotscher M., Schmid S.L. 2001. Receptor and membrane recycling can occur with unaltered efficiency despite dramatic Rab5(q791)-induced changes in endosome geometry. J. Biol. Chem. 276: 9649-9654.

Chavrier P., Parton R.G., Hauri H.P., Simons K., Zerial M. 1990. Localization of low molecular weight GTP binding proteins to exocytic and endocytic compartments. Cell 62: 317-329.

Chen X., Cheung S.T., So S., Fan S.T., Barry C., Higgins J., Lai K.M., Ji J., Dudoit S., Ng I.O., Van De Rijn M., Botstein D., Brown P.O. 2002. Gene expression patterns in human liver cancers. Mol. Biol. Cell 13: 1929-1939.

Chen W., Feng Y., Chen D., Wandinger-Ness A. 1998. Rab11 is required for trans-Golgi network-to-plasma membrane transport and a preferential target for GDP 
dissociation inhibitor. Mol. Biol. Cell 9: 3241-3257.

Chen W., Li N., Chen T., Han Y., Li C., Wang Y., He W., Zhang L., Wan T., Cao X. 2005. The lysosome-associated apoptosis-inducing protein containing the pleckstrin homology (PH) and FYVE domains (LAPF), representative of a novel family of PH and FYVE domain-containing proteins, induces caspase-independent apoptosis via the lysosomal-mitochondrial pathway. J Biol Chem. 280: 40985-40995.

Christoforidis S., Miaczynska M., Ashman K., Wilm M., Zhao L., Yip S.C., Waterfield M.D., Backer J.M. and Zerial M. 1999. Phosphatidylinositol-3-OH kinases are Rab5 effectors. Nat. Cell Biol. 1: 249-252.

Cox R.T., Kikpatrick C., Peifer M. 1996. Armadillo is required for adherens junction assembly, cell polarity, and morphogenesis during Drosophila embryogenesis. J. Cell Biol. 134: 133-148.

Currie R.A., Walker K.S., Gray A., Deak M., Casamayor A., Downes C.P., Cohen P., Alessi D.R., Lucocq J. 1999. Role of phosphatidylinositol 3,4,5-triphosphate in regulating the activity and localization of 3-phosphoinositide-dependent protein kinase-1. Biochem. J. 337: 575-583.

Del Conte-Zerial P., Brusch L., Rink J.C., Collinet C., Kalaidzidis Y., Zerial M., Deutsch A. 2008. Membrane identity and GTPase cascades regulated by toggle and cut-out switches. Mol. Syst. Biol. 4: 206.

Delva E. and Kowalczyk A.P. 2009. Regulation of cadherin trafficking. Traffic 10: 259267.

Desclozeaux M., Venturato J., Wylie F.G., Kay J.G., Jospeh S.R., Le H.T., Stow J.L. 2008. Active Rab11 and functional recycling endosome are required for E-cadherin trafficking and lumen formation during epithelial morphogenesis. Am. J. Physiol. Cell Physiol. 295: C545-C556.

Devergne O., Ghiglione C., Noselli S. 2007. The endocytic control of JAK/STAT signalling in Drosophila. J. Cell Sci. 120: 3457-3464.

DiMario P.J. and Mahowald A.P. 1987. Female sterile (1) yolkless: a recessive female sterile mutation in Drosophila melanogaster with depressed numbers of coated pits and coated vesicles within the developing oocytes. J. Cell Biol. 105: 199-206.

Di Paolo G. and De Camilli P. 2006. Phosphoinositides in cell regulation and membrane dynamics. Nature 443: 651-657.

Dirac-Svejstrup, A.B., Sumizawa T., Pfeffer S.R. 1997. Identification of a GDI displacement factor that releases endosomal GTPases from Rab-GDI. EMBO J. 16: 
$465-472$.

Doherty G.J. and McMahon H.T. 2009. Mechanisms of endocytosis. Annu. Rev. Biochem. 78: 857-902.

Drubin, D.G. and Nelson, W.J. 1996. Origins of cell polarity. Cell 84: 335-344.

Egger-Adam, D. 2005. Identifikation neuer Interaktionspartner des Bazooka Proteins in Drosophila melanogaster. Inaugural-Dissertation, Heinrich-Heine-Universität Düsseldorf.

Entchev E.V., Schwabedissen A., Gonzalez-Gaitan M. 2000. Gradient formation of the TGF- $\boldsymbol{\beta}$ homolog Dpp. Cell 103: 981-991.

Emery G. and Knoblich J.A. 2006. Endosome dynamics during development. Curr. Opin. Cell Biol. 18: 407-415.

Fischer J.A., Eun S.H., Doolan B.T. 2006. Endocytosis, endosome trafficking, and the regulation of Drosophila development. Annu. Rev. Cell Dev. Biol. 22: 181-2006.

Friche R., Gohl C., Dharmalingam E., Grevelhörster A., Zahedi B., Harden N., Kessels M., Qualmann B., Bogdan S. 2009. Drosophila Cip4/Toca-1 integrates membrane trafficking and actin dynamics through WASP and SCAR/WAVE. Curr. Biol. 19: 1429-1437.

Gassama-Diagne, A., Yu, W., ter Beest, M., Martin-Belmonte, F., Kierbel, A., Engel, J., Mostov, K. 2006. Phosphatidylinositol-3,4,5-triphosphate regulates the formation of the basolateral plasma membrane in epithelial cells. Nat. Cell Biol. 8: 963-970.

Gaullier J.M., Simonsen A., D’Arrigo A., Bremnes B., Stenmark H. 1998. FYVE fingers bind PtdIns(3)P. Nature 394: 432-433.

Gaullier J.M., Ronning E., Gillooly D., Stenmark H. 2000. Interaction of the EEA1 FYVE finger with phosphatidylinositol 3-phosphate and early endosomes. Role of conserved residues. J. Biol. Chem. 275: 24595-24600.

Genova J.L., Jong S., Camp J.T., Fehon R. G. 2000. Functional analysis of Cdc42 in actin filament assembly, epithelial morphogenesis, and cell signaling during Drosophila development. Dev. Biol. 221: 181-194.

Georgiou M., Marinari E., Burden J., Baum B. 2008. Cdc42, Par6, and aPKC regulate Arp2/3-mediated endocytosis to control local adherens junction stability. Curr. Biol. 18: 1631-1638.

Gilbert M.M., Robinson B.S., Moberg K.H. 2009. Functional interactions between the erupted/tsg101 growth supressor gene and the DaPKC and rbf1 genes in Drosophila imaginal disc tumors. PloS One 4: e7039. 
Gillooly D.J., Morrow I.C., Lindsay M., Gould R., Bryant N.J., Gaulier J.M., Parton R.G., Stenmark H. 2000. Localization of phosphatidylinositol 3-phosphate in yeast and mammalian cells. EMBO J. 19: 4577-4588.

Gillooly D.J., Simonsen A., Stenmark H. 2001. Cellular functions of phosphatidylinositol 3-phosphate and FYVE domain proteins. Biochem J. 355: 249-258.

Goldstein B. and Macara I.G. 2008. The PAR proteins: fundamental players in animal cell polarization. Dev. Cell 13: 609-622.

Gorvel J.P., Chavrier P., Zerial M., Gruenberg J. 1991. Rab5 controls early endosome fusion in vitro. Cell 64: 915-925.

Grammont M. and Irvine K.D. 2001. fringe and Notch specify polar cell fate during Drosophila oogenesis. Development 128: 2243-2253.

Grosshans B.L., Oritz D., Novick P. 2006. Rabs and their effectors: achieving specificity in membrane traffic. PNAS 103: 11821-11827.

Gruenberg J. 2001. The endocytic pathway: a mosaic of domains. Nat. Rev. Mol. Cell Biol. 2: 721-730.

Harris T.J.C. and Pfeifer M. 2004. Adherens junction-dependent and-independent steps in the establishment of epithelial cell polarity in Drosophila. J. Cell Biol. 167: 135-147.

Harris T.J.C. and Pfeifer M. 2005. The positioning and segregation of apical cues during epithelial polarity establishment in Drosophila. J. Cell Biol. 170: 813-823.

Harris K.P. and Tepass U. 2008. Cdc42 and Par proteins stabilize dynamic adherens junctions in the Drosophila neuroectoderm through reagulation of apical endocytosis. J. Cell Biol. 183: 1129-1143.

Hayakawa A., Hayes S.J., Lawe D.C., Sudharshan E., Tuft R., Fogarty K., Lambright D., Corvera S. 2004. Structural basis for endosomal targeting by FYVE domains. J. Biol. Chem. 279: 5958-5966.

Hong Y., Stronach B., Perrimon N., Jan L.Y., Jan Y.N. 2001. Drosophila Stardust interacts with Crumbs to control polarity of epithelia but not neuroblasts. Nature 414: 634638.

Hou Y.C., Chittaranjan S., Barbosa S.G., McCall K., Gorski S.M. 2008. Effector caspase Dcp-1 and IAP protein Bruce regulate starvation-induced autophagy during Drosophila melanogaster oogenesis. J. Cell Biol. 182: 1127-1139.

Humbert P.O., Dow L.E., Russell S.M. 2006. The Scribble and Par complexes in polarity and migration: friends or foes? Trends Cell Biol. 16: 622-630.

Hutt D.M., Da-Silva L.F., Chang L.H., Prosser D.C., Ngsee J.K. 2000. PRA1 inhibits the 
extraction of membrane-bound Rab GTPase by GDI1. J. Biol. Chem. 275: 1851118519.

Hutterer A., Betschinger J., Petronczki M., Knoblich J.A. 2004. Sequential roles of Cdc42, Par-6, aPKC, and Lgl in the establishment of epithelial polarity during Drosophila embryogenesis. Dev. Cell 6: 845-854.

Ito T., Chiba T., Ozawa R., Yoshida M., Hattori M., Sakaki Y. 2001. A comprehensive two-hybrid analysis to explore the yeast protein interactome. PNAS 98: 4569-4574.

Ivetac I., Munday A.D., Kisseleva M.V., Zhang X.M., Luff S., Tiganis T., Whisstock J.C., Rowe T., Majerus P.W., Mitchell C.A. 2005. The type I $\alpha$ inositol polyphosphate 4phosphatase generates and terminates phosphoinositide 3-kinase signals on endosomes and the plasma membrane. Mol. Biol. Cell 16: 2218-2233.

Izumi G., Sakisaka T., Tanaka S., Morimoto K., Takai Y. 2004. Endocytosis of E-cadherin regulated by Rac and Cdc42 small G proteins through IQGAP1 and actin filaments. J. Cell Biol. 166: 237-248.

Januschke J., Nicolas E., Compagnon J., Formstecher E., Goud B., Guichet A. 2007. Rab6 and the secretory pathway affect oocyte polarity in Drosophila. Development 134: 3419-3425.

Johnson K. and Wodarz A. 2003. A genetic hierarchy controlling cell polarity. Nat. Cell Biol. 5: 12-14.

Katzmann D.J., Babst M., Emr S.D. 2001. Ubiquitin-dependent sorting into the multivesicular body pathway requires the function of a conserved endosomal protein sorting complex, ESCRT-I. Cell 106: 145-155.

Kavran J.M., Klein D.E., Lee A., Falasca M., Isakoff S.J., Skolnik E.Y., Lemmon M.A. 1998. Specificity and promiscuity in phosphoinositide binding by pleckstrin homology domains. J. Biol. Chem. 273: 30497-30508.

Kim S., Gailite I., Moussian B., Luschnig S., Goette M., Fricke K., Honemann-Capito M., Grubmüller H., Wodarz A. 2009. Kinase-activity-independent functions of atypical protein kinase C in Drosophila. J. Cell Sci. 122: 3759-3771.

Kim S., Wairkar Y.P., Daniels R.W., DiAntonio A. 2010. The novel endosomal membrane protein Ema interacts with the class C Vps-HOPS complex to promote endosomal maturation. J. Cell Biol. 188: 717-734.

Knust E. 2000. Control of epithelial cell shape and polarity. Curr. Opin. Gen. Dev. 10: 471-475.

Knust E. and Bossinger O. 2002. Composition and formation of intercellular junctions in 
epithelial cells. Science 298: 1955-1959.

Komada M., Masaki R., Yamamoto A., Kitamura N. 1997. Hrs, a tyrosine kinase substrate with a conserved double zinc finger domain, is localized to the cytoplasmic surface of early endosomes. J. Biol. Chem. 272: 20538-20544.

Kuchinke U., Grawe F., Knust E. 1998. Control of spindle orientation in Drosophila by the Par-3-related PDZ-domain protein Bazooka. Curr. Biol. 8: 1357-1365.

Kutateladze T.G. 2006. Phosphatidylinositol 3-phosphate recognition and membrane docking by the FYVE domain. Biochim. Biophys. Acta 1761: 868-877.

Lakadamyali M., Rust M.J., Zhuang X. 2006. Ligands for clathrin-mediated endocytosis are differentially sorted into distinct populations of early endosomes. Cell 124: $997-$ 1009.

Le T.L., Yap A.S., Stow J.L. 1999. Recycling of E-cadherin: a potential mechanism for regulating cadherin dynamics. J. Cell Biol. 146: 219-232.

Le Borgne R. 2006. Regulation of Notch signalling by endocytosis and endosomal sorting. Curr. Opin. Cell Biol. 18: 213-222.

Leibfried A. and Bellaiche Y. 2007. Functions of endosomal trafficking in Drosophila epithelial cells. Curr. Opin. Cell Biol. 19:446-452.

Leibfried A., Fricke R., Morgan M.J., Bogdan S., Bellaiche Y. 2008. Drosophila Cip4 and WASp define a branch of the Cdc42-Par6-aPKC pathway regulating E-cadherin endocytosis. Curr. Biol. 18: 1639-1648.

Lemmon M.A. 2008. Membrane recognition by phospholipid-binding domains. Nat. Rev. Mol. Cell Biol. 9: 99-111.

Li N., Zheng Y., Chen W., Wang C., Liu X., He W., Xu H., Cao X. 2007. Adaptor protein LAPF recruits phosphorylated p53 to lysosomes and triggers lysosomal destabilization in apoptosis. Cancer Res. 67: 11176-11185.

Li C., Liu Q., Li N., Chen W., Wang L., Wang Y., Yu Y., Cao X. 2008. EAPF/Phafin-2, a novel endoplasmic reticulum-associated protein, facilitates TNF-alpha-triggered cellular apoptosis through endoplasmic reticulum-mitochondrial apoptotic pathway. J. Mol. Med. 86:471-484.

Lin W.J., Yang C.Y., Lin Y.C., Tsai M.C., Yang C.W., Tung C.Y., Ho P.Y., Kao F.J., Lin C.H. 2010. Phafin 2 modulates the structure and function of endosomes by a Rab5dependent mechanism. Biochem. Biophys. Res. Commun. 391: 1043-1048.

Lloyd T.E., Atkinson R., Wu M.N., Zhou Y., Pennetta G., Bellen H.J. 2002. Hrs regulates endosome membrane invagination and tyrosine kinase receptor signaling in 
Drosophila. Cell 108: 261-269.

Lock J.G. and Stow J.L. 2005. Rab11 in recycling endosomes regulates the sorting and basolateral transport of E-Cadherin. Mol. Biol. Cell 16: 1744-1755.

Lopez-Schier H. and St. Johnston D.2001. Delta signaling from the germ line controls the proliferation and differentiation of the somatic follicle cells during Drosophila oogenesis. Genes Dev. 15: 1393-1405.

Lu H. and Bilder D. 2005. Endocytic control of epithelial polarity and proliferation in Drosophila.

Lu Z., Ghosh S., Wang Z., Hunter T. 2003. Downregulation of caveolin-1 function by EGF leads to the loss of E-cadherin, increased transcriptional activity of $\beta$-catenin, and enhanced tumor cell invasion. Cancer Cell 4: 499-515.

Margolis B. and Borg J.P. 2005. Apicobasal polarity complexes. J. Cell Sci. 118: 51575159.

Martin-Belmonte F., Gassama A., Datta A., Yu W., Rescher U., Gerke V., Mostov K. 2007. PTEN-mediated apical segregation of phosphoinositides controls epithelial morphogenesis through Cdc42. Cell 128: 383-397.

Mari M., Bujny M.V., Zeuschner D., Geerts W.J., Petersen C.M., Cullen P.J., Klumperman J., Geuze H.J. 2008. SNX1 defines an early endosomal recycling exit for sortilin and mannose 6-phosphate receptors. Traffic 9: 380-393.

McCall K. 2004. Eggs over easy: cell death in the Drosophila ovary. Dev. Biol. 274: 3-14.

McGregor J.R., Xi R., Harrison D.A. 2002. JAK signaling is somatically required for follicle cell differentiation in Drosophila. Development 129: 705-717.

McLauchlan H., Newell J., Morrice N., Osborne A., West M., Smythe E. 1998. A novel role for Rab5-GDI in ligand sequestration into clathrin-coated pits. Curr. Biol. 8 :3445.

Mellman I. 1996. Endocytosis and molecular sorting. Annu. Rev. Cell Dev. Biol. 12: 575625.

Melnick M.B., Noll E., Perrimon N. 1993. The Drosophila stubarista phenotype is associated with a dosage effect of the putative ribosome-associated protein D-p40 on spineless. Genetics 135: 553-564.

Moberg K.H., Schelble S., Burdick S.K., Hariharan I.K. 2005. Mutations in erupted, the Drosophila ortholog of mammalian tumor susceptibility gene 101, elicit non-cellautonomous overgrowth. Dev. Cell 9: 699-710.

Morrison H.A., Dionne H., Rusten T.E., Brech A., Fisher W.W., Pfeiffer B.D., Celniker 
S.E., Stenmark H., Bilder D. 2008. Regulation of early endosomal entry by the Drosophila tumor supressors Rabenosyn and Vps45. Mol. Biol. Cell 19: 4167-4176.

Mu F.T., Callaghan J.M., Steele-Mortimer O., Stenmark H., Parton R.G., Campbell P.L., McCluskey J., Yeo J.P., Tock E.P.C., Toh B.H. 1995. EEA1, an early endosomeassociated protein. EEA1 is a conserved $\alpha$-helical peripheral membrane protein flanked by cysteine „fingers“ and contains a calmodulin-binding IQ motif. J. Biol. Chem. 270: 13503-13511.

Mullock B.M., Bright N.A., Fearon C.W., Gray S.R., Luzio J.P. 1998. Fusion of lysosomes with late endosomes produces a hybrid organelle of intermediate intensity and is NSF dependent. J. Cell Biol. 140: 591-601.

Müller H.A.J. 2000. Genetic control of epithelial cell polarity: lessons from Drosophila. Dev. Dyn. 218: 52-67.

Müller H.A.J. and Wieschaus E. 1996. armadillo, bazooka and stardust are critical for early stages in formation of the zonula adherens and maintenance of the polarized blastoderm epithelium in Drosophila. J. Cell Biol. 134: 149-163.

Murray J.T., Panaretou C., Stenmark H., Miaczynska M., Backer J.M. 2002. Role of Rab5 in the recruitment of $h \mathrm{Vps} 34 / \mathrm{p} 150$ to the early endosome. Traffic 3: 416-427.

Navarro C., Nola S., Audebert S., Santoni M.J., Arsanto J.P., Ginestier C., Marchetto S., Jacquemier J., Isnardon D., Le Bivic A., Birnbaum D., Borg J.P. 2005. Junctional recruitment of mammalian Scribble relies on E-cadherin engagement. Oncogene 24: 4330-4339.

Palacios F., Tushir J.S., Fujita Y., D’Souza-Schorey C. 2005. Lysosomal targeting of Ecadherin: a unique mechanism for the down-regulation of cell-cell adhesion during epithelial to mesenchymal transitions. Mol. Cell. Biol. 25: 389-402.

Peretz G., Bakhrat A., Abdu U. 2007. Expression of the Drosophila melanogaster GADD45 homolog (CG11086) affects egg asymmetric development that is mediated by the c-Jun N-terminal kinase pathway. Genetics 177: 1691-1702.

Parks A.L. et al. 2004. Systematic generation of high-resolution deletion coverage of the Drosophila melanogaster genome. Nat. Genet. 36: 288-292

Patki V., Lawe D.C., Corvera S., Virbasius J.V., Chawla A. 1998. A functional PtdIns(3)Pbinding motif. Nature 394: 433-434.

Petronczki M. and Knoblich J.A. 2001. DmPar-6 directs epithelial polarity and asymmetric cell division of neuroblasts in Drosophila. Nat. Cell Biol. 3: 43-49.

Pfeffer S.R. 2001. Rab GTPases: specifying and deciphering organelle identity and 
function. Trends Cell Biol. 11: 487-491.

Pfeffer S.R. and Aivazian D. 2004. Targeting Rab GTPases to distinct membrane compartments. Nat. Rev. Mol. Cell Biol. 5: 886-896.

Pons V., Luyet P.P., Morel E., Abrami L., van der Goot F.G., Parton R.G., Gruenberg J. 2008. Hrs and SNX3 functions in sorting and membrane invagination within multivesicular bodies. PLoS Biol. 6: 1924-1956.

Pulipparacharuvil S., Akbar M.A., Ray S., Sevrioukov E.A., Haberman A.S., Rohrer J., Krämer H. 2005. Drosophila Vps16A is required for trafficking to lysosomes and biogenesis of pigment granules. J. Cell Sci. 118: 3663-3673.

Raiborg C., Bremnes B., Mehlum A., Gillooly D.J., D’Arrigo A., Stang E., Stenmark H. 2001. FYVE and coiled-coil domains determine the specific localisation of Hrs to early endosomes. J. Cell Sci. 114: 2255-2263.

Raiborg C., Bache K.G., Gillooly D.J., Madshus I.H., Stang E., Stenmark H. 2002. Hrs sorts ubiquitinated proteins into clathrin-coated microdomains of early endosomes. Nat. Cell Biol. 4: 394-398.

Ricard C.S., Jakubowski J.M., Verbsky J.W., Barbieri M.A., Lewis W.M., Fernandez G.E., Vogel M., Tsou C., Prasad V., Stahl P.D., Waksman G. Cheney C.M. Drosophila GDI mutants disrupt development but have normal Rab membrane extraction. Genesis 31: 17-29.

Rosenfeld J.L., Moore R.H., Zimmer K.P., Alpizar-Foster E., Dai W., Zarka M.N., Knoll B.J. 2001. Lysosome proteins are redistributed during expression of a GTPhydrolysis-defective rab5a. J. Cell Sci. 114: 4499-4508.

Rink J., Ghigo E., Kalaidzidis Y., Zerial M. 2005. Rab conversion as a mechanism of progression from early to late endosomes. Cell 122: 735-749.

Rual et al. 2005. Towards a proteome-scale map of the human protein-protein interaction network. Nature 437: 1173-1178.

Rubino M., Miaczynska M., Lippe R., Zerial M. 2000. Selective membrane recruitment of EEA1 suggests a role in directional transport of clathrin-coated vesicles to early endosomes. J. Biol. Chem. 275: 3745-3748.

Sambrook, J., Russel, D.W. 2001. Molecular cloning: a laboratory manual. 3rd ed. Cold Spring Harbor Laboratory Press, New York, USA.

Schneider, I. 1972. Cell lines derived from late embryonic stages of Drosophila melanogaster. J. Embryol. Exp. Morphol. 27: 353-365.

Schober M., Schaefer M., Knoblich J.A. 1999. Bazooka recruits Inscuteable to orient 
asymmetric cell divisions in Drosophila neuroblasts. Nature 402: 548-551.

Sheff D.R., Daro E.A., Hull M., Mellman I. 1999. The receptor recycling pathway contains two distinct populations of early endosomes with different sorting functions. J. Cell Biol. 145: 123-139.

Shen Y., Hirsch D.S., Sasiela C.A., Wu W.J. 2008. Cdc42 regulates E-cadherin ubiquitination and degradation through an epidermal growth factor receptor to Srcmediated pathway. J. Biol. Chem. 283: 5127-5137.

Simpson J.C., Wellenreuther R., Poustka A., Pepperkok R., Wiemann S. 2000. Systematic subcellular localization of novel proteins identified by large scale cDNA sequencing. EMBO Reports 1: 287-292.

Sisson J.C., Field C., Ventura R., Royou A., Sullivan W. 2000. Lava lamp, a novel peripheral Golgi protein, is required for Drosophila melanogaster cellularization. J. Cell Biol. 151: 905-918.

Sivars U., Aivazian D., Pfeffer S.R. 2003. Yip3 catalyzes the dissociation of endosomal Rab-GDI complexes. Nature 425: 856-859.

Spang A. 2009. On the fate of early endosomes. Biol. Chem. 390: 753-759.

Sriram V., Krishnan K.S., Mayor S. 2003. deep-orange and carnation define distinct stages in late endosomal biogenesis in Drosophila melanogaster. J. Cell Biol. 161: 593-607.

Stenmark H., Aasland R., Toh B.H., D’Arrigo A. 1996. Endosomal localization of the autoantigen EEA1 is mediated by a zinc-binding FYVE motif. J. Biol. Chem. 271: 24048-24054.

Stenmark H. and Olkkonen V. M. 2001. The Rab GTPase family. Genome Biol. 2: reviews3007.1-3007.7

Sun W., Yan Q., Vida T.A., Bean A.J. 2003. Hrs regulates early endosome fusion by inhibiting formation of an endosomal SNARE complex. J. Cell Biol. 162: 125-137.

Suzuki A. and Ohno S. 2006. The PAR-aPKC system: lessons in polarity. J. Cell Sci. 119: 979-987.

Tanentzapf G. and Tepass U. 2003. Interaction between the crumbs, lethal giant larvae and bazooka pathways in epithelial polarization. Nat. Cell Biol. 5: 46-52.

Tanaka T. and Nakamura A. 2008. The endocytic pathway acts downstream of Oscar in Drosophila germ plasm assembly. Development 135: 1107-1117.

Thompson B.J., Mathieu J., Sung H.H., Loeser E., Rorth P., Cohen S.M. 2005. Tumor supressor properties of the ESCRT-II complex component Vps25 in Drosophila. 
Dev. Cell 9: 711-720.

Torres V.A., Mielgo A., Barila D., Anderson D.H., Stupack D. 2008. Caspase 8 promotes peripheral localization and activation of Rab5. J. Biol. Chem. 283: 36280-36289.

Trischler M., Stoorvogel W., Ullrich O. 1999. Biochemical analysis of distinct Rab5- and Rab11-positive endosomes along the transferrin pathway. J. Cell Sci. 122: 47734783.

Twombly V., Blackman R.K:, Jin H., Graff J.M., Padgett R.W. 1996. The TGF- $\beta$ signaling pathway is essential for Drosophila oogenesis. Development 122: 1555-1565.

Ullrich O., Stenmark H., Alexandrov K., Huber L.A., Kaibuchi K., Sasaki T., Takai Y., Zerial M. 1993. Rab GDP dissociation inhibitor as a general regulator for the membrane association of Rab proteins. J. Biol. Chem. 268: 18143-18150.

Ullrich O., Reinsch S., Urbe S., Zerial M., Parton R.G. 1996. Rab11 regulates recycling through the pericentriolar recycling endosome. J. Cell Biol. 135: 913-924.

Vaccari T. and Bilder D. 2005. The Drosophila tumor supressor Vps25 prevents nonautonomous overproliferation by regulating notch trafficking. Dev. Cell 9: 687698.

Vaccari T., Lu H., Kanwar R., Fortini M.E., Bilder D. 2008. Endosomal entry regulates Notch receptor activation in Drosophila melanogaster. J. Cell Biol. 180: 755-762.

Vanlandingham P.A. and Ceresa B.P. 2009. Rab7 regulates late endocytic trafficking downstream of multivesicular body biogenesis and cargo sequestration. J. Biol. Chem. 284: 12110-12124.

Van Meer, G., Voelker D.R., Feigenson G.W. 2008. Membrane lipids: where they are and how they behave. Nat. Rev. Mol. Cell Biol. 9: 112-124.

Varnai P., Lin X., Lee S.B., Tuymetova G., Bondeva T., Spät A., Rhee S.G., Hajnoczky G., Balla T. 2002. Inositol lipid binding and membrane localization of isolated pleckstrin homology (PH) domains. J. Biol. Chem. 277: 27412-27422.

Visser Smit G.D., Place T.L., Cole S.L., Clausen K.L., Vemuganti S., Zhang G., Koland J.G., Lill N.L. 2009. Cbl controls EGFR fate by regulating early endosome fusion. Sci. Signal. 2: ra86.

Vonderheit A. and Helenius A. 2005. Rab7 associates with early endosomes to mediate sorting and transport of Semliki forest virus to late endosomes. PLoS Biol. 3: 12251238.

Weisz A., Basile W., Scafoglio C., Altucci L., Bresciani F., Facchiano A., Sismondi P., Cicatiello L., De Bortoli M. 2004. Molecular identification of ERalpha-positive 
breast cancer cells by the expression profile of an intrinsic set of estrogen regulated genes. J. Cell. Physiol. 200: 440-450.

Wegner C.S., Malerød L., Pedersen N.M., Progida C., Bakke O., Stenmark H., Brech A. 2010. Ultrastructural characterization of giant endosomes induced by GTPasedeficient Rab5. Histochem. Cell. Biol. 133: 41-55.

Wells C.D., Fawcett J.P., Traweger A., Yamanaka Y., Goudreault M., Elder K. et al. 2006. A Rich1/Amot complex regulates the Cdc42 GTPase and apical-polarity proteins in epithelial cells. Cell 125: 535-548.

Willert, K., Brink, M., Wodarz, A., Varmus, H., Nusse, R. 1997. Casein kinase 2 associates with and phosphorylates Dishevelled. EMBO J. 16: 3089-3096.

Wodarz A. 2008. Extraction and immunoblotting of proteins from embryos. From: Methods in Molecular biology: Drosophila: Methods and Protocols. Ed. Dahmann C. Humana Press, Totowa, NJ, pp 335-345.

Wodarz A., Hinz U., Engelbert M., Knust E. 1995. Expression of crumbs confers apical character on plasma membrane domains of ectodermal epithelia of Drosophila. Cell 82: 67-76.

Wodarz A., Ramrath A., Kuchinke U., Knust E. 1999. Bazooka provides an apical cue for Inscuteable localization in Drosophila neuroblasts. Nature 402: 544-547.

Wodarz A., Ramrath A., Grimm A., Knust E. 2000. Drosophila atypical protein kinase C associates with Bazooka and controls polarity of epithelia and neuroblasts. J. Cell Biol. 150: 1361-1374.

Wucherpfennig T., Wilsch-Bräuninger M., Gonzalez-Gaitan M. 2003. Role of Drosophila Rab5 during endosomal trafficking at the synapse and evoked neurotransmitter release. J. Cell Biol. 161: 609-624.

Wurmser A.E., Sato T.K., Emr S.D. 2000. New component of the vacuolar class C-Vps complex couples nucleotide exchange on the Ypt7 GTPase to SNARE-dependent docking and fusion. J. Cell Biol. 151: 551-562.

Yagisawa H., Sakuma K., Paterson H.F., Cheung R., Allen V., Hirata H., Watanabe Y., Hirata M., Williams R.L., Katan M. 1998. Replacements of single basic amino acids in the pleckstrin homology domain of phospholipase $\mathrm{C}-\delta 1$ alter the ligand binding, phospholipase activity, and interaction with the plasma membrane. J. Biol. Chem. 273: 417-424.

Yan Y., Denef N., Schüpbach T. 2009. The vacuolar proton pump, V-ATPase, is required for Notch signaling and endosomal trafficking in Drosophila. Dev. Cell 17: 387-402. 
Yap A.S., Brieher W.M., Gumbiner B.M. 1997. Molecular and functional analysis of cadherin-based adherens junctions. Dev. Biol. 13: 119-146.

Zerial M. and McBride H. 2001. Rab proteins as membrane organizers. Nat. Rev. Mol. Cell Biol. 2: 107-117.

Zhang J., Schulze K.L., Hiesinger P.R., Suyama K., Wang S., Fish M., Acar M., Hoskins R.A., Bellen H.J., Scott M.P. 2007. Thirty-one flavors of Drosophila Rab proteins. Genetics 176: 1307-1322. 


\section{Abbreviations}

Apart from SI units, common abbreviations of the English language and the amino acid single code the following abbreviations were used in this thesis:

\begin{tabular}{|c|c|c|c|}
\hline$\alpha$ & anti & Fig & figure \\
\hline Act & Actin & FLP & Flipase \\
\hline $\mathrm{aPKC}$ & atypical protein kinase $\mathrm{C}$ & FRT & Flipase recognition target \\
\hline APS & ammonium persulfate & & sequence \\
\hline Arm & Armadillo & FYVE & Fablp, YOTB, Vac1p, EEA1 \\
\hline $\operatorname{Arp} 2 / 3$ & Actin related protein & Gal4 & Gal4 transcription factor \\
\hline $\mathrm{Baz}$ & Bazooka & GAP & GTPase activating protein \\
\hline $\mathrm{bp}$ & base pairs & GDF & GDI displacement factor \\
\hline $\mathrm{CA}$ & constitutively active & GDI & GDP dissociation inhibitor \\
\hline $\mathrm{Cdc} 42$ & Cell division control protein 42 & GDP & guanine diphosphate \\
\hline cDNA & complementary DNA & GEF & Guanine nucleotide exchange \\
\hline Cip4 & Cdc42 interacting protein 4 & & factor \\
\hline $\mathrm{Crb}$ & Crumbs & GFP & Green fluorescent protein \\
\hline da & daughterless & GST & Gluthatione-S-transferase \\
\hline DABCO & diazabicyclo(2.2.2)octane & GTP & guanine triphosphate \\
\hline \multirow[t]{2}{*}{ DAPI } & 4',6-diamide-2'-phenylindole & HA & hemagglutinin \\
\hline & dihydrochloride & HEPES & 4-(2-hydroxyethyl)-1- \\
\hline Dlg & Discs large & & piperazine ethanesulfonic acid \\
\hline $\mathrm{DN}$ & dominant negative & HOPS & Homotypic vacuole fusion and \\
\hline DNA & deoxyribonucleic acid & & protein sorting \\
\hline dNTP & deoxynucleotide triphosphate & HRP & horseradish peroxidase \\
\hline DTT & dithiothreitol & Hrs & Hepatocyte growth factor- \\
\hline E-cad & E-cadherin & & regulated tyrosine kinase \\
\hline EDTA & ethylenediaminetetraacetic acid & & substrate \\
\hline EEA1 & early endosomal antigen 1 & $\operatorname{IgG}$ & Immunoglobulin $\mathrm{G}$ \\
\hline Ept & Erupted & JAK & Janus kinase \\
\hline \multirow[t]{2}{*}{ ESCRT } & endosomal complexes required & JNK & Jun-N-terminal kinase \\
\hline & for transport & $\mathrm{kb}$ & kilobase \\
\hline FasIII & Fasciclin III & $\mathrm{kD}$ & kilodalton \\
\hline
\end{tabular}




\begin{tabular}{|c|c|c|c|}
\hline LB & Luria Bertani broth & SDS & sodium dodecyl sulphate \\
\hline Lgl & Lethal (2) giant larvae & Sdt & Stardust \\
\hline LTR & LysoTracker & $\sec$ & second(s) \\
\hline Lva & Lava lamp & sta & stubarista \\
\hline MAGUK & $\begin{array}{l}\text { membrane-associated } \\
\text { guanylate kinase }\end{array}$ & STAT & $\begin{array}{l}\text { Signal transducer and activator } \\
\text { of transcription }\end{array}$ \\
\hline MBP & Maltose binding protein & TEMED & N,N,N',N'- \\
\hline MVB & multivesicular body & & tetramethylendiamine \\
\hline NHS & normal horse serum & TGF $\beta$ & Transforming growth factor $\beta$ \\
\hline Orb & oo18 RNA-binding protein & TGN & trans-Golgi network \\
\hline PAGE & $\begin{array}{l}\text { polyacrylamide gel } \\
\text { electrophoresis }\end{array}$ & Tris & $\begin{array}{l}\text { Trishydroxymethylamino- } \\
\text { methane }\end{array}$ \\
\hline Par & Partitoning defective & $\mathrm{U}$ & unit (enzyme activity) \\
\hline PATJ & $\begin{array}{l}\text { Pals1-associated tight junction } \\
\text { protein }\end{array}$ & $\begin{array}{l}\text { UAS } \\
\text { UTR }\end{array}$ & $\begin{array}{l}\text { upstream activating sequence } \\
\text { untranslated region }\end{array}$ \\
\hline PBS & phosphate buffered saline & $\mathrm{v} / \mathrm{v}$ & volume/volume \\
\hline PCR & polymerase chain reaction & Vps & Vacuolar protein sorting \\
\hline PDZ & $\begin{array}{l}\text { PSD95, Discs large, Zona } \\
\text { occludens-1 }\end{array}$ & $\begin{array}{l}\mathrm{w} \\
\mathrm{w} / \mathrm{v}\end{array}$ & $\begin{array}{l}\text { white } \\
\text { weight/volume }\end{array}$ \\
\hline $\mathrm{PH}$ & pleckstrin homology & $\mathrm{wt}$ & wild type \\
\hline PIP & $\begin{array}{l}\text { phosphatidyl inositol } \\
\text { phosphate }\end{array}$ & YFP & Yellow fluorescent protein \\
\hline
\end{tabular}

PIPES piperazine-1,4-bis-2-

ethanesulfoic acid

pnr pannier

PNS post nuclear supernatant

PRA Prenylated Rab acceptor

protein

rpm rotations per minute

Rush Rush hour

S2 Schneider 2

SE Standard error

Scrib Scribble 


\section{Appendix}

Appendix 1. The sequence of rush cDNA and the amino acid sequence of Rush. The

$\mathrm{PH}$ domain is shown with a yellow box, the FYVE domain is marked with a green box.

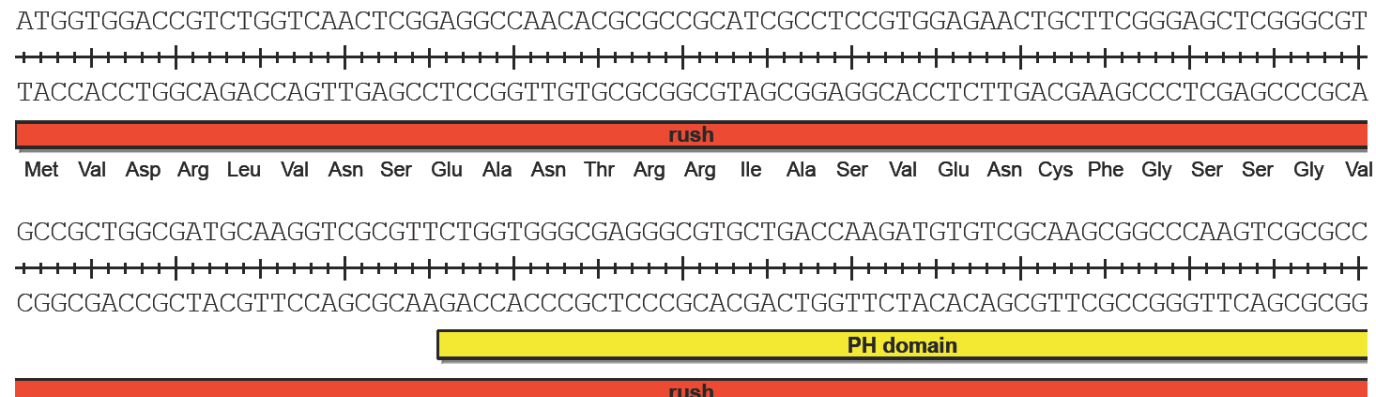

Pro Leu Ala Met Gln Gly Arg Val Leu Val Gly Glu Gly Val Leu Thr Lys Met Cys Arg Lys Arg Pro Lys Ser Arg

AGTTCTTCCTGTTCAACGACATCCTGGTGTACGGAAACATAGTGATTGGCAAGAAGAAGTACAACAAGCAGCATATCATG

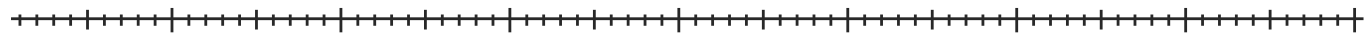
TCAAGAAGGACAAGTTGCTGTAGGACCACATGCCTTTGTATCACTAACCGTTCTTCTTCATGTTGTTCGTCGTATAGTAC

\begin{tabular}{c}
\hline PH domain \\
\hline rush
\end{tabular}
Gln Phe Phe Leu Phe Asn Asp lle Leu Val Tyr Gly Asn lle Val lle Gly Lys Lys Lys Tyr Asn Lys Gln His lle Met CCGCTGGAGGAGGTCTCGCTGGAATCGATTGCCGACAACCAGACGTACAGAAACGGCTGGTACATCCGCACCACCACCAA

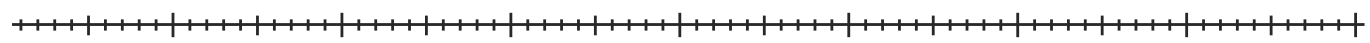
GGCGACCTCCTCCAGAGCGACCTTAGCTAACGGCTGTTGGTCTGCATGTCTTTGCCGACCATGTAGGCGTGGTGGTGGTT \begin{tabular}{cc}
\hline \multicolumn{10}{c}{ PH domain } \\
\hline Pro Leu Glu Glu Val Ser Leu Glu Ser lle Ala Asp Asn Gln Thr Tyr Arg Asn Gly Trp Tyr lle Arg Thr Thr Thr Lys
\end{tabular} GTCGTTTGTGGTGTTTGCGGCCACCAGCACCGAGAAGCAGGAGTGGATGGCTCACATCAACAAGTGCGTGGAGGACCTGC

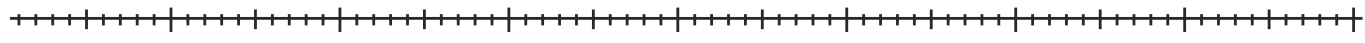
CAGCAAACACCACAAACGCCGGTGGTCGTGGCTCTTCGTCCTCACCTACCGAGTGTAGTTGTTCACGCACCTCCTGGACG PH domain

Ser Phe Val Val Phe Ala Ala Thr Ser Thr Glu Lys Gln Glu Trp Met Ala His lle Asn Lys Cys Val Glu Asp Leu TGCGCAAGAGCGGCAAGAAGCCGGTGGAGAACCACGCCGCCGTTTGGGTGCCCGACACCGACGCCAGCGTCTGCATGCAC

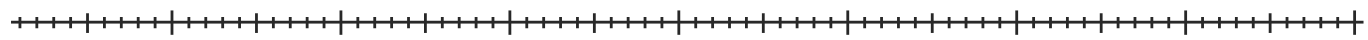
ACGCGTTCTCGCCGTTCTTCGGCCACCTCTTGGTGCGGCGGCAAACCCACGGGCTGTGGCTGCGGTCGCAGACGTACGTG rush FYVE domain

Leu Arg Lys Ser Gly Lys Lys Pro Val Glu Asn His Ala Ala Val Trp Val Pro Asp Thr Asp Ala Ser Val Cys Met His TGCAAGAAGACGCAGTTTACTTTCATCCAGCGCCGGCATCACTGCCGCAACTGCGGCGCTGTTGTCTGCGCCGGCTGCTC

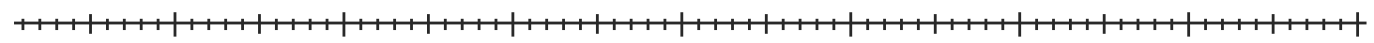
ACGTTCTTCTGCGTCAAATGAAAGTAGGTCGCGGCCGTAGTGACGGCGTTGACGCCGCGACAACAGACGCGGCCGACGAG rush FYVE domain

Cys Lys Lys Thr Gln Phe Thr Phe lle Gln Arg Arg His His Cys Arg Asn Cys Gly Ala Val Val Cys Ala Gly Cys Ser GGCCAAGAAGTTCCTGCTTCCGCAGCAGAGCACCAAGGCGTTGCGCGTCTGTGACGCCTGCTACGAGCGCTTGAAGCACG

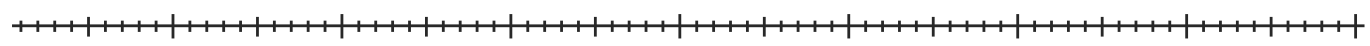
CCGGTTCTTCAAGGACGAAGGCGTCGTCTCGTGGTTCCGCAACGCGCAGACACTGCGGACGATGCTCGCGAACTTCGTGC 
5' TGCCAAGTTCCCTTGGCTCTGGCGAGGACTCGGCAGCGGCTACCGGCGCTGCCTCCGGCAACAAGCTCAACACAACAGCC

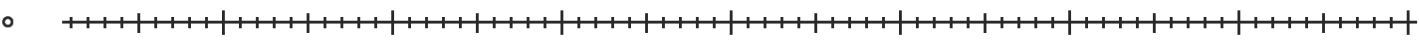
3' ACGGTTCAAGGGAACCGAGACCGCTCCTGAGCCGTCGCCGATGGCCGCGACGGAGGCCGTTGTTCGAGTTGTGTTGTCGG

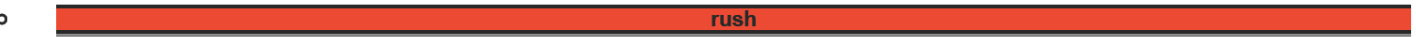

Val Pro Ser Ser Leu Gly Ser Gly Glu Asp Ser Ala Ala Ala Thr Gly Ala Ala Ser Gly Asn Lys Leu Asn Thr Thr Ala

GGCGACAGCTCCAACGATGAGGACTCCGACGAGGAGACTGCCTCCCCTGGTGGCGAGTCGCACGATGAGCCGCGCTTCTA

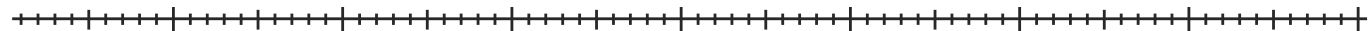
CCGCTGTCGAGGTTGCTACTCCTGAGGCTGCTCCTCTGACGGAGGGGACCACCGCTCAGCGTGCTACTCGGCGCGAAGAT Gly Asp Ser Ser Asn Asp Glu Asp Ser Asp Glu Glu Thr Ala Ser Pro Gly Gly Glu Ser His Asp Glu Pro Arg Phe Tyr CGGGGACAACAGCGTGCTATCCGCCGTCGAAGACTCCTCGACGATAACCTCGCCCTCCTCCGCCACCACTGGCAGCTTGG

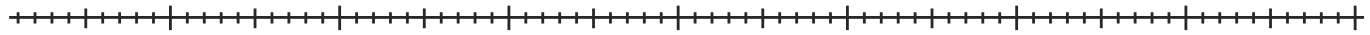
GCCCCTGTTGTCGCACGATAGGCGGCAGCTTCTGAGGAGCTGCTATTGGAGCGGGAGGAGGCGGTGGTGACCGTCGAACC

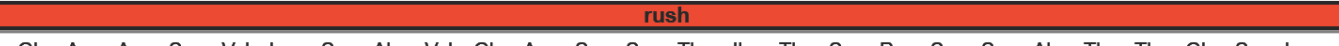

Gly Asp Asn Ser Val Leu Ser Ala Val Glu Asp Ser Ser Thr lle Thr Ser Pro Ser Ser Ala Thr Thr Gly Ser Leu

AGGCTCCCCAGGTGACACCGAGCGTCCAAAGCTCCCCGGCTGCCGTTGCGACGACGGGCAGCCACTGTTGA

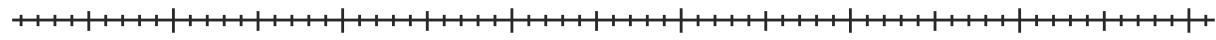
TCCGAGGGGTCCACTGTGGCTCGCAGGTTTCGAGGGGCCGACGGCAACGCTGCTGCCCGTCGGTGACAACT Glu Ala Pro Gln Val Thr Pro Ser Val Gln Ser Ser Pro Ala Ala Val Ala Thr Thr Gly Ser His Cys.

\section{Appendix 2. The sequence of GDI cDNA and the amino acid sequence of GDI.}

5' ATGAATGAGGAATACGATGCGATTGTGCTAGGAACGGGCCTCAAGGAGTGCATCCTCAGCGGGATGCTGTCCGTGTCCGG

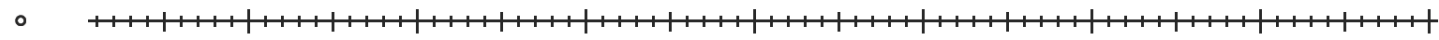
3' TACTTACTCCTTATGCTACGCTAACACGATCCTTGCCCGGAGTTCCTCACGTAGGAGTCGCCCTACGACAGGCACAGGCC

CAAGAAGGTTTTGCATATTGATCGAAACAAGTACTACGGCGGCGAGTCCGCCTCGATAACGCCGCTGGAGGAGCTCTTCC

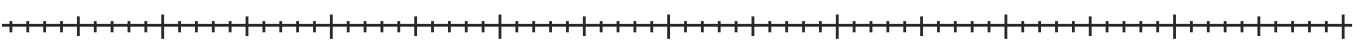
GTTCTTCCAAAACGTATAACTAGCTTTGTTCATGATGCCGCCGCTCAGGCGGAGCTATTGCGGCGACCTCCTCGAGAAGG

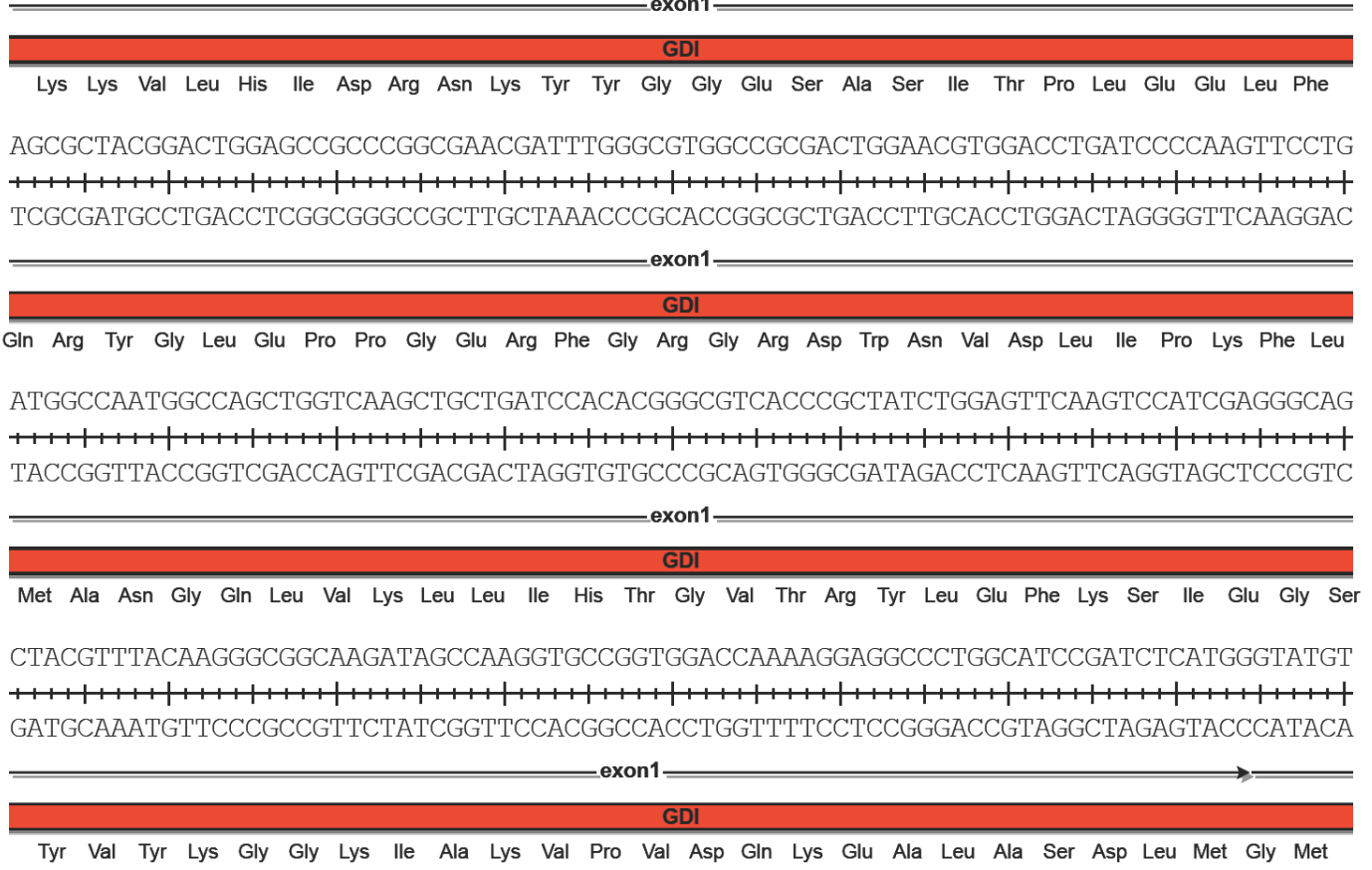


$\circ$

3'

。

1

5

$\circ$

3

o

1

5

$\circ$

3'

$\circ$

5

$\circ$

$3^{\prime}$

。

1

5

$\circ$

o

1

$\circ$

○

TCGAGAAGCGTCGCTTCCGGAACTTCCTCATCTACGTGCAGGATTTCCGAGAAGATGACCCCAAGACCTGGAAGGACTTT

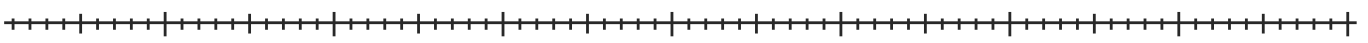
AGCTCTTCGCAGCGAAGGCCTTGAAGGAGTAGATGCACGTCCTAAAGGCTCTTCTACTGGGGTTCTGGACCTTCCTGAAA exon2 Phe Glu Lys Arg Arg Phe Arg Asn Phe Leu lle Tyr Val Gln Asp Phe Arg Glu Asp Asp Pro Lys Thr Trp Lys Asp Phe GACCCCACCAAGGCCAACATGCAGGGTCTGTACGACAAGTTCGGACTGGACAAGAACACGCAGGACT"TCACCGGCCACGC

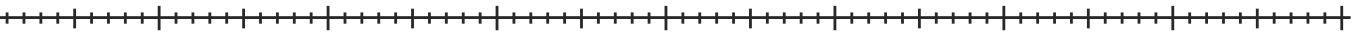
CTGGGGTGGTTCCGGTTGTACGTCCCAGACATGCTGTTCAAGCCTGACCTGTTCTTGTGCGTCCTGAAGTGGCCGGTGCG

$\overline{\text { GDI }}$ exon2
Asp Pro Thr Lys Ala Asn Met Gln Gly Leu Tyr Asp Lys Phe Gly Leu Asp Lys Asn Thr Gln Asp Phe Thr Gly His Ala CCTGGCCCTT"TCCGCGACGATGAGTATCTGAACGAGCCGGCCGTGAACACCATCCGGCGGATTAAGCTCTACTCCGATT

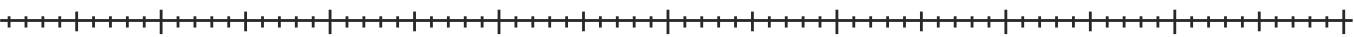
GGACCGGGAAAAGGCGCTGCTACTCATAGACTTGCTCGGCCGGCACTTGTGGTAGGCCGCCTAATTCGAGATGAGGCTAA

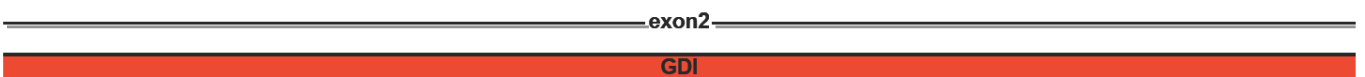

Leu Ala Leu Phe Arg Asp Asp Glu Tyr Leu Asn Glu Pro Ala Val Asn Thr lle Arg Arg lle Lys Leu Tyr Ser Asp

CGCTGGCGCGTTACGGCAAGTCGCCCTACCTTTATCCCATGTACGGCCTGGGTGAGCTGCCCCAGGGATTCGCACGTCTG

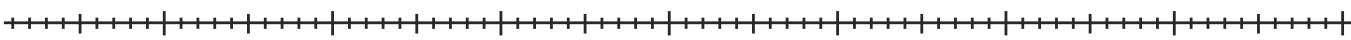
GCGACCGCGCAATGCCGTTCAGCGGGATGGAAATAGGGTACATGCCGGACCCACTCGACGGGGTCCCTAAGCGTGCAGAC -exon2

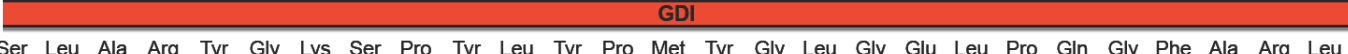
TCGGCCATCTACGGCGGCACCTACATGCTTGACAAGCCCATCGACGAGATTGTCCTCGGCGAGGGCGGCAAGGTGGTGGG

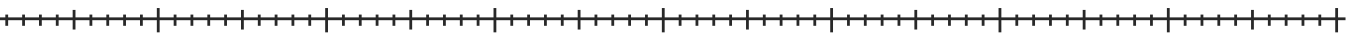
AGCCGGTAGATGCCGCCGTGGATGTACGAACTGTTCGGGTAGCTGCTCTAACAGGAGCCGCTCCCGCCGTTCCACCACCC

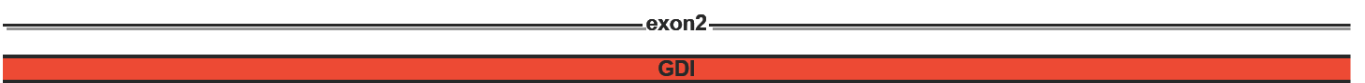
Ser Ala lle Tyr Gly Gly Thr Tyr Met Leu Asp Lys Pro lle Asp Glu lle Val Leu Gly Glu Gly Gly Lys Val Val Gly AGTGCGCTCCGGCGAAGAGGTCGCCAAGTGCAAGCAGGTCTACTGCGATCCCAGCTACGTGCCCGAGAAGGTGCGCAAGC

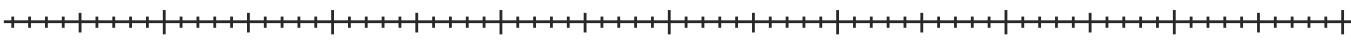
TCACGCGAGGCCGCTTCTCCAGCGGTTCACGTTCGTCCAGATGACGCTAGGGTCGATGCACGGGCTCTTCCACGCGTTCG

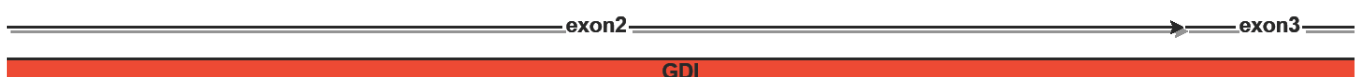

Val Arg Ser Gly Glu Glu Val Ala Lys Cys Lys Gln Val Tyr Cys Asp Pro Ser Tyr Val Pro Glu Lys Val Arg Lys

GTGGCAAGGTGATTCGCTGCATTTGCATTCTGGACCATCCGGTGGCCAGCACCAAGGATGGTCTCTCCACGCAGATTATC

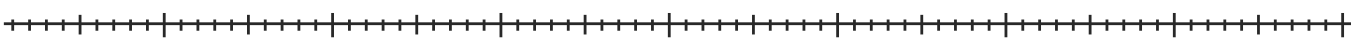
CACCGTTCCACTAAGCGACGTAAACGTAAGACCTGGTAGGCCACCGGTCGTGGTTCCTACCAGAGAGGTGCGTCTAATAG -exon3

GDI

Arg Gly Lys Val Ile Arg Cys lle Cys lle Leu Asp His Pro Val Ala Ser Thr Lys Asp Gly Leu Ser Thr Gln lle lle

ATTCCACAAAAGCAGGTCGGCCGCAAGTCGGACATCTATGTGTCGCTTGTGAGCTCCACTCATCAGGTGGCCGCCAAGGG

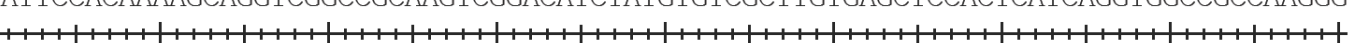
TAAGGTGTTTTCGTCCAGCCGGCGTTCAGCCTGTAGATACACAGCGAACACTCGAGGTGAGTAGTCCACCGGCGGTTCCC -exon3

Ile Pro Gln Lys Gln Val Gly Arg Lys Ser Asp lle Tyr Val Ser Leu Val Ser Ser Thr His Gln Val Ala Ala Lys Gly TTGGTTCGTGGGCATGGTCTCGACCACCGTTGAgACCGAGAACCCGGAGGTGGAGATCAAGCCTGGCTTGGACTTGCTGG +1+1+1+1+1+1+1+1+1+1+1+1+1+1+1+1+1+1+1+1+1+1+1+1+1+1+1+1+1+1 AACCAAGCACCCGTACCAGAGCTGGTGGCAACTCTGGCTCTTGGGCCTCCACCTCTAGTTCGGACCGAACCTGAACGACC -exon3

Trp Phe Val Gly Met Val Ser Thr Thr Val Glu Thr Glu Asn Pro Glu Val Glu lle Lys Pro Gly Leu Asp Leu Leu 
AGCCGATCGCACAAAAGTTTGTAACCATTTCGGACTATTTGGAGCCGATCGATGATGGATCCGAGTCTCAAATCTTTATT

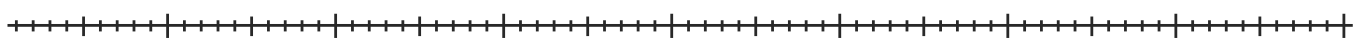
TCGGCTAGCGTGTTTTCAAACATTGGTAAAGCCTGATAAACCTCGGCTAGCTACTACCTAGGCTCAGAGTTTAGAAATAA

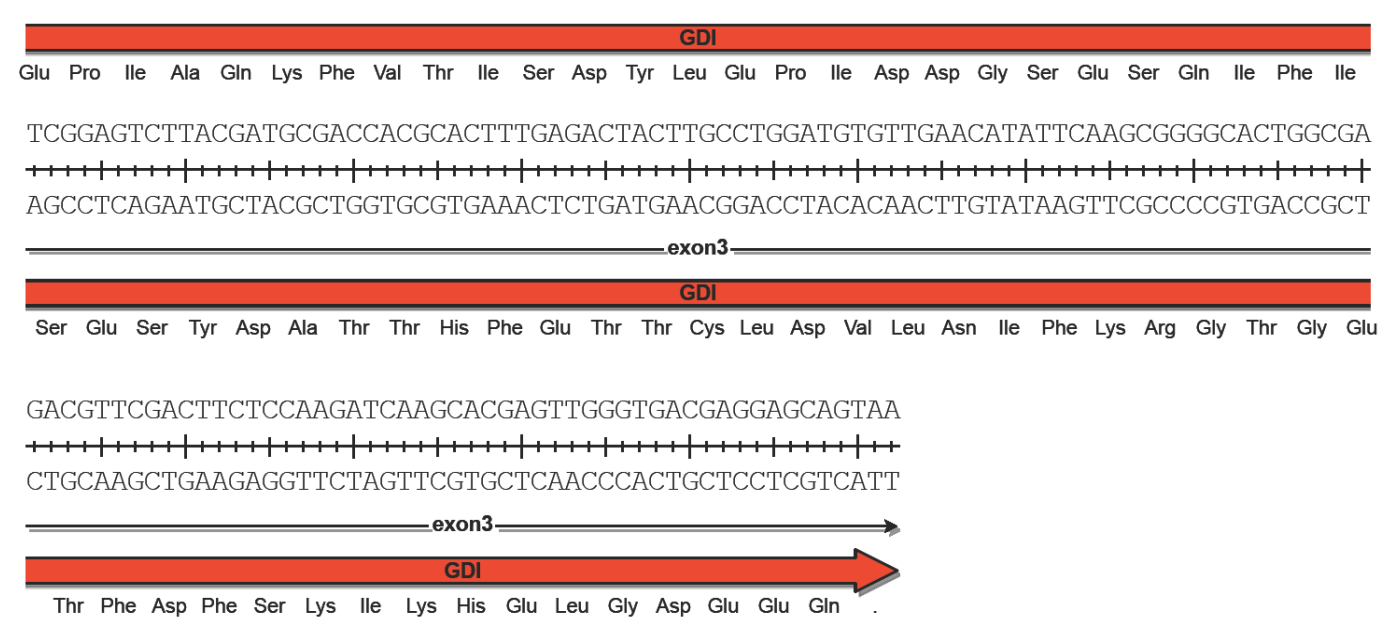

\section{Appendix 3. The sequence of CG1418 cDNA and the amino acid sequence of CG1418.}

ATGGCACACACTGGCGGGAACCTATCCGGTAACATGCAGCCGCCACCGCCTTCCGGAGGCAGGTTCTCCGTGGACATGCA

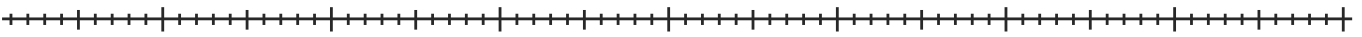
TACCGTGTGTGACCGCCCTTGGATAGGCCATTGTACGTCGGCGGTGGCGGAAGGCCTCCGTCCAAGAGGCACCTGTACGT

\section{exon1}

Trp His Thr Leu Ala Gly Thr Tyr Pro Val Thr Cys Ser Arg His Arg Leu Pro Glu Ala Gly Ser Pro Trp Thr Cys

AAGCCTGCCCTCGCTATCCAACCTGCCATCACCGCTGCAGATCTTCCAAATGGTCCGAAACTCCCTGCGGCCCTGGGTAG

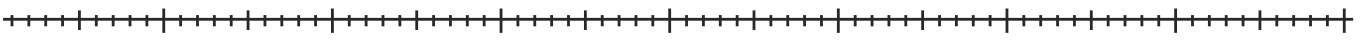
TTCGGACGGGAGCGATAGGTTGGACGGTAGTGGCGACGTCTAGAAGGTTTACCAGGCTTTGAGGGACGCCGGGACCCATC exon2

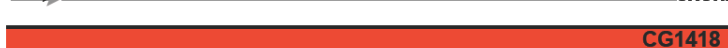

Lys Ala Cys Pro Arg Tyr Pro Thr Cys His His Arg Cys Arg Ser Ser Lys Trp Ser Glu Thr Pro Cys Gly Pro Gly TCTTCTTСАAСАTСААСАATTTCAAAACGGCCATCAGCATGCAGCGGCTAAATAGCCGGGTTATTCGGAATCTCTCCTAT

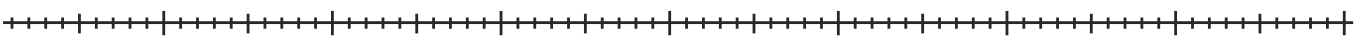
AgAAGAAGTTGTAGTTGTTAAAGTTTTGCCGGTAGTCGTACGTCGCCGATTTATCGGCCCAATAAGCCTTAGAGAGGATA

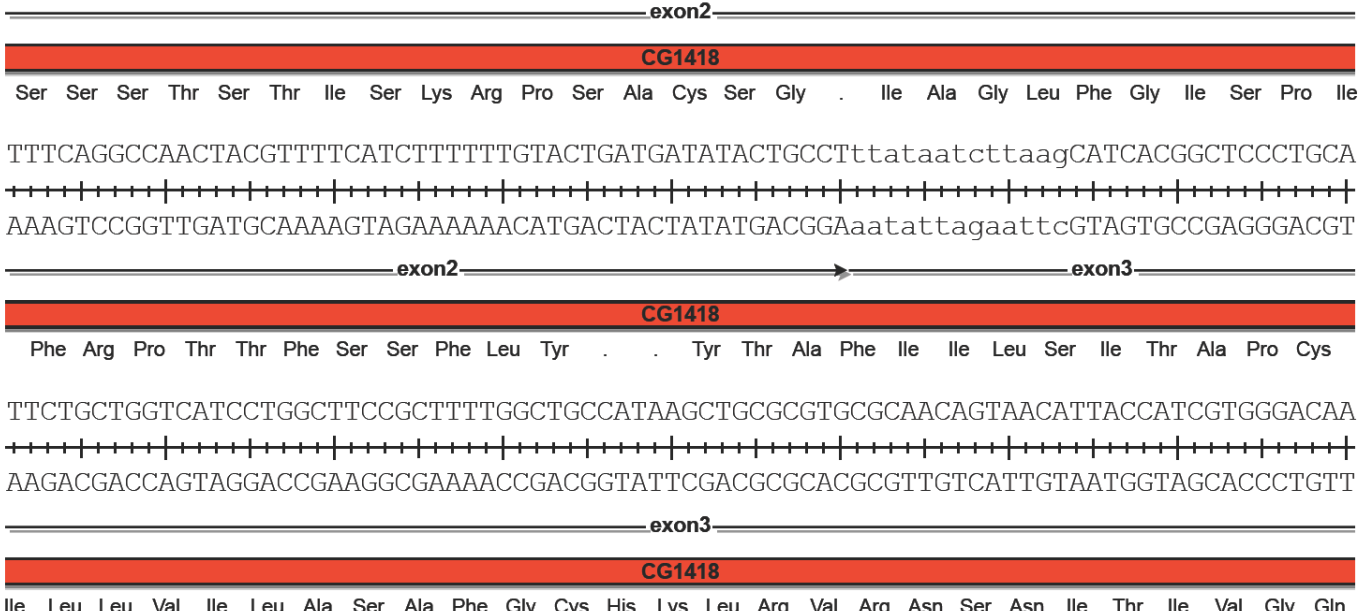


5' CAACTGACGCCCAGCCAGCAGATCATCGCACTCAATCTGGCGACGGCACCAGTGCTATTCCTGGTGGGCGCGGGTGCGGT

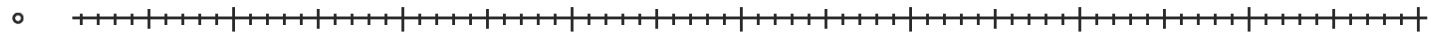

3' GTTGACTGCGGGTCGGTCGTCTAGTAGCGTGAGTTAGACCGCTGCCGTGGTCACGATAAGGACCACCCGCGCCCACGCCA

exon3

Gln Leu Thr Pro Ser Gln Gln lle lle Ala Leu Asn Leu Ala Thr Ala Pro Val Leu Phe Leu Val Gly Ala Gly Ala Va

TTTGTTTTGGACGCTGGGTGCTTCATGCTTCGTGATTGCTATGCATGCTATATTCTACAACATCGATGCTATTGTAACGG

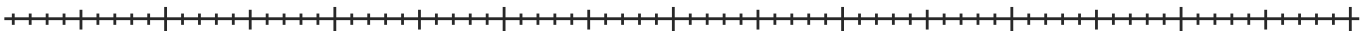

AAACAAAACCTGCGACCCACGAAGTACGAAGCACTAACGATACGTACGATATAAGATGTTGTAGCTACGATAACATTGCC

exon3

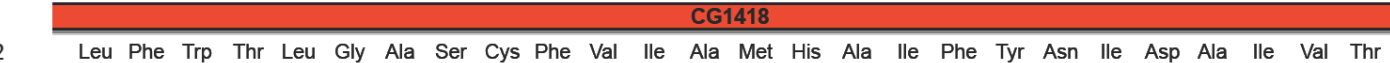

AGGAGAATGAGGGTTTCCTCGCCCAGGTTGTCTGA

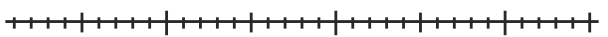

TCCTCTTACTCCCAAAGGAGCGGGTCCAACAGACT

exon3

Glu Glu Asn Glu Gly Phe Leu Ala Gln Val Val 


\section{Curriculum vitae}

\section{Personal information}

$\begin{array}{ll}\text { Name } & \text { Ieva Gailite } \\ \text { Date of birth } & \text { March 28, 1984 } \\ \text { Nationality } & \text { Latvian }\end{array}$

\section{Education}

$2006-2010$ PhD in Molecular Biology in Department of Stem Cell Biology, University of Göttingen, Germany

Thesis: „The role of the novel endosomal protein Rush hour (CG14782) in endosomal trafficking in Drosophila melanogaster"

2006 - 2007 MSc in Molecular Biology in Department of Stem Cell Biology, University of Göttingen, Germany

Thesis: „Analysis of CG14782, the putative interaction partner of Bazooka in Drosophila melanogaster"

2005 - 2006 MSc/PhD Program in Molecular Biology of International Max

Planck Research School

Georg August University of Göttingen, Göttingen, Germany

$2002-2005 \quad$ BSc in Biology in University of Latvia, Riga, Latvia.

Thesis: "Viability in the state of anhydrobiosis of yeast Saccharomyces cerevisiae produced under aerobic and anaerobic conditions"

\section{Teaching}

2007 - $2010 \quad$ Tutor of lectures „Model systems in molecular biology - Drosophila $\mathrm{I}$ and $\mathrm{II}$ “ within the International $\mathrm{MSc} / \mathrm{PhD}$ program „Molecular Biology“ 
Supervisor of labrotations, students Mehdi Goudarzi and Hope Agbemenyah within International $\mathrm{MSc} / \mathrm{PhD}$ programs „Molecular Biology“ and „Neurosciences“

\section{$\underline{\text { Scholarships }}$}

$2006-2008 \quad$ Georg Christoph Lichtenberg Stipend from Ministry of Education of Lower Saxony

2005-2006 Stipend of the International Max Planck Research School for Molecular Biology

2004

Kristaps Morbergs Scholarship, University of Latvia

\section{$\underline{\text { Extracurricular activities }}$}

2007 - 2009 Co-organizer of the International PhD Student Symposium „Horizons in Molecular Biology“, Göttingen, Germany

$2002-2005$ Member of the Students' Council of the Faculty of Biology, University or Latvia

\section{$\underline{\text { Publications }}$}

Kim S., Gailite I., Moussian B., Luschnig S., Goette M., Fricke K., Honemann-Capito M., Grubmüller H., Wodarz A. 2009. Kinaseactivity-independent functions of atypical protein kinase $\mathrm{C}$ in Drosophila. J. Cell Sci. 122: 3759-3771. 